\section{Consenso Latino-Americano de Obesidade}

\section{PREFÁCIO}

A obesidade é, atualmente, um dos mais graves problemas de saúde pública. Sua prevalência vem crescendo acentuadamente nas últimas décadas, inclusive nos países em desenvolvimento. o que levou a doença à condição de epidemia global.

Estudos epidemiológicos em populações latino-americanas têm relatado dados alarmantes. À medida que se consegue erradicar a miséria entre as camadas mais pobres da população, a obesidade desponta como um problema mais freqüente e mais grave que a desnutrição. É o fenômeno da transição nutricional, que sobrecarrega nosso sistema de saúde com uma demanda crescente de atendimento a doenças crônicas relacionadas com a obesidade, como o diabetes tipo 2, a doença coronariana, a hipertensão arterial e diversos tipos de câncer. É provável que 200.000 pessoas morram anualmente na América Latina em decorrência destas complicações.

O tratamento da obesidade, entretanto, continua produzindo resultados insatisfatórios, em grande parte por estratégias equivocadas e pelo mau uso dos recursos terapêuticos disponíveis.

Além de buscarmos planos terapêticos mais eficazes, faz-se necessário, também, que sejam adotadas medidas de prevenção para conter o surgimento de casos novos e evitar que a prevalência da doença continue crescendo a despeito de todos os esforços com seu tratamento.

Este documento, produzido pelo trabalho conjunto de dezenas de especialistas de 12 países latino-americanos, das áreas de Medicina. Nutrição. Psicologia e Educação Física, representa uma revisão dos diversos aspectos relacionados com a obesidade e seu tratamento. São apresentados dados sobre a prevalência, os riscos e os custos associados com a obesidade, são sugeridas medidas que possam contribuir para a prevenção da doença e, finalmente, são analisados os métodos atualmente disponiveis para a avaliação e o tratamento do paciente obeso.

O Documento do Consenso Latino-Americano em Obesidade é destinado principalmente a médicos, nutricionistas, psicólogos, professores de educação física e outros profissionais de saúde que lidam com pacientes obesos. É dirigido, também, a autoridades governamentais, a jornalistas da área de Saúde e a todo profissional que possa contribuir, direta ou indiretamente, para o combate a este grave problema que é a obesidade.

\section{EDITORIAL}

\section{La trascendencia del consenso latinoamericano de obesidad}

La Obesidad, epidemia del Siglo XXI, ha tocado a nuestras puertas. $Y$ aunque era un hecho presentido, nos obliga a tomar medidas rápidas y apropiadas para combatirla.

Talvez lo primero es conocer la magnitud del problema, luego indagar por los medios para encararlo y finalmente diseñar una estrategia para que la "transición nutricional" no se convierta en Obesidad. consenso

\author{
Federação Latino- \\ Americana de Sociedades \\ de Obesidade - FLASO
}

Walmir Coutinho,
Coordenador 


\section{Magnitud del problema}

Es alarmante: En el último Congreso de la Sociedad Internacional para el estudio de la Obesidad (IASO) en París, y justamente en el Simposio Latinoamericano celebrado el dia $1^{\circ}$ de Septimbre de 98 , se presentaron cifras contundentes: Para México (Gonzalez-Barranco): frecuencia de Obesidad en Hombres (población urbana): $33 \%$ y en Mujeres 39\%. En Argentina (Braguinsky / estudio de Venado Tuerto) se encontraron datos de prevalencia de Obesidad del $27 \%$, y de Sobrepeso del $32.5 \%$ es decir una cifra global del $60 \%$.

La experiencia el grupo uruguayo (Nigro) indica que hay una prevalencia de sobrepeso y obesidad del $42 \%$ en varones y del $50 \%$ en mujeres (criterio de mas de $110 \%$ peso actual/ideal) y si se toma como parámetro IMC de $30 / 27$ es $13 \%$ masculino y $26 \%$ femenino, respectivamente. En Chile (Saavedra), la Obesidad se ha incrementado en 4 años en un $14 \%$, y estiman que la proyección de este aumento es de un millón de personas con Obesidad o Sobrepeso en este lapso.

En Peru (Peñaloza), las estadisticas en varias ciudades estudiadas arrojan resultados de un $40 \%$ de Sobrepeso y de un $12 \%$ de Obesidad.

En Brasil (Halpern) las conclusiones presentadas al respecto son: Hubo incremento de la prevalencia de Sobrepeso y Obesidad del $53 \%$ al comparar los censos de los años 74/75 con 1989. Si se continua a este ritmo todos los brasileños seran obesos en la primera mitad del tercer milenio. El crecimiento epidémico es predominante en las clases menos favorecidas.

En Colombia se estiman porcentajes de IMC por encima de 30 en un $21 \%$ y entre 25 y 30 del $32 \%$, aunque faltan poblaciones para estudio.

En otras palabras, se ha demostrado que la Obesidad - como afirmamos al principio - ya está presente en Latinoamerica y es un problema real, que nos atañe a todos.

\section{Metodos para encarar el problema}

En la declaración de principios que rigen a la Federación Latinoamericana de Sociedades de Obesidad - FLASO, uno de los postulados fundamentales (Capítulo II) lo constituye justamente:

"Promover el progreso científico en el estudio y manejo de la Obesidad y la aproximación e intercambio entre los especialistas de America Latina dedicados a esta disciplina y recomendar lineas de conducta comunes en lo referente a nomenclatura, docencia, actividades científicas, $y$ en general en todo lo relacionado con el enfoque y manejo del paciente obeso para ser aplicado en toda Latinoamerica".

Cumpliendo este mandato, la Directiva de FLASO ha venido trabajando con el siguiente "modus operandi":

- Promoción de la Revista de SAOTA, como órgano oficial de la FLASO, y vinculo de comunicación científica entre todos los especialistas de Obesidad en Latinoamerica (Asamblea, Cartagena de Indias, III Congreso Latinoamericano de Obesi- dad, Agosto/96)

- Vinculación de México, paises centroamericanos y del área Bolivariana al nucleo de Sociedades Nacionales de Obesidad fundadoras de la FLASO, buscando una plena integración de toda Latinoamerica. (Asamblea Santafe de Bogota, Primer Curso Panamericano sobre el estudio de la Obesidad, Julio/98)

- Organización y realización del Prólogo al Consenso Latinoamericano de Obesidad (Villa de Leyva, Paipa, Julio/98), donde fueron sentadas las bases científicas y prácticas del Consenso, se constituyeron las Comisiones respectivas, se estableció un cronograma de trabajo y se acordó que un comite "ad hoc" quedase encargado de mantener un dialogo permanente en posteriores Congresos Internacionales sobre Obesidad. Asi, nos reunimos en Montevideo (Agosto/98) y luego en Paris (Septimbre 1/98) y se ha mantenido una constante comunicacion entre todas la Sociedades miembros de la FLASO.

Colaboración entusiasta y decidida con el equipo de la Asociación Brasileña de Obesidad ABESO, y en particular con el colega y amigo Walmir Coutinho, quien es el gestor y principal promotor de este Consenso.

\section{Diseño de una estrategia}

La culminación de todos estos esfuerzos puede resumirse - y como cortesía para los organizadores lo trascribimos en sus propias palabras - asi:

"Elaboração de um documento com recomendações abrangendo os mais diversos aspectos relacionados com o combate à obesidade, como métodos diagnósticos e terapêuticos, medidas preventivas de saúde pública e estratégias de vigilância ética na abordagem do paciente obeso"

Esto fue cristalizado durante los dias 8 a 11 de Octubre en Rio de Janeiro, en una Convención para la redacción final y lanzamiento del documento oficial del Consenso y tuve como feliz colofón la institucionalizacion del "Dia Internacional de Lucha contra la Obesidad ", el dia 11 de Octubre, en las playas de Ipanema. Como Presidente de la FLASO, me es muy grato presentar en estas lineas a manera de Prologo, este positivo informe de labores, y agradecer a todos los colegas, amigos todos, que nos han colaborado en este CONSENSO. Es el momento también de extender nuestra imperecera gratitud a la Industria Farmaceutica por su invaluable mecenazgo, que al final hace posible estos ambicionados logros:

Que tengamos todos, los especialistas en Obesidad, desde Mexico hasta la Patagonia, un punto de referencia, una guia cientifica y practica, comun a todos y entre todos elaborada. Nuestra Biblia.

Finalmente, que los paises latinoamericanos sean por fin uno solo.... entre las lineas de nuestro CONSENSO.

\section{Un abrazo FLASO}




\section{CAPÍTULO I}

\section{EPIDEMIOLOGIA, HISTORIA NATURAL DEL PESO SALUDABLE Y DEL SOBREPESO. PREVENCIÓN .}

\section{Historia natural del peso saludable y composi- cion corporal.}

En las distintas etapas del ciclo de vida los seres humanos son el producto acumulado de la interacción del patrimonio genético heredado de sus progenitores y el macro ambiente socio económico, cultural y educativo y el micro ambiente individual, familiar y comunal en el que las personas son concebidas, nacen, crecen, maduran, se reproducen involucionan y mueren.

Cuando se consideran las condiciones de salud y nutrición de las poblaciones si se realizan análisis situacionales tendremos la oportunidad de identificar no solamente las personas y poblaciones que tienen problemas, sino aquellas que viviendo en ambientes similares tienen las capacidades necesarias para mantener la estatura, un peso y composicion corporal saludable y un adecuado estado de salud y nutrición.

\section{Peso saludable}

Cuando las condiciones del macro y micro ambiente han sido favorables para para alcanzar un crecimiento apropiado, el peso saludable de hombres y mujeres se mueve dentro de un rango que va del percentil cinco (5) al percentil noventa y cinco (95). Cuando el proceso de crecimiento en talla termina en la vida adulta se considera que el peso saludable corresponde a un Indice de Masa Corporal, IMC, de 18 a $25 \mathrm{~kg} / \mathrm{m}^{2}$.

Utilizando este concepto sabemos que para una misma talla hay una gran variedad de pesos que se pueden alcanzar en las distintas edades. Cuando menor es la talla menor es la amplitud del rango de pesos. La amplitud del rango de pesos es mayor cuanto mayor es la talla.
En la Tabla 1 se presenta el rango de valores de peso saludable para valores de estatura seleccionados en mayores de 20 años.

\section{RIESGO Y FACTORES DE RIESGO}

\section{Riesgo}

Los seres humanos a cualquier edad son el resultado del proceso acumulativo de la interacción de diferentes factores. La probabilidad de que las personas estén a riesgo de sufrir problemas de sobrepeso u obesidad en circunstancias definidas y edades determinadas está condicionada al grado de susceptibilidad que tengan y a la exposición continua y acumulativa de diferentes factores de riesgo que puedan afectar tanto a las poblaciones como a las personas.

\section{Factores de riesgo}

Según su procedencia los factores de riesgo de la obesidad y otras condiciones pueden ser endógenos o ambientales.

Riesgos Endógenos: La característica de los riesgos endógenos es que son inherentes a las personas y no son modificables. Estos atributos son el Patrimonio Genético, el Sexo, la Edad y la Raza.

Riesgos Ambientales: La característica de los riesgos ambientales es que son los determinantes de que en una persona suceptible que se exponga a ellos se generen problemas de sobrepeso y obesidad. Las intervenciones orientadas a cambiar la situación encontrada tanto a nivel de personas como de población, están orientadas a modificar favorablemente la acción de los factores de riesgo. Un grupo de factores numéricamente pequeño, pero muy complejo en su interacción, es responsable de que en personas susceptibles se presenten problemas de obesidad. Este mismo grupo de factores actuando con diferentes grados de intensidad y profundidad es responsable de que se presenten otras Enfermedades Crónicas no Transmisibles como Enfermedades Cardiovasculares, Cáncer, Accidentes Cerebro Vascu-

Tabla 1. Rango de Peso Saludable para valores de Estatura Seleccionados en mavores de 20 años.

\begin{tabular}{ccc} 
Estatura $(\mathrm{cm})$ & Peso $(\mathrm{kg})$ Valor Inferior & Peso $(\mathrm{kg})$ Valor Superior \\
145 & 38 & 52 \\
150 & 41 & 56 \\
155 & 44 & 60 \\
160 & 47 & 64 \\
165 & 50 & 68 \\
170 & 53 & 72 \\
175 & 56 & 77 \\
180 & 59 & 81 \\
185 & 62 & 85 \\
190 & 65 & 91 \\
\hline
\end{tabular}


lares, Diabetes e Hipertensión. A su vez algunas ECNT se convierten en factores de riesgo que determinan la aparición de otras enfermedades. La pregunta que surge es porqué aunque las personas estén expuestas a riesgos similares no siempre desarrollan una o más enfermedades?.

Riesgos a Nivel de Población: Cuando la obesidad afecta a un gran número de personas en la población la pregunta que surge es porqué algunas poblaciones tienen problemas de sobrepeso y obesidad y otras no?. Las respuestas son variadas y se orientan a identificar las características de las poblaciones que presentan el problema y las que no lo presentan, para conocer las causas de la incidencia o casos nuevos. La información obtenida sirve para modificar los riesgos de exposición. Las acciones que se realicen para modificar la situación encontrada están dirigidas a toda la población con lo cual se consigue una alta cobertura, eficacia y rendimiento de los programas que se establezcan.

Riesgos a Nivel Individual: Cuando la obesidad se considera a nivel individual la pregunta que surge es porqué algunas personas tienen problemas de sobrepeso u obesidad y otras no?. Al igual que ocurre con la consideración de los riesgos a nivel de población las respuestas son variadas y se orientan a identificar las características de las personas que presentan el problema y las razones por las cuales ocurre. De esta manera se identifican los susceptibles de alto riesgo y se les ofrece la atención personal que cada uno de ellos requiere para modificar la situación encontrada. Este grupo de personas es una proporción relativamente baja dentro de la población que requiere intervenciones costosas, con eficacia y rendimientos bajos y unas tasas altas de recidivas.

Indice de Masa Corporal y Magnitud del Riesgo: Se considera que el Indice de Masa Corporal, IMC, o la relación del peso en kilogramos sobre la estatura elevada al cuadrado es el índice de elección para valorar la magnitud del riesgo. Sin embargo, la controversia científica sobre los criterios que se deben utilizar para definir los riesgos no está completamente dilucidada.

Una alternativa que se sugiere es la siguiente: En cualquiera de los grupos la presencia de comorbilidades o de otros factores de riesgo aumenta la magnitud del riesgo.

\begin{tabular}{lll} 
Magnitud del Riesgo & $\mathrm{IMC}\left(\mathrm{kg} / \mathrm{m}^{2}\right)$ & \\
\hline Peso Saludable & 18 a 24.9 & \\
Moderado & 25 a 29.9 & Preobesidad \\
Alto & 30 a 34.9 & Obesidad grado I \\
Muy Alto & 35 a 39.9 & Obesidad grado II \\
Extremo & 40 y $(+)$ & Obesidad grado III \\
\hline
\end{tabular}

El manejo integral de la situación requiere tanto las intervenciones a nivel de población como a nivel individual.

\section{LA OBESIDAD COMO FACTOR DE RIESGO}

Un número importante de patologías están asociadas con la obesidad. La obesidad como factor de riesgo de estas condiciones aumenta sustancialmente el riesgo de padecerlas y aumenta la probabilidad de enfermar y morir.

\section{Enfermedades Cardiovasculares}

Los estudios epidemiológicos establecen una asociación entre obesidad y varios factores de riesgo de ECV tales como Intolerancia a la Glucosa, Diabetes, Hipertensión e Hiperlipidemia. Las enfermedades cardiovasculares constituyen la primera causa de muerte en los países tecnológicamente desarrollados y se perfila como la primera causa de muerte por ECNT en los países en vías de desarrollo. En la obesidad de tipo central la mayor biodisponibilidad de ácidos grasos para el metabolismo tisular induce a la resistencia periférica a la insulina e hiperinsulinemia lo cual favorece el desarrollo de hipertensión y aterosclerosis.

La mayor evidencia del efecto de la obesidad en relación a las ECV es el hecho que la disminución progresiva del peso disminuye la tasa de mortalidad por ECV en un 50\%. Cuando el IMC se mantiene dentro de los valores del peso saludable, 18 a 24 , disminuye la frecuencia de ECV en un $25 \%$ y la mortalidad por enfermedad coronaria en un 15\%. La proporción de riesgo atribuíble a la obesidad en la enfermedad cardíaca coronaria ha sido estimada entre el 32 y el $40 \%$ en mujeres mayores de 40 años.

La Obesidad como Factor de Riesgo de Enfermedades $y$ Condiciones Asociadas:

\begin{tabular}{ll}
\hline \multicolumn{1}{c}{ Enfermedades } & Condiciones Asociadas \\
\hline - Cardiovasculares & - Hipercolesterolemia \\
- Diabetes Mellitus, DMNID & - Dislipidemia \\
- Cerebrovasculares & - Disminución LAD (HDL) \\
- Cáncer & - Intolerancia a la glucosa \\
- Hipertensión & - Hiperinsulinemia \\
- Osteoartrtitis & - Trastornos Menstruales \\
- Colelitiasis & - Apnea del sueño \\
\hline
\end{tabular}




\section{Diabetes}

Entre un 80 y $90 \%$ de pacientes con Diabetes NID son obesos. La mayor prevalencia de diabetes ocurre con IMC mayores de 28. El riesgo de desarrollar Diabetes NID aumenta al doble en obesidad baja; aumenta 5 veces en obesidad moderada y 10 en obesidad severa. Por otra parte con pérdidas moderadas de peso del 5 al $10 \%$ mejora el control de la glicemia y reduce la hiperinsulinemia.

\section{Hipertensión}

El aumento de peso con valores superiores al peso saludable está asociado con la hipertensión. El riesgo de hipertensión es dos veces mayor en pacientes obesos. De cada dos pacientes hipertensos uno es hipertenso a consecuencia de la obesidad. Por otra parte disminuciones significativas de 3 a $5 \mathrm{~kg}$ de peso reducen la necesidad de utilizar medicamentos en aproximadamente el $50 \%$ de los pacientes hipertensos.

\section{Cáncer}

Estudios epidemiológicos realizados en diferentes países reflejan que los pacientes obesos tienen riesgos aumentados de cánceres digestivos tanto en varones como en mujeres, especialmente después de la menopausia. En igual forma, hay una asociación entre obesidad y cánceres de próstata, útero y seno. El papel de la alimentación en los cánceres colorectales se asocia con la ingestión de un exceso de grasas animales y escasa o ninguna ingestión de frutas y verduras que son ricas en beta carotenos y antioxidantes. Sin embargo, la reducción de peso es la que tiene un efecto significativo mayor en la disminución de la incidencia de cáncer digestivo.

\section{Osteoartritis}

El exceso de carga en los pacientes obesos sobre las articulaciones, particularmente de cadera y rodilla estimula y favorece las lesiones de las superficies articulares. Estudios epidemiológicos realizados en Estados Unidos y Finlandia revelaron que una alta proporción de hombres y mujeres que padecían de osteoartritis eran obesos. Al igual que en otras condiciones mencionadas anteriormente una disminución progresiva y sostenida del peso mejora la condición de osteoartritis.

\section{PREVALENCIA}

Aún con las diferencias existentes en los países para definir los puntos de corte del Indice de Masa Corporal para elaborar la clasificación de obesidad, se considera que este problema tiene características epidémi- cas, con aumentos sostenidos en los últimos años, particularmente en los países tecnológicamente desarrollados. Sin embargo, la situación emergente en los países en vías de desarrollo es particularmente critica y afecta no solamente a los grupos económicamente favorecidos, sino a los menos favorecidos. Aunque la prevalencia sea sustancialmente menor que en los países desarrollados, el número total de personas afectadas es proporcionalmente mayor.

La información disponible para América Latina en la década del 80 al 90 utilizando el Indice de Masa Corporal igual o superior a 25 , refleja que la prevalencia de sobrepeso en Uruguay era de $50 \%$ para hombres y mujeres. En Chile de $50 \%$ para las mujeres y $40 \%$ para los varones. En Colombia de $50 \%$ para los varones y $30 \%$ para las mujeres. En Brasil de $40 \%$ para las mujeres y $27 \%$ para los varones; En Costa Rica de $40 \%$ para los varones y $20 \%$ para las mujeres. En Cuba de 38\% para los varones y $30 \%$ para las mujeres. En Perú de 38\% para los varones y $28 \%$ para las mujeres. En México de $30 \%$ para los varones y $35 \%$ para las mujeres.

La tendencia en Estados Unidos desde 1960 ha sido a un aumento constante de la prevalencia de sobrepeso en la población de 20 a 74 años de edad con los mayores valores en las mujeres negras y méxico-americanas. Los niños y adolescentes fueron clasificados con sobrepeso cuando el índice de Masa Corporal era igual o superior al percentil 95. Los adultos fueron clasificados con sobrepeso cuando el Indice de Masa Corporal era igual o superior a 27.8 para los varones y 27.3 para las mujeres. Estos valores corresponden al percentil 85 . La información disponible del NHANES III refleja que el $14 \%$ de los niños y el $12 \%$ de los adolescentes tenían sobrepeso. En los adultos las cifras eran de $33 \%$ para los varones y $36 \%$ para las mujeres. Entre las mujeres blancas no hispanas la prevalencia era de $34 \%$, en las negras no hispanas era de $52 \%$ y en las méxico-americanas $50 \%$.

Informaciones basadas en los resultados de la Fase I del NHANES III indican que la prevalencia de sobrepeso aumentó, en los períodos 1976-1980 a 1981-1991, en los niños de $7.6 \%$ a $10.9 \%$ y en los adolescentes de $5.7 \%$ a $10.8 \%$; en los adultos el aumentó fué de $25.4 \%$ a $33.3 \%$. La prevalencia fué mayor en la población negra que en la población blanca. El aumento en la prevalencia es el resultado de un cambio positivo en el balance gasto energético y actividad física.

Para los años 90 un 53\% de los adultos con sobrepeso estaban tratando de perder peso. Se estima que los gastos asociados a las pérdidas voluntarias de peso oscilaban entre 30 y 50 mil millones de dólares anualmente, sin que se obtengan resultados efectivos. 
Para la realización de estudios de prevalencia en el Anexo №. I se sugiere la metodología que puede utilizarse.

\section{ETAPAS Y NIVELES DE PREVENCION Y TRATAMIENTO}

El manejo integral de la obesidad en sus aspectos preventivos y de tratamiento es una responsabilidad compartida por distintos profesionales que de una manera coordinada trabajan con distintas alternativas. La aproximación integral incluye los siguientes aspectos: Mantenimiento del Peso Saludable, Prevención de la Ganancia de Peso, Estabilización del Peso, Manejo de Comorbilidades, Pérdida de Peso. Para conseguir resultados satisfactorios en el proceso es necesario tener en cuenta la superposición que existe en la realización de las distintas actividades.

Una vez identificada la situacion existente y los factores que intervienen se tienen los elementos de juicio para definir las etapas y niveles de intervencion. La Característica multifactorial de la obesidad y otras enfermedades crónicas no transmisibles hace necesario buscar una aproximación diferente a los niveles de prevención que corresponden a los aspectos mencionados en la aproximación integral de la situación.

Se consideran cuatro niveles de prevención: Prevención Primordial, Prevención Global o Universal, Prevención orientada a grupos específicos y Prevención orientada a grupos de alto riesgo.

\section{Etapa de Prevencion Primordial}

En esta etapa hay un equilibrio inestable en la interacción de personas, factores de riesgo y el macro y micro ambiente en que se vive que permiten mantener un peso saludable. Considerando un enfoque positivo, los esfuerzos que se hagan se dirigen a la poblacion que mantiene condiciones favorables de salud y de peso, independiente de la etapa del ciclo de vida en que se encuentre. Se busca, en lo posible que las personas y poblaciones no se expongan a factores de riesgo y estilos de vida que modifiquen la situacion favorable que tienen o han tenido para mantener un peso saludable.

\section{Nivel de Mantenimiento del Peso Saludable a traves del Ciclo de Vida}

Si se utiliza como criterio el peso al nacimiento, la gran mayoria de los recién nacidos tienen pesos apropiados para su edad gestacional (iguales o mayores de 2.500 gramos). Esta proporción oscila entre 91 y $94 \%$ en los países tecnológicamente desarrollados. En los países menos desarrollados los valores estan entre 85 y $91 \%$. En ambos grupos de países la proporción de recién nacidos con sobrepeso ocurren en condiciones patológicas definidas como es el caso de madres diabéticas y se presentan en proporción relativa a la prevalencia de embarazadas diabéticas.

Considerando el patrimonio genético de las poblaciones, las características del macro y microambiente en que vivan determina en última instancia si se puede mantener el peso saludable o por el contrario se inicia la historia natural del sobrepeso y la obesidad o la historia natural de la desnutricion.

\section{Estilos de Vida Saludables}

Si se modifican los paradigmas que habitualmente se utilizan para referirse básicamente solo a situaciones

Característica del Riesgo y Manejo de la Enfermedad:

\begin{tabular}{|c|c|c|c|}
\hline Riesgo & IMC & Manejo & Participación Profesional \\
\hline Peso Saludable & $18-24.99$ & $\begin{array}{l}\text { Alimentación } \\
\text { saludable. } \\
\text { Actividad Física Regular }\end{array}$ & $\begin{array}{l}\text { Autoregulación } \\
\text { y Educación en salud }\end{array}$ \\
\hline Moderado & $25-29.99$ & $\begin{array}{l}\text { Idem (+) } \\
\text { Dieta } \\
\text { Farmacoterapia si } \\
\text { hay comorbilidad }\end{array}$ & $\begin{array}{l}\text { Idem (+) } \\
\text { Médicos y Nutricionistas }\end{array}$ \\
\hline Alto & $30-34.99$ & $\begin{array}{l}\text { Idem(+) } \\
\text { Terapia Farmacológica }\end{array}$ & $\begin{array}{l}\text { Idem (+) } \\
\text { Ciencias de la conducta }\end{array}$ \\
\hline Muy Alto & $35-39.99$ & $\begin{array}{l}\text { Idem (+) Posibilidad } \\
\text { Cirugía }\end{array}$ & Idem (+) Médico Cirujano \\
\hline Extremo & $40 \vee(+)$ & Idem (+) Cirugía & Idem \\
\hline
\end{tabular}

Nota: Com cualquier nivel de riesgo si hay comorbilidad puede ser necesaria la utilización de medicamentos. 
problemáticas, tendremos elementos de juicio para identificar los factores positivos que permiten a una parte de la población mantener pesos saludables, aunque vivan en ambientes similares a los que tienen problemas de obesidad.

Los estilos de vida saludables están estrechamente relacionados con la satisfacción integral de las necesidades básicas. Además, de la satisfacción de las necesidades básicas, es necesario tener:

\section{Una alimentación saludable}

La alimentación saludable es necesario mantenerla a través de todo el ciclo de vida de acuerdo a los hábitos costumbres y patrones alimentarios de las poblaciones que conforman la cultura alimentaria de los pueblos. Para conseguirlo es necesario mantener los principios de que sea adecuada, suficiente, armónica y que esté de acuerdo a las condiciones de salud y nutrición de las personas y las poblaciones.

\section{Realizacion Regular de Actividades Físicas}

Uno de los cambios más notables que han ocurrido en las últimas décadas ha sido la tendencia a una disminución de la actividad física regular. Esta situación se ha hecho más notoria con el desplazamiento de la población del campo a las ciudades y la tendencia a realizar menor actividad física. Por otra parte, el advenimiento de la televisión, contribuye a la disminución de actividades al aire libre que demandan esfuerzos fisicos y se sustituyen por programas de televisión. La revisión de los currículos escolares para mantener o incluir clases de educación física con una frecuencia de por lo menos tres veces a la semana, lo cual es una forma práctica de promover la formación de hábitos apropiados de actividad física que puedan mantenerse a lo largo del ciclo de vida.

\section{Educación Permanente y Sistemática en Nutri- ción, Peso Saludable Sobrepeso y Obesidad a Profesionales de la Salud y otras disciplinas}

Una limitación muy frecuente que se encuentra en la vida real para la aplicación de medidas que modifiquen hábitos y patrones de la población, es la escasez o ausencia de personal calificado con el conocimiento necesario para mantener y fomentar modificaciones en las condiciones de salud, nutrición y peso saludable, sobrepeso y obesidad de las personas. Con las característica epidémicas que tiene la obesidad, debería ser prioritario el que se incluya como parte de los currículos de profesionales de la salud y otras disciplinas la enseñanza sobre estos temas.

\section{Etapa de Prevención Global}

En la etapa de prevención global las acciones que se realicen deben tener una orientación similar a la realizada durante la etapa de prevención primordial, excepto que los esfuerzos se dirigen a toda la población independiente de las características de peso que tenga. Proporciones importantes de personas pueden estar en dsitintas etapas de modificación del peso saludable y puede haber manifestaciones de aumento de la prevalencia e incidencia y de la comorbilidad mediada por el sobrepeso o la obesidad.

\section{Formulacion de Políticas Gubernamentales}

El manejo de situaciones críticas como la obesidad que tienen una prevalencia tan elevada hacen necesario el que se definan políticas gubernamentales que guien y orienten el manejo de la situación a nivel individual y colectivo. Para conseguir una formulación apropiada se requiere la participacion de la Industria Alimentaria, Industria Farmacé́tica, Entidades No Gubernamentales, Entidades Privadas, Instituciones Académicas, Asociaciones Científicas y Profesionales, Grupos Organizados de la Comunidad y Pacientes. Uno de los aspectos fundamentales en los que queremos llamar la atención es la importancia de la industria alimentaria y los medios de comunicación en relación a la información que proporcionan sobre temas de salud y nutrición.

\section{Rotulación del valor nutricional de los alimento} Como parte del proceso alimentario educativo para la población es necesario que se establezca, sino existe, una regulación de la información nutricional de los alimentos procesados. La información debe permitir que la población que no sabe leer pueda identificar los alimentos cuyos contenidos nutricionales han sido modificados, para disminuir o aumentar el contenido de determinados macro y micro nutrientes.

\section{Prevención orientada a grupos específicos}

Las actividades que se realizan están orientadas a grupos identificados como de riesgo para desarrollar obesidad. Además, de los aspectos mencionados en la etapa de prevención primordial, es necesario el mejorar la capacidad educativa que les permita manejar efectivamente los factores que los ponen en riesgo de desarrollar la obesidad. La realización de las estrategias de acción debe involucrar la participación de los gobiernos, la industria alimentaria y los medios de comunicación.

\section{Prevención orientada a grupos de alto riesgo}

Las consecuencias de la acción de los factores de riesgo determina que estos sean grupos que presentan ma- 
nifestaciones de sobrepeso y marcadores biológicos asociados con aumento del compartimento graso. De no establecer estrategias apropiadas con estos grupos, aumenta la probabilidad de presentar la enfermedad obesidad.

\section{METODOLOGÍA SUGERIDA PARA ESTUDIOS DE PREVALENCIA DE OBESIDAD}

\section{Muestreo Aleatorio por Conglomerados:}

I. Identificación de municipios de la zona de estudio por categorías de acuerdo a la distribución de la población.

2. Distribución geográfica proporcional de los municipios.

3. Utilizar un nivel de confianza del $95 \%$.

4. Nivel de precisión relativa del $10 \%$.

\section{LECTURAS RECOMENDADAS}

1. Albernathy RP, Black R. Healthy body weights: an alternative perspective. Am J Clin Nutr 1996;63(suppl):51S.

2. Committee on Diet and Health, National Research Council. Diet and Health: implications for reducing chronic disease risk. Washington. DC: National Academic Press, 1989:564.

3. Blackburn GL, Dwyer JT, Flanders WD, et al. Report of the American Institute of Nutrition Steering Committee on Health Weigth. J Nutr 1994;124:2240-3.

4. Dietz WH. Critical periods in childhood for the development of obesity. Am J Clin Nutr

5. Kuczmarski RJ, Flegal K, Campbell S, Johnson C. Increasing prevalence of overweight among US adults. JAMA 1994;272:205- 11 .

6. Popkin BM. The nutrition transition in low income countries. An emerging crisis. Nutrition Reviews 1994:52:28598.

7. Troiano R, Flegal K, Kuczmarski RJ, Campbell S, Johnson C. Overweight prevalence and trends for children and adolescent. Arch Pediatr Adolesc Med 1995;149:108591.

8. Pi-Sunyer FX. Medical hazards of Obesity. Ann Intern Med 1993: 119:655-60.

9. Blokstra A, Krombout D. Trend in obesity in young adults in the Netherlands from 1974 to 1986. Int J Obes $1991 ; 15: 513-21$.

10. Pagano R. La Vechia C. Overweight and obesity in Italy, 1990. Int J Obes Relat Metab Disord 1994;18:665-9.

11. Seidell JC. Obesity in Europe. Obes Res 1995;3(suppl 2):89S-93S.

12. World Health Organization. Report of a WHO Consultation on Obesity. Obesity, Preventing and Management the Global Epidemic. Geneva, 1997.

\section{CAPÍTULO 2}

\section{ETIOPATOGENIA Y FISIOPATOLOGÍA}

Obesidad es una, incremento de la incidencia de algunos tipos de carcinoma y de la mortalidad.

Se define la obesidad como la acumulación excesiva de grasa de una magnitud tal que compromete la salud.

En el origen de la obesidad existen factores genéticos, sicosociales, culturales nutricionales, metabólicos y endócrinos que le dan un carácter multifactorial. La obesidad se genera por una interacción entre factores genéticos y culturales, así como familiares.

Existe una clara tendencia entre los miembros de una familia a tener un IMC (índice de masa corporal) similar. Diversas publicaciones han demostrado una correlación entre el IMC de los padres y los de sus hijos, lo cual sugiere que probablemente tanto los genes como un ambiente familiar compartido contribuyen al desarrollo de obesidad.

Los estudios com gemelos monocigotas muestran que entre ellos hay una mejor correlación entre el IMC que entre gemelos dizigotas a pesar de que estos últimos comparten un mismo ambiente familiar. Se há demostrado que entre los gemelos idénticos una similitud de otros indicadores de composición corporal, no solo el índice de masa corporal como la determinacion de grasa corporal y masa magra.

Todo ello, apoya la evidencia de que los genes tienen un papel relevante en la determinacion del índice de masa corporal y en la distribución corporal del tejido adiposo.

Análisis estadísticos confiables han demostrado que el $25 \%$ de la varianza trasmisible total es atribuible al factor genético, $30 \%$ a la trasmisión cultural y $45 \%$ a otros factores ambientales no trasmisibles. Estis mismos análisis tambié n sugieren que existe una mayor influencia genética en el acúmulo de grasa visceral que en la subcutánea.

Por lo tanto el exceso de grasa corporal está determinado por la herencia cultural y la herencia genética. O sea que la interacción genético-ambiental es la que promueve el desarrollo de obesidad en un individuo.

\section{ASPECTOS METABÓLICOS Y ENDÓCRINOS}

A) Gasto energético reducido; B) Cociente respiratorio elevado; C) Resistencia a la insulina; D) Hiperinsulinismo compensatorio; E) Acúmulo excesivo de grasa visceral; F) Hipercortisolismo funcional; G) Hipogonadismo secundario; H) Hiperactividad del sistema nervioso simpático; I) Hiperleptinemia; J) 
Hiperestimulación del eje hipofiso-adrenal; K) Actividad neurofisiológica aumentada del neuropeptido Y.

A) Gasto energético reducido: Estudios realizados han concluido que el gasto energético está reducido en los obesos, por lo que aún com la ingesta calórica diaria relativamente normal su baja inversión de calorías en los procesos metabólicos favorece el ahorro de energía y la acumulación de grasa, que se favorece por la termogénesis inadecuada y la menor respuesta termogénica adrenérgica.

B) Cociente respiratorio elevado: Predice una mayor ganancia de peso, parece estar determinado geneticamente, habiendoselo encontrado elevado en familias de obesos en comparación com sujeros delgados.

C) Resistencia a la insulina: Se define como una respuesta menor a la esperada.y se estudia mediante el clamp de insulina. Una disminución en la utilización de glucosa se interpreta como una disminución de la respuesta biológica a la hormona. Durante los últimos anos a sido sumamente estudiado siendo discutido si es causa o consecuencia

D) Hiperinsulinismo compensatorio: Efectos derivados:

Acumulación incrementada de grasa visceral; $\mathrm{Au}-$ mento en la liberación de ácidos grasos libres hacia el hígado vía portal; Perfil lipidico alterado (disminución de HDL, aumento de LDL pequenas y densas, APO B elevado); Aumento en la resorción de sodio y agua; Cifras elevadas de tensión arterial; Intolerancia a los carbohidratos; Actividad aterogénica alterada; Enfermedad arterial coronaria prematura; Incremento en el riesgo de padecer cáncer de mama, endometrio y colon

\section{Factores Nutricios:}

Ya se senalo que la obesidad es el resultado de ingerir mas energía que la que se necesita. No hay duda que las personas obesas consumen una mayor cantidad de calorías en su alimentación diaria. Este consumo excesivo puede iniciarse en tempranas muy de la vida y en ello las influencias culturales y los hábitos de cada familia juegan en particular un rol fundamental.

A su vez, quienes defienden que la resistencia a la insulina es en algunos casos causa mas que efecto de la obesidad, subraya las siguientes modificaciones que se han descrito con relativa constancia en los pacientes obesos, y que pudieron responder a un origen genético:

Una disminución del transportador de la glucosa (GLUT 4) en sus células musculares, mientras que los adipositos se encuentra aumentado, lo que se a asociado a hiperplasia de los mismos;

- Resistencia intracelular para la acción de la insulina, ocasionandose modificaciones en las enzimas que regulan el metabolismo energético. Cuando los sujetos obesos disminuyen de peso se mejora pero no se revierte por completo la disminución de la capacidad funcional de alguna de estas enzimas;

- En aquellos sujetos com obesidad androide, hiperinsulinemia y resistencia a la insulina, es mas frecuente encontrar alteraciones en la región hipervariable del gen de la insulina;

- Los obesos que presentan hiperinsulinemia en ayunas son homocigotos para alteraciones en varios fragmentos del gen que codifica al receptor de glucocorticoides.

\section{ASPECTOS NUTRICIONALES}

La composición de la dieta es importante. Los lactantes que se alimentan com formulas artificiales tienen mas problemas de sobrepeso que los alimentados com leche materna.

Los hijos de padres obesos aceptan mas facilmente alimentos de sabor dulce. Esta conducta que posiblemente es condicionada geneticamente es perceptible desde el 6 mês de vida postnatal, presentando una incidencia mayor de obesidad en la vida adulta.

Se há observado que los individuos obesos, comen menos veces al dia que los no obesos. La personas que realizan una o dos comidas fuertes al dia, suelen tener mas sobrepeso, mas altos niveles de colesterol y alteraciones de la tolerancia de carbohidratos, que las personas que cumplen 3 o mas comidas al dia.

Otros estudios sobre los hábitos alimentarios de los obesos, muestran que estos por lo general tienden abusar de alimentos grasos, que por ser de una elevada densidad energetica, favorece su deposito en forma de grasa corporal. Así como tambien de cantidades altas de hidratos de carbono que incrementan el valor calorico total de la dieta.

Se piensa que la grasa es menos eficaz que las proteinas y de los hidratos de carbono para enviar la senales de saciedad que va del tracto gastrointestinal al centro del control del apetito en el cerebro. De manera que las personas que comen dietas muy ricas en grasas, comen por periodos mas largos y en cantidad mayor.

El grado de actividad fisica es menor en los obesos, tanto en adolescentes como en los adultos, tendiendo a ser mas sedentarios que las personas no obesas. El fenomeno de la urbanización trae aparejado una disminución de la actividad fisica de la población en su 
conjunto, lo que, aunado a los cambios observados en la alimentación desde hace varias decadas, se constituye en un factor adicional para explicar el incremento de la obesidad y sus complicaciones.

En la evaluación individual del obeso, debe incluirse una revisión de los habitos alimentarios del paciente, y de su familia, mediante una encuesta que puede ir desde la mas sencilla (suceptible a cometer un subregistro de alimento) basada en un registro de la ingesta del dia anterior a la consulta, hasta encuestas de 3 dias o 1 semana, registradas en un diario de alimentación, que se le proporciona junto com las instrucciones para anotar su consumo detallado de nutrientes.

\section{MEDICAMENTOS QUE INDUCEN AUMENTO DE PESO}

Varias drogas pueden producir aumentos ponderales: los glucocorticoides, los antidepresivos tricíclicos (particularmente la amitriptilina), la ciproheptadina, las fenotiazinas, los progestagenos como la medroxiprogesterona y el litio. Es bien conocida la ganancia de peso y el aumento de la sensación de hambre, que se produce al dejar el hábito de fumar, confirmando que la nicotina tiene cierto efecto supresor sobre apetito.

Se asume que en los sujetos obesos existe una alteración de las senales humorales, que funcionan como aferentes para la regulación del apetito a nivel hipotalamico, ya que existe un aumento de la sensibilidad para el neuropeptido $\mathrm{Y}$ a nivel del nucleo paraventricular, lo que condiciona tanto un aumento del apetito de la insulinemia, de la lipogenesis y por outra parte una disminución del metabolismo basal y del consumo de oxigeno. El aumento de la actividad de este neuropeptido $Y$ también condiciona un aumento del tono simpatico que puede empeorar aun mas la resistencia a la insulina, generada ya por otros mecanismos.

\section{NEUROTRASMISORES QUE INFLUYEN SOBRE EL APETITO Y SACIEDAD}

Aminoacido Gamma-Aminobutirico (Gaba); Factor Liberador de Hormona de Crecimiento; Neuropeptidos Opiodes; NPY; PYY; Galanina; Dopamina; Norepinefrina; Neurotensina; Calcitonina; Glucagon; $\mathrm{CRH}$; Serotonina

\section{OTROS ASPECTOS HORMONALES Y NEUROENDOCRINOS}

Las monoaminas y péptidos neurotrasmisores poseen potentes y variados efectos sobre los centros cerebrales que regulan la conducta alimentaria. Al menos seis distintos neurotrasmisores influyen para estimular el aumento de apetito, entre los que cuentan la noradrenalina, el aminoacido gamma-aminobutirico (GABA), la hormona liberadora de hormona de crecimiento y tres clases de neuropéptidos: los opioides, neuropeptido Y y péptido YY y galanina. Por outro lado entre los neurotrasmisores com efecto inhibitorio sobresale la dopamina, la misma norepinefrina actuando a través de receptores adrenérgicos beta, la nerotensina, la calcitonina, el glucagón, la hormona liberadora de corticotropina (CRH), y la serotonina, está última com interesantes implicaciones desde el punto de vista de la intervención farmacológica.

\section{ASPECTOS SOCIOECONÓMICOS Y SICOLÓGICOS EN EL DESARROLLO DE OBESIDAD}

En los países industrializados, la obesidad es más prevalente en los grupos socioeconómicos de menores ingresos y de menor nivel educacional. De acuerdo con los resultados de las últimas encuestas de salud en América Latina, también se ha encontrado un mayor porcentaje de población obesa en los sectores menos favorecidos.

También se han reconocido factores sicológicos en la génesis de la obesidad. Las perturbaciones emocionales a menudo precipitan episodios de sobrealimentación. Este fenómeno se le ha denominado "Obesidad reactiva".

En personas deprimidas o con otro tipo de deprivación emocional la comida puede jugar un papel compensatorio que favorezca crónicamente la ganancia de peso. Sin embargo, no existe una sola definición de la personalidad del paciente obeso, asi como tampoco alguna alteración siquiátrica característica. La sicopatología que pueda acompañar a la obesidad no debe considerarse necesariamente la causa primaria de la misma, pero es de gran importancia no pasarla por alto ya que su tratamiento deberá orientar también las estrategias generales de la atención del paciente obeso. En no pocos casos puede ser necesaria la evaluación sicológica o siquiátrica del paciente por un especialista en esas áreas si se considera que el factor síquico es relevante e interfiere con el manejo convencional de la obesidad.

\section{LECTURAS RECOMENDADAS}

1. Bouchard C. Genetic aspects of Human Obesity. En: Bjomthorp P. Brodoff BN (eds). Philadelphia: Lippincott Company, 1995: 343-351. 
2. Bray $G A$. An approach to the classification and evaluation of Obesity. Ibid 294-308.

3. Eckel, RH. Insulin Resistance: An adaptation for weight maintenance. Lancet 1992:340: 1452-1462.

4. Lissner L, Heitmann BL. Dietary fact and obesity: evidence from epidemiology. Eur J Clin Nutr 1995: 49:79-90.

5. Ravussin E, Swinburn BA. Pathophisiology of Obesity. Lancet 1992; 340:404-408.

6. Sorensen TIA. The Genetics of Obesity. Metabolismo 1995;44(9, suppl 3): 4-6

7. Stunkard AJ. Obesity. En: Kaplan HI, Freedman AM, Sadock BJ (eds). Comprehensive Texbook of Psychiatry. Baltimore: Williams and Wilins, 1985:1133.

8. Wadden TA, Stunkard AJ. Psychopathology and Obesity. Ann NY Acad Sci 1987: 55

\section{CAPÍtUULO 3}

\section{TRANSTORNOS ALIMENTARES ASSOCIADOS COM A OBESIDADE}

Apesar de não encontramos uma psicopatologia específica, o obeso apresenta um sofrimento psicológico decorrente dos problemas relativos ao preconceito social com a obesidade e também com características peculiares do seu comportamento alimentar. A presença freqüente de alterações do comportamento alimentar em pacientes obesos torna imprescindível o reconhecimento e diagnóstico clínico dos transtornos alimentares nesta população.

O conhecimento da atual classificação dos transtornos alimentares, segundo a quarta edição do Manual Diagnóstico e Estatístico dos Transtornos Mentais da Associação Psiquiátrica Americana (DSM-IV) pelo profissional de saúde que atende pacientes obesos, pode auxiliá-lo no acompanhamento destes pacientes. A seguir encontraremos uma apresentação resumida dos transtornos alimentares e a relevância de cada diagnóstico para o profissional de saúde que trata de pacientes que procuram tratamento para perder peso.

\section{OS TRANSTORNOS ALIMENTARES}

Os transtornos alimentares são enfermidades psiquiátricas caracterizadas por alterações graves do comportamento alimentar. $\mathrm{Na}$ seção dedicada aos transtornos alimentares da DSM-IV iremos encontrar duas categorias diagnósticas principais: a Anorexia Nervosa (AN) e a Bulimia Nervosa (BN). Na AN a recusa em manter um peso corporal mínimo aceitável para a idade é uma das características essenciais da síndrome. $\mathrm{O}$ aspecto central da $\mathrm{BN}$ é o episódio de compulsão alimentar (ingestão de uma grande quantidade de comida num curto intervalo de tempo), seguidos por comportamentos inapropriados como os vômitos auto-induzidos. Entretanto, a alteração na percepção que as pacientes ( 1 ) tem da sua forma $\mathrm{e}$ do seu peso corporal têm sido considerada como a característica psicopatológica comum a todos os trantornos alimentares.

Um terceiro tipo de transtorno alimentar têm sido proposto por alguns pesquisadores. Esta terceira categoria diagnóstica é chamada de Transtorno da Compulsão Alimentar (TCA). Sua característica central é também, o episódio de compulsão alimentar, sendo que o paciente não se engaja em comportamentos compensatórios para controle do peso, o que o diferencia do paciente com $\mathrm{BN}$. O TCA pode ser considerado como um outra modalidade de transtorno do comportamento alimentar situado entre a Bulimia Nervosa e a Obesidade. A DSM-IV já exibe em seu Apêndice B (destinado ao conjunto de critérios e eixos sugeridos para estudos adicionais) as diretrizes diagnósticas para o TCA. Faremos a seguir uma apresentação resumida sobre os transtornos alimentares.

\section{O TRANSTORNO DO BINGE OU TRANSTORNO DA COMPULSÃO ALIMENTAR:}

O transtorno da compulsão alimentar é o que mais comumente se associa à obesidade. Caracteriza-se por episódios do tipo "binge eating". O estudo de suas características particulares e sua diferenciação com a bulimia nervosa de um lado, e a obesidade no outro extremo ainda se encontra em estágio inicial de desenvovimento.

Nesse ponto parece importante esclarecer uma certa confusão provocada pelas traduções utilizadas para o termo binge eating. A tradução literal para o português seria "farra ou orgia alimentar". A nossa equipe num artigo de revisão sobre o assunto já havia proposto a denominação de "ataque de comer", muito usada pelos pacientes como uma possível alternativa em português para a atitude alimentar patológica expressa em inglês, com muita propriedade, pela expressão binge eating. No entanto, observamos atualmente a utilização na nossa língua, de vários termos para definir o mesmo fenômeno, como: episódios bulímicos, episódios de compulsão alimentar, ataques de comer. O próprio nome "binge" é utilizado para definir o episódio central do transtorno, alternativa proposta pelos filólogos quando não encontramos um termo exato para traduzir uma expressão em outra língua e utilizamos a palavra ou expressão na língua de 
origem. Em castelhano a utilização da expressão "atracones" parece bastante adequada e satisfatória.

\section{Apêndice B (DSM-IV): Critérios diagnósticos para o Transtorno de CompulsãoAlimentar:}

A. Episódios recorrentes de compulsão alimentar. Um episódio de compulsão alimentar é caracterizado por:

(1) Comer num breve período de tempo (p.ex.: num período de 2 horas) uma quantidade de comida considerada definitivamente maior do que a maioria das pessoas comeriam durante período de tempo similar e em circunstâncias similares;

(2) Um sentimento de falta de controle sobre os episódios (p.ex.: um sentimento de não conseguir parar ou controlar o que ou o quanto se está comendo).

B. Os episódios de compulsão alimentar estão associados a pelo menos três (3) ou mais dos seguintes ítens:

(1) Comer mais rápido do que o usual;

(2) Comer até se sentir inconfortavelmente "cheio";

(3)Comer grandes quantidades de comida, sem se sentir com fome;

(4)Comer sozinho por se sentir constrangido com a quantidade que está comendo;

(5)Sentir-se decepcionado, deprimido, ou sentindo-se culpado após a superingestão;

C. O episódio de compulsão alimentar provoca um marcante desconforto;

D. Os episódios de compulsão alimentar ocorrem em média duas (2) vezes por semana durante 6 meses.

E. O episódio de compulsão alimentar não está associado com o uso regular e inapropriado de comportamento compensatório (p.ex: do tipo purgativo, jejuns ou exercício excessivo) e não ocorre exclusivamente durante o curso de anorexia nervosa ou bulimia nervosa.

\section{Quadro Clínico}

O fenômeno central do TCA é o episódio de "binge" ou episódio de compulsão alimentar. $\mathrm{O}$ episódio de compulsão alimentar pode ocorrer em associação com vários transtornos tanto psiquiátricos como clínicos. Assim podemos observar episódios de compulsão alimentar nos transtornos alimentares (na anorexia nervosa e bulimia nervosa), mas também nos transtornos depressivos, na obesidade, no diabetes, etc. Os estudos epidemiológicos, no entanto, têm demonstrado que, além de ocorrer associadamente com outros transtornos, o comer compulsivo pode ser encontrado como uma síndrome isolada como proposta pela DSM-IV.

\section{Epidemiologia}

SPITZER relatou que $30 \%$ dos pacientes que procuravam tratamento para perda de peso apresentavam o transtorno, enquanto que, somente $2 \%$ da população geral preenchia os critérios diagnósticos para o TCA. A distribuição por sexos evidenciava um predomínio do sexo feminino na proporção de $3 / 2$.

\section{Diagnóstico diferencial}

A principal preocupação é descartar a presença de outros transtornos alimentares. $\mathrm{Na} A \mathrm{~N}$ o baixo peso, o comportamento restritivo e as outras características típicas deste transtorno fazem o diagnóstico diferencial. A diferenciação com a $\mathrm{BN}$ é feita através da busca de comportamentos compensatórios (purgativos ou não purgativos).

Conforme já citado, o episódio de compulsão alimentar pode ocorrer em diversas condições médicas, sendo necessário realizar uma anamnese clínica exaustiva. Quadros psiquiátricos como a Depressão Maior, Distimia, Abuso de Substâncias e outros dignósticos, devem ser pesquisados.

\section{Tratamento}

O tratamento de escolha para o TCA é a psicoterapia cognitivo-comportamental. O tratamento psicoterápico é imprescindível para melhorar a psicopatologia da paciente e para facilitar o cumprimento das orientações nutricionais. A orientação nutricional deve ser uma das primeiras estratégias propostas pois podem regularizar e atenuar o desequilíbrio hormonal e psicológico que a alimentação caótica produz sobre os sistemas homeostáticos. A base da orientação deve ser em ordenar e distribuir regularmente as ingestas ao longo do dia. Evitar os alimentos que desencadeiam o "binge' (fenômeno do gatilho).É extremamente importante que a paciente aceite interromper a seqüência restrição $\rightarrow$ binge. Os antidepressivos podem beneficiar muitos pacientes com TCA. As drogas mais indicadas são os ISRS (Inibidores Seletivos de Recaptação da Serotonina), dado o seu perfil de efeitos colaterais favorável e, dentre eles a fluoxetina foi a mais estudada.

Um grupo de pacientes com TCA normalmente procura atendimento em clínicas de emagrecimento, conforme salientou inicialmente STUNKARD. Uma outra parte dos pacientes procura centros especializados no tratamento de transtornos alimentares e 
uma terceira parcela de indivíduos procura auxílio através de grupos de auto-ajuda como os Comedores Compulsivos Anônimos. Apesar de ocorrer com uma certa freqüência, só atualmente, com a sistematização do diagnóstico do TCA, é que podemos começar a avaliar a dimensão deste comportamento patológico alimentar.

A verificação da presença dos episódios compulsivos alimentares é um fator extremamente importante no planejamento terapêutico dos pacientes obesos. Os obesos com estes episódios têm um risco aumentado de interromperem prematuramente tratamentos para perder peso e tendem a ganhar novamente o peso que perderam durante o tratamento se comparados aos obesos sem este tipo de perturbação do comportamento alimentar.

\section{OUTRAS ANORMALIDADES DO COMPORTAMENTO ALIMENTAR:}

NIBBLING, BELISCAR OU ENTRE COMIDAS: Caracterizado por ingestas repetidas, sem fome ou desejo, de pequenas quantidades de alimentos. Estas ingestas tem caráter prazeiroso.

CRAVING, ÂNSIA ou PICOTEOS:É um termo assemelhado a compulsão ou desejo intenso por uma substância em particular. Se caracteriza por um ataque súbito ou irresistível em comer, com urgência, um alimento em particular, fora das refeições. A comida é seletiva para um alimento ou grupo determinado de alimentos. Ocorre uma sensação de ansiedade prévia e um relaxamento e calma depois do episódio ter ocorrido. WURTMAN considerou que a deficiência de serotonina seria a responsável pelo comportamento denominado "carbobydrate craving" ou ânsia por carboidratos. Os pacientes com este comportamento tendem a usar determinados alimentos ricos em carboidratos para compensar uma atividade serotoninérgica central defeituosa.

\section{BINGE EATING, COMPULSÃO ALIMENTAR OU ATRACONES}

Os episódios de binge podem ocorre sem a ocorrência de todos os critérios diagnósticos para o TCA como vimos anteriormente.

\section{SÍNDROME DO COMER NOTURNO:}

Descrita por Stunkard, caracteriza-se por hiperfagia noturna, insônina e anorexia matinal. Os pacientes com a síndrome do comer noturno não devem ser confundidos com aqueles insones que comem porque não podem dormir, já que neste caso o transtorno alimentar é secundário ao transtorno do sono. Esta síndrome é mais freqüente no sexo masculino.

\section{LEITURA RECOMENDADA}

1. AMERICAN PSYCHIATRIC ASSOCIATION. Diagnostic and Statistical Manual of Mental Disorders, 4th Edition. Washington, DC, American Psychiatric Association, 1994.

2. APPOLINARIO JC. Transtorno do Comer Compulsivo. Em: NUNES MA, APPOLINÁRIO JC e cols. Transtornos Alimentares e Obesidade. Artes Médicas, Porto Alegre, 1998.

3. APPOLINÁRIO JC, COUTINHO W. PÓVOA LC. O Transtorno do Comer Compulsivo. Revisão de Literatura J Bras Psiquiat 1995;44(Supl 1):S38-S45.

4. APPOLINÁRIO JC, COUTINHO W, PÓVOA LC. O Transtorno do Comer Compulsivo no Consultório Endocrinológico: comunicação preliminar. J Bras Psiquiat 1995B:44(Supl 1):S38-S45

5. AZEVEDO AMC, ABUCHAIM ALG. Bulimia nervosa: classificação diagnóstica e quadro clínico. Em: NUNES MA, APPOLINÁRIO JC e cols. Transtornos Alimentares e Obesidade. Artes Médicas, Porto Alegre, 1998.

6. FAIRBURN CG, WILSON GT. Binge Eating: Definition and Classification. Em: FAIRBURN CG, WILSON GT. Binge Ealing: Nature, Assessment and Treatment, Guilford Press, New York, 1993.

7. NUNES MA, RAMOS DC. Anorexia nervosa: classificação diagnóstica e quadro clínico. Em: NUNES MA APPOLINÁRIO JC e cols. Transtornos Alimentares e Obesidade. Artes Médicas, Porto Alegre, 1998.

8. RICA V. MANNUCCI M, e cols. Caratteristiche psicopatologiche e cliniche di una popolazione ambulatoriale di pazienti obesi. Minerva Psichiatrica 1996:37:53-8.

9. SPITZER RL, DEVLIN MJ, WALSH BT, HASIN D, WING R, MARCUS MD, e cols. Binge Eating Disorder: A Multisite Field Trial of The Diagnostic Criteria. Int $J$ Eating Dis 1992; 11:191-203.

10. SPITZER RL, YANOVSKI S, WADDEN T, WING R, MARCUS MD, STUNKARD A, e cols. Binge Eating Disorder: Its Further Validation in a Multisite Study. Int J Eating Dis 1993; 13:137-153.

\section{CAPÍTULO 4}

\section{DIAGNÓSTICO Y METODOS DE EVALUACIÓN}

Definición: Comúnmente se utilizan los términos sobrepeso y obesidad como si fueran sinónimos, sin embargo son dos conceptos diferentes, el primero se refiere a un aumento exclusivo del peso, mientras que el segundo se relaciona con el incremento de adiposidad corporal. 


\section{Para aclarar dichos conceptos y evitar confu-} siones recordemos la definición de obesidad:

"La obesidad es una enfermedad crónica que se caracteriza por la acumulación excesiva de grasa, a un nivel tal que la salud esta compromerida".

También se debe tener en cuenta que los individuos obesos, difieren no solo en relación al exceso de grasa que ellos guardan, sino también en la distribución regional de la grasa corporal, ya que el "exceso de grasa abdominal es un factor de riesgo mayor para enfermedad que el exceso de grasa corporal per se".

\section{MÉTODOS DE EVALUACIÓN DE LA GRASA CORPORAL}

Con los antecedentes expuestos, el diagnóstico de obesidad se debe sustentar en la evaluación del comportamiento graso, para lo cual se puede utilizar métodos de análisis de tipo directo e indirecto.

\section{Métodos directos:}

Los únicos métodos directos para evaluación de la grasa corporal son: la determinación histica de células adiposas por biopsia y el estudio en cadáver, los cuales han aportado datos para el conocimiento de las características histicas y morfológicas de la especie, métodos que por razones obvias son de uso exclusivo para la investigación.

\section{Métodos indirectos:}

Estos métodos son actualmente cada vez más utilizados y se basan en la evaluación ya sea cualitativa o cuantitativa de uno o varios compartimentos corporales, asumiendo que estos son constantes y que la diferencia existente en relación al peso total corresponde al resto de componentes, la mayoría de estos métodos basan su análisis en modelo de dos compartimentos (graso, no graso [magro]).

\section{Métodos de evaluación del contenido magro}

Estos métodos asumen que al determinar el componente magro se puede calcular el graso. En este grupo se encuentran los métodos que evalúan el contenido de agua corporal, potasio y nitrógeno corporal total, así como la conductibilidad eléctrica; los dos primeros utilizan técnicas dilucionales ya sea con sustancias isotópicos o no isotópicas.

\section{Determinación de la densidad corporal:}

Esta evaluación introducida por Behnke, Feen y Wellham en 1943 se constituyó durante años en el "gold standard" de la determinación de la composición corporal.
Este método asume que la densidad de los componentes corporales es constante, por lo tanto la gravedad especifica de cada uno de ellos (tejido graso y magro: 0.9 y $1.1 \mathrm{~g} / \mathrm{cc}$, respectivamente) permitiría calcular el porcentaje de los constituyentes.

La técnica requiere pesar a los individuos tanto en el aire como en una completa sumersión bajo agua para determinar el volumen corporal al cual debe sustraerse el volumen residual pulmonar.

La ecuación mas utilizada para el cálculo del porcentaje graso ha sido la desarrollada por Siri:

$$
\% \text { graso }=[(4,95 / \text { densidad })-5,5] \times 100
$$

\section{Absorciometría de rayos $\mathrm{X}$, doble fotón}

Este método a diferencia de los anteriores se basa en un modelo de tres compartimentos, paulatinamente parece reemplazar a la estudios de densidad bajo el agua como método "gold standard" aunque existen discrepancias. Por medio de esta técnica se puede validar el componente mineral, graso y magro tanto en cuerpo total como regional.

\section{Métodos para la estimación objetiva de la grasa corporal}

A este grupo pertenecen técnicas como la topografía computarizada (TC), resonancia magnético nuclear (RMN), y el ultrasonido, gracias a los cuales se puede visualizar y determinar la proporcionalidad de grasa total y en especial la regional.

\section{Aproximación antropométrica a la evaluación corporal grasa (plicometría)}

La medicion de pliegues subcutaneos es un metodo antropometrico que permite la evalucion indirecta del compartimento graso, com las limitaciones que se expondran posteriormente.

De todos los métodos disponibles, algunos por sus características, hacen que sean de más fácil uso y mayor utilidad, tal como se puede ver en la tabla 1.

\section{DIAGNOSTICO CLÍNICO DE OBESIDAD}

\section{Evaluación antropométrica:}

Si bien el diagnóstico adecuado de obesidad debe basarse en la determinación del componente corporal graso, la disponibilidad, factibilidad, y costos de los diversos métodos limitan su uso en la práctica clínica y en estudios poblacionales, por otro lado no existe hasta este momento evidencias claras de la relación entre las variaciones de los compartimentos determinados por estos métodos y la morbimortalidad a largo plazo. 
Tabla 1. Comparacion de los Metodos de Determinacion de la Grasa Corporal y su Distribucion.

\begin{tabular}{lllcc}
\hline MÉTODO & COSTO & USO & EXACTITUD & REGIONAL \\
\hline T/E & $\$$ & Fácil & alta & no \\
plicometría & $\$$ & Fácil & baja & si \\
diámetros & $\$$ & Fácil & moderada & si \\
ultrasonido & $\$ \$$ & Mod. & Moderada & si \\
bioimpedancia & $\$ \$ \$$ & Mod. & Alta & no \\
Resonancia & $\$ \$ \$$ & difc. & Alta & si \\
TC & $\$ \$ \$$ & difc. & Alta & si \\
absortimetría $/ \mathrm{Rx})$ & $\$ \$ \$$ & Fácil & alta & no \\
\hline
\end{tabular}

También se ha demostrado que el exceso de grasa localizada mayormente a nivel abdominal tiene un mayor riesgo cardiovascular que el incremento de peso o de grasa corporal per se.

Por lo tanto, y como se ha expuesto previamente, la obesidad es un problema general y de salud pública de nuestros pueblos por lo que es necesario disponer de instrumentos de diagnóstico de fácil uso y bajo costo, razón por la cual se recomienda la utilización de tres parametros antropométricos para uso general, como son:

a) el Indice de Masa Corporal (IMC) y

b) la evaluación de los diámetros de la cintura y la cadera (Indice CC)

c) Plicometria

La antropometría es unos de los métodos indirectos que ayuda a evaluar obesidad, cuando se usa apropiadamente, con una técnica cuidadosa puede distinguir categorías de obesidad, puede predecir los niveles de grasa corporal y estimar el riesgo relativo de enfermedad. Sin embargo, puede tener significativos errores cuando no se utiliza la técnica correcta, los instrumentos adecuados y no se considera los errores del examinador o no se interpreta correctamente los resultados.

\section{Evaluación del peso:}

Anteriormente se intentó tipificar la obesidad en función de diversos criterios como: observación subjetiva, tipología, patrones culturales de belleza y en base a la determinación exclusiva del peso de los individuos, basándose en conceptos erróneos que no consideraban la composición corporal ni el incremento de adiposidad.

Posteriormente se procuró evaluar al individuo de manera mas objetiva a través de la utilización de la relación entre el peso y la talla, las que eran analizadas frente a patrones standard, en algunos casos en función de edad y sexo, con lo que se determinaba que era lo normal y que no.

Sin embargo estas consideraciones tienen algunos defectos:

- Los estudios poblacionales, reportan variaciones estadísticas en la distribución de la población de referencia;

- Los valores de referencia son personas que se presumen sanas o normales;

- Las tablas de peso ideal, y otros han sido creadas en función de riesgos de salud y sobreviva, naciendo de instancias ajenas al sector de la salud (Compañías de seguros), quienes además tomaron las mediciones en condiciones no optimas.

Con estos criterios se crearon términos como peso ideal o peso corporal relativo (porcentaje de peso para una talla dada a determinada edad), los cuales se establecían usando tablas de referencia, con las cuales se intentaba diagnosticar bajo peso, sobrepeso e indirectamente desnutrición y sobrenutrición, este método cumplió una función en su momento histórico, sin embargo, en la actualidad y a la luz de los nuevos conocimientos científicos no se recomienda su uso.

\section{Utilidad del Indice de masa corporal}

Durante el desarrollo de la humanidad se han estudiado diversos índices que intentan relacionar el peso y la talla, estableciéndose diversas fórmulas, muchas de las cuales fueron quedando en el olvido. No así la fórmula desarrollada por Quetelet hace 150 años y que hoy conocemos como IMC.

Hace pocos años han sido revisadas algunas de estas principalmente en población adulta y se ha concluido que la relación peso/talla ${ }^{2}$, también llamada Indice de Masa Corporal (IMC) correlaciona alta- 
mente con el peso y poco con las variaciones de talla, y sobretodo correlaciona con la determinación de grasa corporal total obtenida con mediciones de densidad corporal.

En la literatura médica el IMC es comúnmente usado para clasificar el baja peso, normopeso, sobrepeso y obesidad en adultos, la OMS actualmente recomienda su uso basándose en la asociación que existe entre IMC elevado y morbi-mortalidad, como lo demuestran varios estudios, en los cuales se evidencia que a partir de un IMC de 30 el riesgo de enfermedad cadiovascular, diabetes mellitus, enfermedad de vias biliares, algunos tipos de cáncer, entre otras, aumenta considerablemente.

Es de tomar en cuenta que por lo general se asume que un individuo con un IMC mayor de 30 tiene un exceso de masa grasa, pero no necesariamente es así, ya que a igual IMC se puede tener diferente porcentaje graso, o tambien con IMC menor de 30 tener porcentaje graso elevado. Por otro lado este último aumenta con la edad, especialmente sobre los 60 años en ambos sexos, por lo que los valores del IMC deben ser cuidadosamente interpretados si lo que se busca es estimar la grasa corporal en forma precisa.

Diferencias en las proporciones corporales y la relación entre el IMC y el contenido graso corporal pueden afectar los valores considerados como saludables en algunos grupos poblacionales.

La validez del IMC como un indicador indirecto de adiposidad ha sido investigado por muchos autores, Womersly y Durnin encontraron correlaciones entre 0.49-0,62 entre IMC y la grasa corporal estimada por densitometría en hombres de mediana edad, en mujeres la correlación alcanzó 0,64-0.9l, Norgam y Ferroluzzi encontraron una correlación de 0,75 entre IMC y porcentaje de grasa corporal estimada por densitometría.

La forma de obtener el IMC es dividiendo el peso en kilogramos para la talla en metros elevada al cuadrado.

$$
\mathrm{IMC}=\text { peso }(\mathrm{kg}) / \text { talla }(\text { metros })^{2}
$$

La clasificación de sobrepeso y obesidad recomendado por la OMS considerando el IMC y basado en el riesgo de mortalidad, independiente del sexo y la edad se observa en la tabla 2.

El IMC es considerado un método útil para medir obesidad en grupos poblacionales, por lo tanto puede ser usado para estimar la prevalencia de obesidad y sus riesgos asociados, sin olvidarse que existen variaciones en la existencia de la obesidad entre individuos y poblaciones.
Tabla 2. Clasificación del Sobrepeso en Adultos de Acuerdo al IMC

\begin{tabular}{|c|c|c|}
\hline Clasificación & $\mathrm{IMC}(\mathrm{Kg} / \mathrm{m} 2)$ & $\begin{array}{l}\text { Riesgo } \\
\text { comorbilidad }\end{array}$ \\
\hline Bajo peso & $<$ de 18,5 & $\begin{array}{l}\text { baja (riesgo de } \\
\text { otros problemas } \\
\text { clínicos) }\end{array}$ \\
\hline Normal & $18.5-24.9$ & \\
\hline Preobeso & $25,0-29,9$ & aumentado \\
\hline Obesidad clase I & $30,0-34,9$ & moderado \\
\hline Obesidad clase II & $35.0-39.9$ & severo \\
\hline Obesidad clase III & $\geq 40,0$ & muy severo \\
\hline
\end{tabular}

En estudios clínicos y de investigación se utilizan además del peso y la talla métodos selectivos de adiposidad, tales como la plicometría ya que proveen información adicional para aproximarse a la estimación del compartimento graso.

\section{Distribución regional de la grasa}

Actualmente se reconoce que no solo se debe considerar la cantidad de grasa corporal total si no también su localización, ya que factores de tipo hormonal determinan que esta tienda a predominar en el caso de los varones en el segmento superior del cuerpo (tipo androide), o en el segmento inferior (tipo ginoide) en el caso de las mujeres, tal como lo describio Vague en 1947.

Debido a que está ampliamente demostrado que el aumento de la grasa visceral (abdominal) se relaciona con un alto riesgo de morbilidad y mortalidad principalmente cardiovascular, su determinación es necesaria.

Se puede utilizar diversas formas de valorarla, como por ejemplo la tomografia computarizada, resonancia magnética nuclear, ultrasonido, etc, métodos que son muy útiles en investigación pero que por sus costos y disponibilidad no puede ser utilizados rutinariamente. Por estas razones, en la práctica clínica y en investigaciones epidemiológicas la utilización de índices basados en mediciones de circunferencias corporales puede dar información válida y fácil de lograr.

A partir de 1980 diversos estudios han demostrado la asociación entre el índice cintura/cadera [ICC] y la prevalencia de diabetes mellitus y factores de riesgo metabólico, tanto en hombres como en mujeres con o sin obesidad, estudios prospectivos han demostrado que el ICC es un predictor de enfermedad cardiovascular, enfermedad cercbrovascular, diabetes mellitus, algunas formas de cáncer y aumento de la mortalidad.

Determinación del Indice Cintura Cadera (ICC) El ICC se calcula dividiendo el diámetro de la cintura para el de la cadera. En forma general actualmente se 
acepta que existe riesgo en los adultos si esta mayor a 0.9 en varones y mayor a 0.85 en mujeres.

\section{Circunferencia del abdomen:}

Tambien existen evidencias que sugieren que la sola determinación de la circunferencia de la cintura, medida en el punto medio entre la parrilla costal y la cresta iliaca puede proveer en forma practica y sencilla correlación entre distribución grasa y alteraciones de la salud.

Esta medición que no se relaciona con la talla y se correlaciona estrechamente con el IMC y el ICC, es un indicador aproximado de grasa abdominal y grasa corporal total, las variaciones de este parámetro reflejan cambios en severidad de los factores de riesgo para enfermedad cardiovascular y otras formas de enfermedades crónicas. A pesar de esto existen diferencias poblacionales en su asociación.

Datos provenientes de población holandesa denotan riesgos asociados cuando el diámetro de la cintura es superior a los puntos establecidos en la tabla 3 .

Tabla 3. Riesgos de Complicaciones Metabólicas Asociadas a Obesidad en Función de Circunferencia de la Cintura por Sexo.

\begin{tabular}{lcc}
\hline & Aumentada & Muy aumentada \\
\hline Hombre & $94 \mathrm{~cm}$ & $102 \mathrm{~cm}$ \\
Mujer & $80 \mathrm{~cm}$ & $88 \mathrm{~cm}$ \\
\hline
\end{tabular}

Nota: Estos valores pueden ser población específicos y depender de otros factores, lo cual esta en investigación.

\section{Plicometria}

La plicometría es útil para determinar los depósitos grasos subcutáneos, de manera indirecta determina el compartimento graso del cuerpo; la estimacion de la grasa corporal total con estas mediciones se basan en el supuesto que el $50 \%$ de la grasa corporal es subcutánea

La medición del grosor del pliegue de grasa o pliegue cutáneo es práctica y útil, aunque su validez depende de la precisión de la técnica para medirlo, la misma que disminuye cuando es mayor la obesidad.

Los sitios donde los pliegues cutáneos reflejan más la adiposidad son: tricipital, bicipital, subescapular, suprailiaco y parte superior del muslo, los más útiles son el tricipital y subescapular porque se dispone de estándares de referencia y tienen una correlación elevada con la grasa corporal total y el porcentaje de grasa determinado por otros métodos.

La plicometría no puede ser usado para definir el valor total de la grasa corporal o determinar el grado de obesidad en obesos mórbidos, ya que los calipers por lo general no miden más allá de 50 milímetros y es imposible tomar un pliegue de ese grosor.

\section{Diferentes marcas de caliper tienen alta correlación pero sistemáticamente diferentes lecturas.}

Además los pliegues tienen variaciones raciales, por sexo y edad; aumentan con la edad, sin embargo no tan rápidamente como durante el crecimiento, después de los 60 años, los pliegues disminuyen.

Los valores de referencia para el pliegue tricipital y subescapular están dados por Tanner y Whitehouse, Johnston, Durnin y Womersly, y Frisancho, sin embargo no existen estudios poblacionales sistemáticos y los valores no han sido ampliamente aceptados.

Con la finalidad de calcular el porcentaje de grasa y evitar la heterogeneidad de la distribución corporal se han construido diferentes tablas basadas en sumatoria de varios pliegues, considerando diferencias por edad y sexo, siendo las mas utilizadas las del porcentaje graso determinado por la sumatoria de cuatro pliegues desarrollada por Durnin.

La gran limitante de este método en la clínica diaria es la necesidad de un plicómetro calibrado y la amplia variabilidad intra e interindividual si no es realizada por personal entrenado, lo que puede determinar una baja reproductibilidad.

\section{Cálculo del porcentaje graso:}

El porcentaje graso a partir de la plicometria se puede determinar por:

1) Calculo de la densidad corporal por formulas;

2) Sumatoria de pliegues;

3) Fórmulas: como la de Dueremberg.

\section{CLASIFICACIÓN DE LA OBESIDAD}

Cuando se desea clasificar a la obesidad debe tomarse en cuenta de que esta es una enfermedad heterogénea, multifactorial, ya sea por su etiopatogenia, sus características anatomopatologicas, la presentación y evolución de su cuadro clínico, así como por la conocomitancia o no de factores de riesgo de salud, lo que determina que se la clasifique en varias formas, dependiendo del factor a considerar.

\section{Según el grado de obesidad:}

Para esto utilizamos el criterio de diagnostico clínico de obesidad basado en el IMC, previamente descrito, lo que determina peso bajo, peso normal y sobrepeso el que a su vez se divide en preobeso, y obesidad grado I, II y III (ver diagnóstico).

Cuando se utiliza métodos de determinación del componente corporal graso se define obesidad si este 
supera el $25 \%$ en varones y $33 \%$ en las mujeres; no existe todavía total consenso.

\section{Según su distribución grasa:}

Dependiendo del segmento corporal predominante se divide en dos grupos:

\section{- Generalizada;}

- Obesidad androide, también llamada troncular o central, y se la relaciona con la forma de una manzana; su presencia se relaciona con alto riesgo cardiovascular;

- Obesidad ginoide: se caracteriza por un deposito aumentado de grasa a nivel de caderas, lo que a hecho que se compare con una pera; su presencia está relacionado con un riesgo mayor de artrosis y várices.

\section{Según factores etiológicos:}

Existe una variedad de factores etiológicos asociados con el desarrollo de obesidad, como genéticos, alteraciones endocrinas y otras como se puede evidenciar en la tabla 4

Tabla 4. Clasificación Etiológica de las Obesidades (Adap. de Bray)

\begin{tabular}{l} 
Obesidad por Disbalance Nutricional: \\
Dietas altas en grasa (saturadas) \\
Dietas cafetería \\
Obesidad por Inactividad Física: \\
Sedentarismo \\
Obligada (discapacidad) \\
Vejez \\
Obesidades Secundaria a Alteraciones Neuroendócrinas: \\
Sindrome hipotálamico \\
Síndrome de Cushing \\
Hipotiroidismo \\
Ovarios poliquísticos \\
Pseudohipoparatiroidismo \\
Hipogonadismo \\
Déficit de hormona de crecimiento \\
insulinoma e Hiperinsulinismo \\
Obesidades Secundarias: \\
A Drogas: psicotrópicos, glucocorticoides, antidepre- \\
sivos tricicilicos, litio, fenotiazinas, \\
ciproheptadina, medroxiprogesterona \\
Cirugia hipotalámica \\
Obesidades Genéticas: \\
Autosómica recesiva (Sindrome Bardet-Biedl, Ahistrom, \\
Cohem, Carpenter) \\
Ligada al X \\
Cromosómicas (Prader-Willi) \\
Laurence-Moon-Biedl \\
Deficit de leptina \\
Mutacion del receptor de leptina \\
Mutacion de receptor POMC \\
Mutacion de gen de proconvertasa (PC1) \\
Mutacion de receptor de metacortina (MC4R) \\
\hline
\end{tabular}

Adap. Bray

\section{Enfermedades asociadas a obesidad:}

El sobrepeso y la obesidad determinan un mayor riesgo de sufrir diferentes enfermedades y alteraciones metabólicas, como la diabetes mellitus, hipertensión arterial, aterosclerosis, y otras.

\section{Evaluación clínica del paciente obeso}

Cuando se evalúa un paciente con obesidad hay que hacerlo de manera integral tan igual como se examina a otro paciente con otra patología. Por lo tanto es necesario la elaboración de una historia clínica completa, un minucioso examen físico, solicitud y evaluación de exámenes de laboratorio y de gabinete necesarios según el caso.

Historia Clínica: debe ponerse énfasis principalmente en los antecedentes personales y familiares, la edad de inicio de la obesidad y curso clínico, factores desencadenantes y de mantenimiento, hábitos nutricionales, actividad fisica y estilos de vida, aspectos psicológicos, tratamientos anteriores y resultados, síntomas sugestivos de patologías endócrinas, uso de fármacos, concomitancia de otros factores de riesgo asociados y sus tratamientos.

Examen Físico: debe ser completo, en piel buscar acantosis, calcular el IMC, no olvidar medir diámetros de la cintura y cadera, tomar presión arterial, buscar signos de patología endócrina y otras.

Exámenes de Laboratorio: deben estar destinados a confirmar los hallazgos de la historia clínica y buscar alteraciones endocrino metabólicas y otros factores de riesgo determinantes o asociados (hipertiroidismo, Cushing, diabetes, dislipidemias, hiperuricemia, etc). Desde el punto de vista cardiorespiratorio deberá evaluarse su función tanto en forma clínica como de gabinete según el caso (Rx de Tórax, ECG, prueba esfuerzo, etc)

Para la valoración nutricional y de hábitos de vida, la utilización de métodos como recordatorios o registros de alimentación y actividad, son de ayuda.

Una vez realizada la evaluación integral del paciente desde el punto de vista clínico y de gabinete, de haber clasificado su obesidad considerando diversos criterios, una vez identificados las complicaciones y definido los riesgos deacuerdo a la presencia o no de enfermedades asociadas, estamos en capacidad de planificar un tratamiento específico.

Tabla 6. Examenes de Laboratorio Minimo en el Diagnostico de Obesidad

1. Biometria hematica

2. Quimica sanguinea (urea, glucosa, creatinina, acido urico)

3. Colesterol total, colesterol HDL, colesterol LDL y trigliceridos

4. Examen de orina 
Utilizando el nivel de IMC y la presencia o no de enfermedades asociadas, se puede definir el riesgo, tal como se expresa en la tabla 7.

Tabla 7. Clasificación del Riesgo de Acuerdo al IMC y Enfermedades Asociadas.

\begin{tabular}{|c|c|c|c|}
\hline IMC & \multicolumn{2}{|c|}{$\begin{array}{l}\text { Enfermedades } \\
\text { asociadas }\end{array}$} & Riesgo $(\mathrm{kg} / \mathrm{m} 2)$ \\
\hline $\begin{array}{c}<25 \\
<25 \\
25-30 \\
25-30 \\
30-35 \\
30-35 \\
35-40 \\
35-40 \\
>40\end{array}$ & SI & $\begin{array}{l}\mathrm{NO} \\
\mathrm{NO} \\
\mathrm{NO} \\
\mathrm{NO}\end{array}$ & $\begin{array}{l}\text { MUY BAJO } \\
\text { BAJO } \\
\text { BAJO } \\
\text { MODERADO } \\
\text { MODERADO } \\
\text { ALTO } \\
\text { ALTO } \\
\text { MUY ALTO } \\
\text { MUY ALTO }\end{array}$ \\
\hline
\end{tabular}

\section{LECTURAS RECOMENDADAS}

1. Report of a WHO Consultation on Obesity. Defining the problem of overweight and obesity. In: Obesity. Preventing and managing the global epidemic. WHO, 1998.

2. AFERO. Association Francaise d'Etudes et de Recherches sur l'Obesite. Recommandations pour le diagnostic, la prevention ef le traitment de l'obesite. Diab Metab 1998;24:Supl 2.

3. Bray G. Obesidad. En: OPS-ILSI. Conocimientos Actuales en Nutrición. 6 edición. OPS 1992, Publica científica No. 532:614.

4. Maham K, Arlin M. Valoración del estado nutriciongl. En: Nutrición y dietoterapia. Interamericana, 1992. $8^{9}$ edición. pp.297-315.

5. Sjostrom L. Impact of body weight, body composition and adipose tissue distribution on morbidity and mortality. En: Stunkard A, Wadden T. Obesity theory and therapy. $2^{2}$ edition, Raven Press 1993.

6. Harsha D, Bray $G$. Body composition and chilhoood obesity. Endocrinol Metab Clin N Amer 1996;25(4).

7. ASCOM. Enfoque y manejo del paciente obeso, propuesta para un consenso Nacional. ASCOM 1997.

8. Pasquel M. El laboratorio en el diagnostico de obesidad. PCM Progresos en ciencias medicas 1992;6(Supl 1)

9. Bray G. An Approach to the classification and evaluation of Obesity. In: Bjorntorp P. Obesity. Lippincott, Philadlphia. 1992.

10. Spurr G, Reina J, Jiang Shi, Orozco, Dufour D. Body composition of colombian women. AJCN 1994;60:279-85.

11. Revicki D, Israel R. Relationship between body mass index and measures of body adiposity. AJPH 1986;76:992-994.

12. Wang J, et al. Asian have lover BMl but higher percent body fat than whites. Comparation of antropometric measurements. AJCN 1994;60:23-8.

13. Lemieux $S$, et al. Sex differences in the relation of viscer- al adipose tissue accumulation to total body fatness AJCN 1993:58:463-7.

14. Lemieux $S$, et al. A single threshold value of waist girth identifies normal weight and overweight subjects with excess visceral adipose tissue. AJCN 1996;64:685-93.

15. Zamboni $M$, et al. Effect of age on body fat distribution and cardiovascular risk factors in women. AJCN 1997:66: $111-5$.

16. Walton $\mathrm{C}$, ef al. Body fat distribution, rather than overall adiposity influence serum lipids in healthy men independently of age. AJM 1995;99:459-64.

17. Heymsfield $S$, et al. Assessment of body composition. An overview. In: Bjorntorp P. Obesity. Lippincott, Philadelphia. 1992

18. Wang $Z$, et al. Systematic organization of body composition methodology. An overview with emphasis on component-based methods. AJCN 1995;61:457-65.

19. Wang $Z$. The five level model. A new approach to organizing body composition research. AJCN 1992;56:19-28.

20. Lean M. Han T, Seidel J. Impairment of health and quality of life in people with large waist circunference. Lancet 1998;351:853-56.

21. Moreno B, Lopez M, Monereo S. Obesidad, concepto Y clasificación. En: Obesidad, presente y futuro. Biblioteca aula médica, España 1997.

\section{CAPÍTULO 5}

\section{PRINCIPIOS GENERALES EN LA TERAPEUTICA DE LA OBESIDAD}

La obesidad debe ser reconocida como una enfermedad y tratada como tal; por lo tanto los servicios de prestación de salud deben cubrir los costos generados por el tratamieto.

El manejo de la obesidad es un tema en constante evolución dada la profusión de hipotesis etiologicas, matices y complicaciones propias de la enfermedad. Este consenso busca una guia ética y científica adaptable para nuestros paises. Tenemos en cuenta que los pilares fundamentales en el tratamiento de la obesidad son modificaciones del comportamiento y hábitos de vida que incluyen cambios en el plan alimentario y actividad fisica pautada. Otras alternativas a considerar son la farmacoterapia y la cirugía bariátrica.

\section{OBJETIVOS DEL TRATAMIENTO}

El individuo obeso debe ser tratado porque presenta una condición que predispone a riesgos de enfemedades y muerte precoz. Por lo tanto el tratamiento de la obesidad debe ser realizado con el objetivo de prevenir o tratar estas enfermedades asociadas y no exclusivamente para el tratamiento del exceso de peso. 
El objetivo del tratamiento es por lo tanto alcanzar un estado de salud, sea atraves del equilibrio metabólico en el que se consigue niveles normales o cercanos a la normalidad en los valores sanguineos de glucosa, trigliceridos, colesterol total y subfracciones, acido urico e insulina, sea la salud como un todo incluyendo aqui la mejoria de problemas osteoarticulares, psicologicos y otros.

Estos objetivos en general se alcanzan con una discreta o moderada perdida de peso de $5-10 \%$ en relacion al peso inicial. En este sentido es necesario que los individuos obesos y los profesionales que los tratan tengan expectativas realistas en cuanto a su perdida de peso.

\section{CAPÍTULO 6}

\section{ATIVIDADE FÍSICA E EXERCícIO}

\section{Definiçōes de Atividade Física, Exercício e Esporte}

De acordo com o Consenso da OMS (Organização Mundial da Saúde) e da ACSM (American College of Sports Medicine) consideramos:

Atividade fisica é qualquer movimento do corpo produzido pelo músculo esquelético que resulta em um incremento do gasto energético.

Exercício é uma atividade física planejada e estruturada com o propósito de melhorar ou manter o condicionamento fisico.

Esporte é uma atividade física que envolve competição.

\section{Evidências Epidemiológicas}

A inatividade física e a obesidade são considerados, isoladamente, fatores de alto risco de doença arterial coronariana (Project PACE, 1992). Os primeiros dados a mostrar uma relação entre o estilo de vida e a prevalência de doenças crônicas não transmissíveis, foram apresentados pelo grupo norte-americano do Centro de Controle de Doenças (CDC) em 1976, evidenciando que o estilo de vida em relação a outros fatores como a genética, a assistência médica e o ambiente contribui em $54 \%$ para o risco de morte por cardiopatia, $50 \%$ para o risco de morte por acidente vascular cerebral e $37 \%$ para a morte por câncer. Levando em conta todas as causas de mortalidade o estilo de vida seria responsável por $51 \%$ do risco de morte.

Considerando as doenças cardiovasculares como uma das principais causas de mortalidade, as evidências apontam para as vantagens das mudanças do estilo de vida: o indivíduo sedentário que passa a ser pelo menos um pouco mais ativo já diminuiria para $40 \%$ o risco de morte por doenças cardiovasculares. Estudos epidemiológicos e experimentais demonstram uma correlação positiva entre a atividade física e a diminuição da mortalidade, sugerindo também um efeito positivo nos riscos de enfermidades cardiovasculares, no perfil dos lipídeos plasmáticos, na manutenção da densidade óssea, na redução das dores lombares e melhores perspectivas no controle de enfermidades respiratórias crônicas e no diabetes. Tem sido também relatados efeitos positivos no tratamento primário ou complementar da arteriosclerose, da enfermidade venosa periférica, da osteoporose assim como a menor prevalência de certos tipos de câncer em indivíduos ativos. Mas os benefícios da atividade física regular não se restringem aos aspectos organicos. Estudos de metaanálise relatam também beneficios psicológicos a curto prazo (melhora da auto-imagem, do humor e do autoconceito) e a longo prazo (diminuição da ansiedade, do estresse e da depressão). Mais recentemente o impacto tem sido verificado também na longevidade da população.

Outros estudos demonstraram que mesmo pessoas que foram sedentárias até os 40 anos mas, a partir de então, passaram a adotar um estilo de vida ativo, tiveram um ganho médio de dois anos e meio na expectativa de vida. Atualmente, aponta-se uma prevalência de $70 \%$ para o sedentarismo, valor extremamente superior à outros fatores de risco como obesidade, diabetes, hipercolesterolemia, hipertensão e tabagismo, confirmando que "o sedentarismo está se tornando o inimigo número um da saúde pública".

\section{Efeitos da Atividade Física no Tratamento da Obesidade}

Existem várias evidências científicas apontando que o controle da ingestão alimentar junto com atividade fisica regular são mais efetivos no controle do peso corporal do que apenas a dieta. Os efeitos que a literatura científica aponta para esse beneficios do exercício são:

\section{Efeitos Gerais:}

Aumento do gasto energético. Estímulo à resposta termogênica, aumentando a taxa metabólica de repouso e a termogênese induzida pela dieta. Aumento na capacidade de mobilização e oxidação da gordura.

Melhora do condicionamento físico e da circulação cardiaca, diminuição da pressão sanguiínea, aumento da capacidade vital.

A sensação de fome, embora de pouca duração, foi suprimida significativamente logo após os exercícios 
fisicos intensos (King et al., 1994). Os de baixa intensidade, porém mais prolongados (60 minutos), suprimem a fome por espaço de tempo maior (Reger et al., 1984). Isso vai contra a idéia popular que o exercício aumenta a fome.

A mobilização de gordura abdomino-visceral provocada pelos exercícios físicos foi demonstrada por Tremblay et al., 1988, mas os depósitos de gorduras femuro-glíteas foram mais resistentes.

O exercício leva a um aumento do colesterol HDL e uma diminuição do LDL e dos triglicerídeos. Estas modificações são uma consequiência do aumento da atividade da LPL muscular e da diminuição da insulina e da atividade da lipase hepática.

Efeitos psicológicos: melhora da auto-estima, autoimagem, ansiedade e depressão.

\section{Efeitos no peso, alimentação, composiçāo} corporal, tecido adiposo e gorduras circulantes:

Os pacientes obesos perdem mais rapidamente peso tanto de tecidos graxos como de massa magra.

A diminuição de peso não e imediata, se não que se produz depois de 2 meses de praticar uma atividade física intensa, melhorando a relação massa gorda / massa magra, alterada no obeso.

Diminuição do IMC, que se associa com diminuição do perímetro da cintura e da relação cintura / quadril.

As concentrações de leptina estão elevadas na obesidade. Refletem o aumento de massa graxa (Maffei et al., 1995) c a sua resistência à leptina. Essa resistência pode ser melhorada através da atividade fisica que favorece o emagrecimento e previne o reganho de peso, evitando a queda do consumo metabólico basal (Björntorp, 1978) e a perda de massa muscular (Forbes, 1991).

\section{Efeitos do Exercicio Sobre a Alimentação:}

$O$ exercício nos indivíduos com baixo coeficiente respiratório, lhes ocasiona uma ingesta menor (32).

O exercício aumenta a síntese de CRF e de seus receptores a nível do núcleo paraventricular, cuja conseqüência seria a anorexia.

Tende a diminuir a produção de insulina e isto reduz a repressão que este hormônio produz sobre o sistema NPYérgico hipotálamico.(Tremblay e Almeras, 1995). Assim se explicaria a preferencia por ingerir carbohidratos após o exercício (Richard, 1995) .

A regulação do eixo hipotálamo-hipófise-adrenal (HHA) evidenciada pelo aumento do neurotransmissor 5-hidroxitriptamina (serotonina) é ser promovida pelo exercício fisico, assim como a dosagem do metabólito 3-metoxi-4-hidroxifeniletileno-glicol reflete a atividade aumentada do sistemas noradrenérgico e serotoninérgico (Dumn \& Dishman, 1991).

\section{Recomendações de Atividade Física no Trata- mento da Obesidade}

Dentre os fatores comportamentais mais associados à saúde estão os hábitos alimentares, o controle do estresse e, aqui chamamos a atenção, a atividade física regular. Neste sentido tem surgido estratégias voltadas para estabelecer programas de informação e educativos para difundir na população conhecimentos sobre a saúde e estimular o desenvolvimento de um estilo de vida sadio, assim como apoiar a geração, avaliação, difusão e utilização de informações relativas à saúde em geral $\mathrm{c}$ à promoção $\mathrm{e}$ proteção da saúde através de um estilo de vida ativo. A maioria das iniciativas nesse sentido está scndo concretizada em países industrializados como é o caso da Inglaterra, Austrália, Finlândia, Canadá e Estados Unidos. O único pais em desenvolvimento com uma proposta similar é o Brasil com o Programa "Agita São Paulo", que pelo impacto alcançado (mais de 30 milhões de pessoa-mensagem em um ano) tem recebido um reconhecimento internacional, particularmente da Organização Mundial da Saúde (OMS).

A tendência internacional proposta pelo Programa "Agita São Paulo", assim como pelos programas internacionais e pela própria OMS, é de que os programas de intervenção na população levem em consideração as seguintes recomendações:

1) Incremento do nível de atividade física a longo prazo é mais provável de ser atingido por meio de mudanças ambientais que aumentem a atividade diária rotineira e mantenham a ocupação do tempo livre, praticando exercícios de baixa intensidade em lugar de estimular o exercício vigoroso ocasional. Deve ser enfatizada a atividade física de longa duração que possa ser convenientemente incorporada à vida diária. Alguns exemplos populares incluem: passear com o cachorro, cuidar do jardim, dançar, pedalar, limpar vidros, lavar o carro, varrer, nadar, caminhar, evitar de usar o carro, preferir realizar atividades em pé ao invés de sentado, usar escada ao invés do elevador, etc.

2) O exercício pode ser estimulado mas não de forma que leve à exaustão envolvendo rotinas cansativas ou que requeiram equipamentos custosos.

3) A atividade deve ser prazerosa de forma a estimular uma participação regular e desestimular o comportamento sedentário.

4) Promover e estimular variedade de atividades físicas nas crianças uma vez que existem evidências de que crianças fisicamente ativas permanecem ativas na idade adulta.

As cvidências atuais sugerem que o nível de atividade requerido para manter e perder peso e ganhar 
benefícios fisiológicos e psicológicos para a saúde, não é tão vigoroso como se imaginava antes. O US Surgeon General Report enfatiza que a atividade fisica prolongada, de baixa intensidade como caminhar por 30 a 60 minutos por dia, incrementa significativamente o gasto energético e assim reduz o peso e a gordura corporal.

Propostas tradicionais tem sido usadas para promover a atividade fisica:

Incremento do exercício diário, como caminhar ou pedalar, em que o gasto energético é de aproximadamente 60 a 200 kilocalorias/hora, dependendo da sua intensidade.

Pacientes obesos e com sobrepeso, sedentários, 3 horas diárias, extra, de qualquer atividade em pé ao invés de sentado aumenta o gasto energético de 24 horas de $25 \%$ a $75 \%$ acima da taxa metabólica basal.

Deve-se atentar que o exercício moderado e vigoroso, realizado em forma de sessões de 45 a $60 \mathrm{mi}$ nutos, 3 vezes por semana, é dificil de ser mantido por pessoas obesas.

Problemas respiratórios e músculo-esqueléticos são comuns em pacientes obesos e podem inibi-los de participar em exercícios de longa duração.

\section{Diversas análises têm indicado que a partici- pação é melhorada por :}

Promover atividades em casa ao invés de programas estruturados em locais especiais.

Contato profissional freqüente por telefone ou visita domiciliar.

Suporte social, particularmente da família.

Exercício informal e não supervisionado, para os menos resistentes.

Exercício de intensidade baixa a moderada.

Promover caminhadas como forma de exercício.

Acumular atividade física durante o dia ao invés de fazer atividade de forma continua.

Obs.:(Ler também o capítulo sobre Psicoterapia)

A proposta internacional é a promoção de um estilo de vida ativo estimulando a população a totalizar pelo menos 30 minutos de atividade física por dia, de intensidade leve a moderada, o equivalente a 2,4 a $3,2 \mathrm{~km}$ em 30 minutos de caminhada. $\mathrm{Na}$ maior parte dos dias da semana e de forma contínua ou fracionada em outras atividades que possam ser facilmente introduzidas na rotina diária: como jardinagem, consertos domésticos, dança e atividades recreativas com crianças. Uma diminuição de aproximadamente $200 \mathrm{kcal} /$ dia na dieta, é suficiente para prevenir doenças e promover a saúde (Physical Actipity and Public Health, 1995).

\section{Planejamento}

O obeso deve realizar Teste Ergométrico antes de se integrar a um programa de exercícios, independente da idade e sexo, por possuir dois fatores de risco de doença coronariana: a obesidade e o sedentarismo (American College of Sports Medicine, 1991).

O médico deve supervisionar o tipo, quantidade e qualidade de exercício e adequa-lo até conseguir e manter os objetivos propostos. Para planificar um programa de atividade fisica, deve-se ter em conta os seguintes fatores: idade, tipo de exercício, duração, freqüência, intensidade, presença de outros síndromes concomitantes e prevenção de recaídas.

Idade: Em mulheres menopausadas, muitas delas com osteoporoses, se recomenda exercício de baixo impacto, para evitar o risco de fraturas. Em uma pessoa sedentária, o programa de exercícios deve ser realizado através de um condicionamento progressivo e lento.

Tipo de exercício: o mais adequado é o tipo dinâmico (aeróbico), no qual se utilizam grandes grupos musculares, em forma continua e repetida e a possibilidade de alcançá-lo, para o paciente obeso. Dentro da variedade de atividades aeróbicas: caminhada, ciclismo, natação, trote, ginastica, etc), a que tem melhor possibilidade de aceitabilidade por parte do obeso é a simples caminhada, que apresenta múltiplas vantagens já que não requer treinamento prévio, pode ser realizada em qualquer lugar, não necessita vestimenta especial de segurança para poder realizá-la, não apresenta perigo cardiovascular, e é tão eficaz como o trote e outros.

Duração: deve ser igual ou superior a 30 minutos. Se é feita uma atividade diferente da caminhada, deve ser indicado uma etapa de pré aquecimento de $10 \mathrm{mi}$ nutos, com o qual se consegue elevar levemente a FC, aquecer os músculos e assim impedir danos músculotendinosos. Uma vez finalizado o exercício é necessário culminar com uma etapa de esfriamento de 5 a 10 minutos, com o qual se evita o risco de hipotensão pós exercício.

Freqüência: pelo menos três vezes por semana; entretanto, se indicada caminhada, esta deve ser pelo menos praticada diariamente ou complementada com ela nos dias em que não se faz exercício. Os beneficios aparentes consistem em uma maior aderência e facilidade para a prática. Seu efeito sobre a aptidão cardiorespiratoria é igualmente eficaz.

Intensidade: Se desejamos realizar exercício fisico aeróbico pleno, esta atividade deveria alcançar em torno de 60 a $80 \%$ da máxima captação de oxigênio. Como está medida só é aplicada em Institutos espe- 
cializados, como alternativa se utiliza a medição da freqüência cardíaca durante o exercício, estimando-se que quando se encontra entre 70 e $85 \%$, é uma atividade aeróbica plena, que equivale à máxima captação de oxigênio.

Presença de outras síndromes concomitantes: Ter presente que a terapia fisica inadequada nos obesos pode ocasionar lesões do aparelho osteoarticular devido a sobrecarga funcional; nos diabéticos afora as hipoglicemias, merece destacar-se as isquemias cardíacas em enfermos silenciosos, com o qual é concebido risco de morte súbita ou hipotensão ortostática nos que padecem de neuropatía autônoma, hemorragias do vítreo e/ou descolamento de retina. Ademais, se padecem de alguma cardiopatía ou enfisema, a todos eles se recomenda exercício de baixo impacto.

Prevenção da Recaída: O modelo dos programas de prevenção à recaída da manutenção dos exercícios físicos pode requerer uma modificação que se traduz nas "intervenções de reforço" para evitar o retrocesso à inatividade fisica (Knapp, 1988). Uma dessas "intervenções de reforço" é o Project PACE, 1992. Como parte do esforço para alcançar este objetivo, profissionais que cuidam da saúde devem ser encorajados a perguntar a seus pacientes sobre a freqüência, duraçăo, tipo e intensidade da atividade fisica e fornecer avaliação e aconselhamento nutricional (Patrick et al., 1994).

\section{Conclusões}

Frente às atuais evidências podemos estimar que o mesmo padrão de vida sedentária vai continuar e piorar no futuro; portanto, novas estratégias devem ser implementadas para aumentar a atividade física da população e tentar evitar o progressivo aumento da prevalência da obesidade. Novos dados, evidenciados na última década, demonstram que a atividade fisica embora seja um fator de auxílio importante para diminuir o peso corporal é crítico para mante-lo com sucesso.

\section{LEITURAS RECOMENDADAS}

1. American College of Sports Medicine (ACSM). Guidelines for Exercise Testing and Prescription. 4th.ed. Philadelphia, Lea \& Febinger, 1991.

2. Bielinski R, Schutz $Y$, ef al. Energy expenditure during the postexercise recovery in man. Am.J. Clin. Nutric. 1985 ;42:69-82.

3. Björntorp P. Exercise in obesity. Psychiatr Clin North Am. 1978;1:691-696.

4. Björntorp P. Brodoff BN.Obesity. Philadelphia, Lea \& Febinger, 1992.pp. 454-462

5. Bouchard C, Deprés JP, Tremblay A. Exercise and obesity. Obesity Res 1993;1:133-147.
6. Deprés JP. Obesity, regional adipose tissue distribution, effect of exercise. Japan Scien Soc Press 1991:251-259.

7. Dishman RK. Compliance/adherence in health-related exercise. Health Psychol. 1982; 1:237-267.

8. Dunn AL, Dishman RK. Exercise and neurobiology of depression. Exerc Sports Sci Ver 1991;19:41-98.

9. Forbes GB. Exercise and body composition. J Appl Physiol 1991;70:994-997.

10. Forehand R, Wierson M, McCombs A. Brody G, Fauber R. Interparental conflict and adolescent problem behavior: An examination of mechanisms. Behav Res Ther 1989;27:365-371.

11. King NA, Burley VJ, Blundell JE. Exercise-induced suppression of appetite. Effect on food intake and implication for energy balance. Eur J Clin Nutr 1994;48:715724.

12. Kleges RC, Eck LH, et al. Physical activity, body composition and blood pressure. Med Sci Sports Exerc 1991;23:759-765.

13. Knapp DN. Behavioral management techniques and exercise promotion In: Exercise Adherence: Its Impact on Public Health. RK Dihsman (ed). Champaig, Human Kinetics Publishers, 1988, pp.203-236.

14. Maffel M, Halaas J, Ravussin E, Patley RE, Lee GH, Zhang $Y$, et al. Exercise applications and promotion in behavioral medicine. J Consult Clin Psycho 1982;50:1004-1017.

15. National Institute of Health. Conference on diet and exercise in DNID. Diabetes Care 1987;10:639-644.

16. Paffenbarger RS, Hyde RT, Wing AL, Hsieh C-C. Physical activity, all-cause mortality, and longevity of college alummi. N Engl J Med 1986;314:605-613.

17. Patley RE, ef al. Physical activity and public health. JAMA 1995;273(5).

18. Perusse L,Tremblay A, Leblanc C, Bouchard C. Genetic and familial environmental influences on level of habitual activity. Am J Epid 1989;129:1012-1022.

19. Physical Activity and Public Health. A recommendation from the centers for disease control and prevention and the American College of Sports Medicine. JAMA 1995;273(5):402-407.

20. Pollock ML, Miller HA, Linnernd AC, et al. Arm pedaling as an endurance training regimen for the disabled. Arch Phys Med Rehabil 1974;55:418-424.

21. Pollock ML, Miller HS, Linnernd AC, Cooper KH. Frequency of training as a determinant for improvement in cardiovascular function and body compositon of middleage men. Arch Phys Med Rehabil 1975;.58:141-145.

22. Pollock ML. Prescribing exercise for fitness and acherence.In: Dishman RK (ed). Exercise Adherence.Champaign. Human Kinetics Publishers, 1998, pp.259-277.

23. Pollock ML. Exercise prescription for the elderly. In: Ecker $H$. Spirduso WW (eds). Physical Activity and Aging. Champaign, Human Kinetics Publishers, 1989. pp.163174

24. Pollock ML, Wilmore JH. Exercicios na saúde e na doença. In: Prescrição de exercício para endurance cardiorrespiratório e para redução de peso. MEDISI, 1993, pp.367-379. 
25. Project PACE. Phisician Manual. Atlanta: Centers for Desease Control, Cardiovascular Health Branch, 1992.

26. Reger WE, Allison TA, Kurucz RL. Exercise, post-exercise metabolic rate and appetite. Sport Health Nutr. 1984:2:117-123.

27. Roberts SB, Savage J, Coward WA, Chew B, Lucas A. Energy expenditure and intake in infants born to lean and overweight mothers. N Engl J Med 1988;318(8):461466.

28. Tremblay A. Deprés JP, et al. Physical activity, body fatness and fat distribution. Am J Clin Nutric 1990;51:153157.

29. Tucker LA. Television viewing and physical fitness in adults. Res Q Exerc Sport 1990;61:315-320.

30. US. Department of Health and Human Services. Physical Activity and Health: A report of the Surgeon General. US Dept of Health and Human Service, Atlanta, 1996.

31. Wilfley DE, Brownell KD. Physical activity and diet weight loss. In: Advances in Exercise Adherence. Champaign. Human Kinetics Publishers, 1994, pp.351-383. Perseghin T, et al. N Engl J Med 1996;335:1357-62.

32. Almerás, et al. Exercise and energy intake: effect of sustrate oxidation. Int J Obes 1994;4.

33. Richard D. Exercise and the neurobiological control of food intake and energy expendidure. Int $\mathrm{J}$ Obes 1995; 19(Supp 14):S97-101.

34. Calles, et al. Exercise enhances fat oxidation in overfed normal individuals. Int J Obes 1994; 18(4)

35. Simoneau JA. Adoption of human skeletal muscle to exercise-training. Int J Obes 1995; 19(Supp.4):S9-S13.

36. Tremblay, et al. Physical activity, macronutrient balance and body weight control. In: Angel A, ed; Progress in Obesity Research. 1996. pp.725-731.

\section{CAPÍTULO 7}

\section{ALIMENTOS Y DIETOTERAPIA}

\section{MANEJO de los ALIMENTOS en el PLAN de ALI- MENTACION del OBESO}

Basado en los cinco grupos basicos de alimentos, debe ser de baja densidad calórica y cumplir con las claves de la alimentación saludable, que son: Variedad, Proporción y Equilibrio.

Para alcanzarlos se propone modificar la base de la piramida nutricional clasica, disminuyendo los hidratos de carbono complejos e incrementando los hidratos de carbono simples. Se disminuye el area de la base de la pirámide, que corresponde a los almidones y se incrementa la correspondiente al grupo de verduras y frutas.

\section{Introducción}

La alimentación es imprescindible para mantener la composición corporal y el nivel de actividad. Los ali-
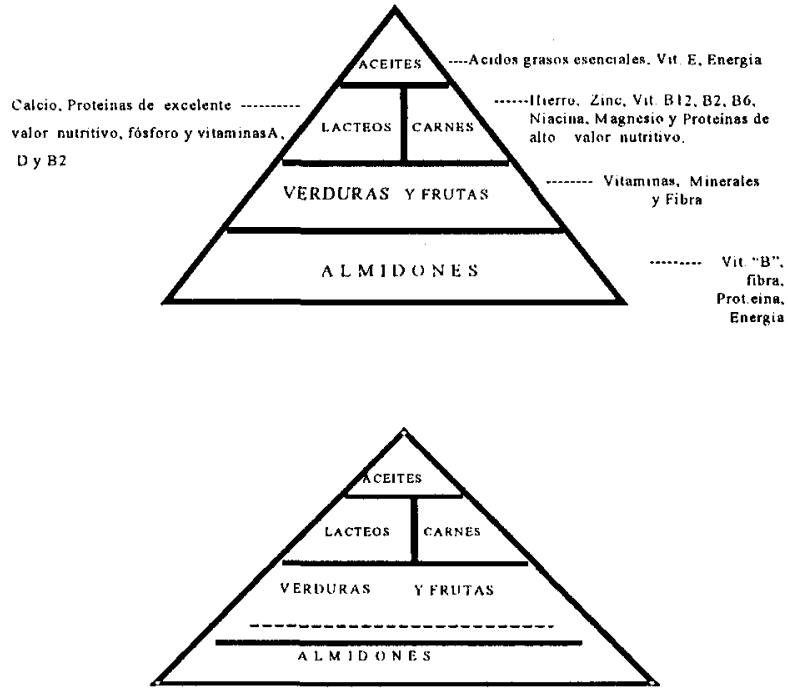

mentos son necesarios para la vida aunque también pueden ser causa de enfermedad, no existiendo persona libre de sus efectos y consecuencias.

Los pueblos adoptan los alimentos que les ofrece el medio geográfico en el que viven y a través de las sucesivas generaciones van mejorando su adaptación a ellos. Por esta razón existen grandes diferencias en la alimentación humana en relación con la geografia, el poder adquisitivo y las costumbres.

Aquellos pueblos que eligen o disponen más adecuadamente sus alimentos, gozan de mejor salud y desarrollo. es un antiguo aforismo que evita mayores aclaraciones.

\section{Manejo actual y sus inconvenientes}

Para el manejo profesional, los alimentos son clasificados químicamente según el nutriente predominante, como hidrocarbonados, proteicos, grasos, etc. También se los agrupa utilizando un nombre genérico que engloba a los que comparten origenes y/o propiedades comunes, p.ej. carnes, leche y derivados, frutas, golosinas.

La prescripción nutricional racional, a cargo del especializado se realiza por medio de la "Fórmula sintética", que es luego traducida en términos de alimentos y comidas por la dietista-nutricionista. Esto exige conocimientos precisos del cálculo del requerimiento energético y de las propiedades de los alimentos. Estos conocimientos y no están disponibles en la mayor parte de los niveles sanitarios en latinoamérica.

El médico no especializado, que es quien mayor volumen de pacientes asiste, desconoce los principios de la nutrición, la composición de los alimentos y la manera de prescribir una dieta. 
El conocimiento técnico del alimento y de las modificaciones producidas por la manipulación industrial y doméstica son imprescindibles para elegir y recomendar aquellos más convenientes para nuestros pueblos: Es tarea que incumbe al profesional especializado, analizar y transmitir sus experiencias a las Autoridades de la Salud, a sus colegas y a la población.

\section{Comercialización los de alimentos y salud}

Los intereses económicos y el espíritu competitivo conducen a una oferta masiva de alimentos y productos alimentarios. La necesidad de comercializarlos es canalizada a través de la propaganda masiva, que muchas veces es confusa y contradictoria.

La composición química de los alimentos se presenta en etiquetas de dificil lectura e interpretación, con las cuales ni aun los expertos se sienten cómodos. En ocasiones el contenido de nutrientes se expresa en porcentaje y en otras, en cantidades absolutas, en relación al tamaño de una porción, de dificil de determinación, a veces expresada en unidades ajenas al sistema métrico decimal.

Esta información "dirigida al consumidor" es un jeroglífico dificil de interpretar que conduce a errores en la alimentación. Esta situación es agravada cuando existen limitaciones psicológicas, intelectuales, sensoriales, etc. por parte del consumidor.

La Food and Drug Administration (FDA) reconoce la necesidad de un etiquetado que, responda a los avances de la ciencia y la tecnología y provea a los consumidores consejo, utilizando métodos de fácil interpretación (1).

Dificultades prácticas para la prescripción de la alimentación

Por parte del médico:

- Desconocimiento de la composición de los alimentos.

- Desconocimiento de los efectos de los alimentos.

- Dificultad para transmitir el concepto al paciente.

Por parte del paciente:

- Limitaciones educacionales (ignorancia, analfabetismo).

- Limitaciones psicológicas.

- Limitaciones sensoriales (dificultades visuales, etc).

- Costumbres y creencias populares.

Por parte del alimento:

- Etiquetas de dificil acceso.

- Información inadecuada, mal expresada, confusa, engañosa.

- Propaganda masiva basada únicamente en intereses económicos.

\section{Alimentos y su relación con la obesidad}

La problemática poblacional de la obesidad, no ha sido evaluada en la mayor parte de los países latinoamericanos, excepto algunos estudios poblacionales, como el caso de Brasil y en la ciudad - estado de Montevideo, que indican un fuerte incremento de la ya elevada tasa de prevalencia en estas poblaciones. En otro sector del Continente, la población norte-americana, una de las más obesas del mundo, con alrededor de un $40 \%$ de prevalencia, está amenazada de llegar a serlo en su totalidad en el año 2230.

Estudios sobre la etiopatogenia de la obesidad, de los trastornos alimentarios y de algunas enfermedades metabólicas, han demostrado la influencia de la alimentación como causante, agravante o predisponente de las mismas, como producto de una respuesta biológica adaptativa a las condiciones ${ }^{3}$ impuestas por el medio. Adaptarse a condiciones desfavorables, conduce a organismos vulnerables a enfermar, luego de una latencia, que puede llegar a décadas.

Ningún argumento médico ni legal justifica la enfermedad. Cualquier condición perjudicial para la salud es combatida por organismos nacionales e internacionales.

\section{Estas enfermedades son evitables.}

Las Sociedades Científicas integrantes de la FLASO, reunidas en Consenso Latinoamericano para tratar la problemática de la obesidad y sus asociaciones metabólicas y alimentarias consideran conveniente instrumentar los medios para conseguir una alimentación adecuada para nuestras poblaciones.

\section{Para ello consideramos imprescindible:}

1) Individualizar los alimentos relacionados con las enfermedades de la nutrición, apuntando a la prevención y tratamiento de las más frecuentes;

2) Establecer un sistema basado en un criterio biológico, para establecer la recomendación a la población;

3) Identificar y señalizar los alimentos de manera clara e inequívoca, tanto para el profesional como para el consumidor;

4) Prevenir a las nuevas generaciones, por medio de educación alimentaria en el hogar, en la escuela y por medio de la información pública.

\section{Fundamentaciones}

De acuerdo con los conocimientos surgidos de nuestra experiencia y en concordancia con lo aceptado por organismos internacionales, consideramos prioritario distinguir a los alimentos en base a: 
1. Su contenido energético - graso.

2. Su capacidad potencial para producir enfermedades metabólicas.

3. Su relación con trastornos de la conducta alimentaria.

Los resultados de este análisis deben ser expuestos fácil y claramente en el envase o envoltorio del alimento, de manera que no existan dudas en la transmisión de la información a los consumidores.

\section{Criterios e instrumentación}

Quedan a consideracion de las Autoridades de Salud Publica y Sanitarias en general de cada pais.

Educación nutricional. Hacia generaciones más sanas

La cultura, a través de creencias y costumbres determina la adopción de un sistema alimentario particular. Relatos bíblicos comentan que algunos pueblos privilegian alimentos que son rechazados por otros, indicando la importancia de la alimentación desde los comienzos de la Civilización. Una vez que el sistema de alimentación se ha instalado tal vez resulte imposible de cambiarlo a nivel individual.

Por esa razón consideramos imprescindible la:

- Información nutricional a las embarazadas.

- Instrucción sobre alimentación entre los requisitos prenupciales.

- Información y formación de educadores de nivel preescolar y escolar.

- Inclusión de una materia sobre Educación alimentaria, en los primeros años de la enseñanza.

- Insistencia y ejemplificación sobre estos temas, modificando los alimentos provistos en los comedores escolares y los ofrecidos en los stands o kioscos que suelen existir los colegios, etc.

\section{Tareas societarias}

Encuadrar los alimentos regionales en cada una de las categorías.

\section{CAPÍTULO 8}

\section{PSICOTERAPIA}

Estratégias de tratamento psicoterápico para obesidade têm sido intensamente estudadas. Fatores cognitivos e comportamentais parecem influenciar o padrão de ingestão alimentar e de atividade física de um indivíduo (28). Diversos estudos demonstram que a associação de Psicoterapia Cognitivo-Comportamental ao tratamento da obesidade melhora os resultados deste último (1-11).

\section{Psicoterapia cognitivo-comportamental}

A Psicoterapia Cognitivo-Comportamental objetiva a modificação do repertório de comportamentos que o indivíduo apresenta (ex: hábitos alimentares inadequados, padrões de raciocínio errôneos) e do meio ambiente com que ele tem contato, a fim de tornar o meio facilitador da perda de peso $(1,12)$.

\section{Auto-Monitoramento}

Consiste em registrar de forma detalhada os alimentos ingeridos diariamente $\mathrm{e}$ as condições em que a ingestão ocorreu. A auto-monitoração tem se mostrado um preditor de sucesso no tratamento, aumentando a conscientização das variáveis que induzem à alimentação inadequada, favorecendo a adesão às estratégias de tratamento $(13,14)$. É também útil na obtenção de dados e na avaliação precisa dos progressos que estão sendo obtidos, funcionando como fator motivacional $(1,4,12)$.

\section{Controle de estimulo}

Os procedimentos que envolvem controle de estímulos dão importante contribuição para os programas de emagrecimento $(1,4,12)$. Eles objetivam diminuir a exposição do paciente às situações que incentivam a alimentação inadequada; ou seja, diminuir o número de "pistas" que controlam a alimentação, tornando-a um ato deliberado regulado pela fome e não pelo "desejo de comer".

Por exemplos, não envolver-se em outras atividades enquanto come evita o aumento da ingestão alimentar por distração; comer lentamente, cortando o alimento em pedaços pequenos e mastigando-o bem, aumenta a conscientização do que está sendo ingerido e permite o treino da percepção da sensação de saciedade; evitar ingerir alimentos diretamente de panelas, sacos ou potes permite um melhor dimensionamento da quantidade de alimento que está sendo ingerido; manter em casa apenas os alimentos com baixo valor calórico evita a ingestão de alimentos calóricos apenas porque estão disponíveis, etc . 


\section{DESENVOLVIMENTO DE COMPORTAMENTOS ALTERNATIVOS À ALIMENTAÇĀO INADEQUADA}

A identificação de situações que favorecem a alimentação inadequada (ex: ansiedade, tristeza, conflitos interpessoais, etc) e o planejamento de comportamentos alternativos que possam ser utilizados nessas situações são elementos fundamentais para o progama de tratamento. Neste sentido, p.ex., têm se mostrado eficazes o Treino em Solução de Problemas, as Técnicas de Distração, as Técnicas de Relaxamento e o envolvimento imediato em atividades incompatíveis com o comer inadequado nas situações em que há alta probabilidade deste ocorrer $(6,12,15)$.

\section{Treino em habilidades sociais}

O Treino em Habilidades Sociais objetiva desenvolver a capacidade de expressão de sentimentos e pensamentos; a capacidade de estabelecer limites e defender direitos; de fazer e negar pedidos; de lidar com críticas, etc. Foi demonstrado que essas habilidades favorecem o aumento da auto-estima e permitem um melhor enfrentamento de estressores interpessoais que geram ansiedade, tristeza e consequente alimentação inadequada $(1,6,12,16)$.

\section{Aumento do nível de atividade física}

Diversos estudos demonstram que o aumento da frequência da atividade fisica é determinante para a perda de peso $(15,17)$. Assim, é fundamental o desenvolvimento de estratégias para adesão ao programa de atividade fisica (ex: compatibilização das modalidades de exercício com o estilo de vida do indivíduo; maior ênfase na continuidade do exercício do que em sua intensidade e tipo; ampliação do conceito de exercício de modo a incluir sob o rótulo de atividade física algumas das atividades cotidianas; antecipação de possíveis situações que poderiam dificultar a execução do exercício e o planejamento de possíveis soluções, etc). $\mathrm{O}$ estabelecimento de reforçadores, a elaboração de gráficos de perda de peso e a auto-monitoração do exercício mostraram-se eficazes no aumento da adesão $(1,15,17,18)$. Para maiores informações sobre estratégias para adesão à atividade física consulte o capítulo sobre exercício.

\section{Reetruturação cogbitiva}

Para conseguir a modificação dos comportamentos alimentares inadequados associados ao ganho de peso, faz-se necessário modificar os pensamentos disfuncionais associados. Os pensamentos são disfuncionais e desadaptados quando incorporam distorções da realidade.
Um padrão de pensamento disfuncional frequentemente encontrado é o Pensamento Dicotômico ou "Tudo ou Nada". Este se apresenta como uma tendência a raciocinar em termos absolutos $\mathrm{e}$ extremos, sem categorias intermediárias. Por exemplo: "Ou sigo a dieta completamente ou, já que ingeri um pouco de doce, estraguei tudo". Este pensamento dificulta a perda de peso porque, frente a uma falha no programa de tratamento, há uma tendência a abandonar temporariamente qualquer tentativa de emagrecimento.

É muito frequente também que os obesos apresentem crenças errôneas acerca do que consiste uma alimentação adequada, o que faz com que eles eliminem da dieta vários tipos de alimentos saudáveis. Essas crenças têm que ser modificadas de modo a viabilizar melhores escolhas alimentares (para maiores informações consulte o capítulo sobre alimentos e dietoterapia).

Estudos evidenciam que a reestruturação cognitiva favorece a adesão por viabilizar raciocínios mais realistas com relação à alimentação, regulação de peso e aos métodos para obtenção de perda de peso $(1,6,12,16)$.

\section{Abordagem da imagem corporal}

Muitos obesos apresentam percepção negativa de sua imagem corporal. Um aspecto importante do tratamento é modificar a atitude que eles têm em relação ao próprio corpo. O questionamento dos estereótipos negativos associados à obesidade e a modificação das crenças disfuncionais sobre aparência física parecem ajudar nesse sentido. Um programa de exposição gradual às situações evitadas pelos obesos (ex: fazer exercício em público, usar roupas mais justas) pode facilitar a reestruturação do sistema de crenças e diminuir a ansiedade associada à imagem corporal. Além disso, é importante fazer a auto-estima apoiar-se em outros aspectos que não apenas a aparência (19).

\section{Estratégias para aumento da motivação.}

O auto-controle alimentar é dificultado pelo fato de que os comportamentos de comer em grande quantidade ou de optar por alimentos com alto valor calórico são fáceis de serem emitidos e têm consequências agradáveis imediatas. Por outro lado, as consequências aversivas associadas a comer inadequadamente são tardias e nem sempre claramente discriminadas pelo indivíduo. Assim, os comportamentos necessários para a perda de peso são de difícil estabelecimento e manutenção, sendo parte fundamental do tratamento criar um sistema motivacional que permita a adesão. Uma estratégia eficaz para a adesão é o uso de "Contratos Comportamentais”. Estes consistem num acor- 
do que especifica as metas de tratamento, os comportamentos relevantes para a perda de peso e as consequências para estes comportamentos, estabelecendo reforçadores imediatos para os novos comportamentos que estão sendo estabelecidos $(4,9)$.

Diversos estudos demonstram que o apoio dos grupos sociais próximos é importante reforçador para a maioria dos obesos, servindo como fator motivacional $(1,4,12)$.

\section{Consideraçōes sobre a eficácia do tratamento}

A eficácia do tratamento psicoterápico depende da escolha de metas de peso realistas e da adequação das técnicas utilizadas ao perfil do caso. Assim, é a análise dos fatores que favoreceram o desenvolvimento da obesidade e dos fatores que colaboram para sua manutenção que viabiliza a seleção das estratégias que serão utilizadas om melhores resultados $(2,12)$.

Diversos estudos têm documentado a eficácia da Psicoterapia Cognitivo-Comportamental na obtenção de perda de peso em obesidade leve a moderada (1-5,7,9,20-23). Ela é eficaz em programas individuais e em grupo $(5,8,17)$. Muitas vezes, inserir o paciente em um programa de grupo permite que seus membros forneçam sugestões de comportamentos alternativos para as situações em que o comer inadequado ocorre, atuem como modelos para comportamentos apropriados e forneçam incentivo e reforço para as mudanças necessárias.

Contudo, sendo a obesidade um problema crônico, mesmo a Psicoterapia Cognitivo-Comportamental apresenta limitações quanto à manutenção da perda de peso a longo prazo $(8,10,12,21)$.

Assim, tratamentos prolongados são mais indicados do que os modelos com limite de tempo. Isto talvez se deva ao fato de que só a prática continuada das novas habilidades aprendidas pode transformá-las em hábitos, permitindo a manutenção destas $(1,3,4,9,26)$.

O estabelecimento de estratégias para prevenção de recaída aumenta a probabilidade de manutenção dos ganhos obtidos durante o tratamento. Mostra-se útil neste sentido a manutenção de contato periódico com o terapeuta após o término do tratamento. O obtenção de uma rede de apoio e encorajamento por parte das pessoas próximas também colabora para a manutenção da perda de peso $(1,4,11,27)$.

Os programas para controle de peso apresentam melhores resultados quando podem ser implementados ainda na infância e na adolescência. $A$ intervenção nesta fase permite que os padrões de comportamento inadequados sejam modificados antes que se tornem muito arraigados $(10,12)$.
Outro fator que parece aumentar a probabilidade de sucesso do tratamento é o envolvimento ativo dos familiares. Estes podem criar um ambiente de cooperação que permite a modificação do meio em que os esforços para mudança têm lugar, facilitando as mudanças desejadas. A participação da família é particularmente importante no tratamento de crianças e adolescentes. Um programa "familiar" que enfatize uma modificação do "estilo de vida" obtém melhores resultados, pois as modificações do meio, que facilitam a ocorrência dos novos comportamentos desejados, tendem a se manter. Além disso, a orientação aos pais sobre as condutas mais adequadas em situações problemáticas reduz conflitos familiares, que poderiam dificultar a perda de peso. Em alguns casos, a associação de Psicoterapia Familiar ao tratamento permite a solução de conflitos, favorecendo a adesão ao programa de emagrecimento $(1,7,10,12,25,26)$.

Além de ajudar na perda de peso, a Terapia Cognitivo-Comportamental tem sido útil também na modificação de comportamentos que dificultam uma melhor qualidade de vida em obesos, mesmo quando a perda de peso não se mantém. Assim, ela pode ajudálos a lidar melhor com os estressores de modo geral e com as pressões sociais decorrentes de estar acima do peso, melhorando a auto-estima $(1,6,15,26)$. Além disso, podem melhorar seus sentimentos associados à imagem corporal $(1,19)$.

Não existem estudos suficientes demonstrando a eficácia de Psicoterapias Psicodinâmicas na redução de peso.

\section{LEITURA RECOMENDADA}

1. WHO - Obesity. Preventing and managing the global epidemy. Report of the World Health Organization consultation on obesity, Geneve, 1997.

2. Keller C, Oveland D. Hudson S. Strategies for Weight Control Success in Adults. Nurse Pract 1997;22(3):33.

3. Fuller PR, Perri MG, Leermakers EA, Guyer LK. Effects of a personalized system of skill acquisition and an educational program in the treatment of obesity. Addict Behav 1998;23(1):97-100.

4. Williamson DA, Perrin LA. Behavioral therapy for obesity. Endocrinol Metab Clin North Am 1996;25(4):943-54.

5. Braet C, Van Winckel M. Van Leeuwen K. Follow-up results of different treatment programs for obese children. Acta Pcediatr 1997:86(4):397-402.

6. Tanco S, Linden W, Earle T. Well-being and morbid obesity in women: a controlled therapy evaluation. Int J Eat Dis 1998;23(3):325-339.

7. Roongpisuthipong $C$, Boontawee $A$, Kulapongse $S$. Behavior modification in the treatment of obesity: acceptability profiles. J Med Assoc Thai 1995;78(5):232-237. 
8. Kern PA, Trozzolino L, Wolfe G, Purdy L. Combined use of behavior modification and very low-calorie diet in weight loss and weight maintenance. Am J Med Sci 1994:307(5):325-28.

9. Foreyt JP, Goodrick GK. Evidence for success of behavior modification in weight loss and control. Ann Intern Med 1993:119(7 P+ 2):698-701.

10. Epstein LH. Ten-Year outcomes of behavioral familybased treatment for childhood obesity. Health Psych 1994:13:373-83.

11. Baum JG, Clark HB, Sandler J. Preventing relapse in obesity through posttreatment maintenance systems: comparing the relative efficacy of two levels of therapist support. J Behav Med 1991;14(3):287-302.

12. Kirschenbaum DS, Johnson WG, Stalonas PM. Elements of success in the treatment of childhood and adolescent obesity. Treating Childhood and Adolescent Obesity. Pergamon Press, NY, 1987.

13. Foreyt, JP, Poston WS. What is the Role of CognitiveBehavior Therapy in Patient Management? Obes Res $1998 ; 6(1): 18-22$.

14. Boutelle KN, Kirchenbaum DS. Further support for consistent self-monitoring as a vital component of successful weight control. Obes Res 1998;6(3):219-224.

15. Clifford PA, Tan SY, Gorsuch RL. Efficacy of a self-directed behavioral health change program: weight, body composition, cardiovascular fitness, blood pressure, health risk, and psychosocial mediating variables, J Behav Med 1991;14(3);303-23.

16. Miller PM, Sims KL. Evaluation and component analysis of a comprehensive weight control program. Int J Obes $1981 ; 5(1): 57-65$.

17. Hayaki J, Brownell KD. Behavior change in practice:group approaches. Inf J Obes Relat Mefab Disord 1996;20(1):27-30

18. Brownell, KD. Exercise in the Treatment of Obesity, In Brownell KD, Fairburn $C G$ (eds). Eating Disorders and Obesity. A Comprehensive Handbook. Guilford Press. NY,1995

19. Rosen JC, Orosan P, Reiter J. Cognitive Behavior Therapy for Negative Body Image in Obese Women. Beh Ther $1995 ; 26: 25-42$.

20. Agras WS, Telch CF, Arnow B, Eldredge K, Marnell M. One-year follow-up of cognitive-behavioral therapy for obese individuals with binge eating disorder. J Consult Clin Psychol, 1997:65(2):343-7

21. Wadden TA, Sternberg JA, Letizia KA, Stunkard AJ, Foster GD. Treatment of obesity by very low calorie diet, behavior therapy, and their combination: a five year perspective. Int J Obes 1989; 13(2):39-46.

22. Wadden TA, Foster GD, Letizia KA. One-Year behavioral treatment of obesity: comparison of moderate and severe caloric restriction and the effects of maintenance therapy. J Cons Clin Psychol 1994:62(1):165-71.

23. Stunkard AJ. Current views on obesity. Am J Med 1996; 100(2):230-6

24. Epstein LH, et al. Five-year follow-up of family-based behavioral treatments for childhood obesity. J Consul Clin Psychol 1990;58(5):661-4.
25. Epstein LH. Management of Obesity in Children. In Brownell KD. Fairburn $C G$ (eds). Eating Disorders and Obesity. A Comprehensive Handbook. Guilford Press, NY, 1995.

26. Wilson GT. Behavioral Approaches to the Treatment of Obesity. In Brownell KD, Fairburn CG (eds). Eating Disorders and Obesity. A Comprehensive Handbook. Guilford Press, NY, 1995.

27. Sternberg B. Recaida no Controle de Peso: Definições, Processos e Estratéglas de Prevenção. In: Marlatt GA, Gordon JR (eds). Prevenção de recaída. Artes Médicas, Porto Alegre, 1985.

28. Nunes MA, Appolinario JC, e cols. Transtornos Alimentares e Obesidade. Editora Artes Médicas, Porto Alegre, 1998.

\section{CAPÍTULO 9}

\section{FARMACOTERAPIA}

Considerando que la Obesidad es una enfermedad cronica y que las medidas de plan nutricional y actividad fisica pautada no son frecuentemente cumplidas con la constancia y duracion adecuadas, se considera necesario el uso coadyuvante de medicamentos en su manejo. La prescripcion de medicamentos debe ser considerada en estos pacientes:

- IMC igual o mayor de 30 ;

- IMC igual o mayor de 25, si se acompaña de otros Factores de Riesgo, como la Hipertension Arterial, Diabetes Mellitus tipo 2, Hiperlipidemia, etc;

- Cuando el tratamiento convencional no ha logrado exito;

Las premisas fundamentales para indicacion de farmacoterapia en la Obesida son:

- La medicación no debe constituirse en criterio único de tratamiento;

- Debe estar enfocada al tratamiento integral del paciente obeso y no exclusivamente a la reducción de peso;

- Siempre debe ser prescrita y vigilada por un médico.

\section{Clasificación:}

Fundamentalmente los medicamentos antiobesidad se dividen en tres categorias:

1. Actuan sobre sistema nervioso central, modificando el apetito o la conducta alimentaria;

2. Actúan incrementando la termogénesis;

3. Actúan sobre el sistema gastrointestinal, inhibiendo la absorción de grasas. 


\section{Clasificación:}

De acuerdo con su modo de accion los medicamentos mas utilizados son:

\begin{tabular}{|c|c|}
\hline MODO DE ACCION: & NOMBRE GENERICO: \\
\hline Catecolaminergico: & $\begin{array}{l}\text { Fentermina, Fenproporex, An- } \\
\text { fepramona (Dietilpropiona), } \\
\text { Mazindol, Fenilpropanolamina }\end{array}$ \\
\hline Serotoninergico: & Fluoxetina, Sertralina \\
\hline \multicolumn{2}{|c|}{ Serotoninergico + Catecolaminergico: Sibutramina } \\
\hline 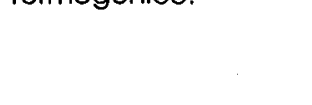 & $\begin{array}{l}\text { Efedrina, } \\
\text { Cafeina, } \\
\text { Aminofilina }\end{array}$ \\
\hline Inhibidor de Abso & de grasas: Orlistat \\
\hline
\end{tabular}

\section{Duración del tratamiento.}

Es sabido que al suspender temporalmente estos farmacos se observa pérdida de su efecto (como ocurre también con la medicación antidiabética, o antihipertensiva) por lo que se aconseja que la duración del tratamiento debe ser prolongada, tanto cuanto se estime necesario, en particular en pacientes que presenten otros factores de riesgo. Sin embargo debe ser previsto que los farmacos disponibles actualmente no tienen un largo tiempo de evaluación.

\section{Características del farmaco elegido:}

- Que su principal efecto final, se logre sobre tejidos adiposos (no sobre agua o músculo);

- Que no tenga efectos secundarios importantes y sea bien tolerado (a corto y largo plazo);

- Que existan en proyecto de ejecucion o bien en desarrollo, estudios clinicos en cada pais y que estos sean avalados por la respectiva Sociedad Científica Nacional, afiliada a la FLASO.

Esto ultimo es deseable para que sea aconsejada su prescripción al cuerpo médico.

\section{Perfil de los principales medicamentos:}

\section{Catecolaminergicos}

Fentermina: Mecanismo de acción: Disminuye ingestion alimentaria por mecanismo noradrenergico. Dosis: $30-60 \mathrm{mg} / \mathrm{dia}$. Efectos colaterales: Boca seca, insomnio, taquicardia, ansiedad.

Fenproporex: Mecanismo de accion: Disminuye ingestion alimentaria por mecanismo noradrenergico. Dosis: $20-50 \mathrm{mg} /$ dia. Efectos colaterales: Boca seca, insomnio, taquicardia, ansiedad.

Anfepramona (Dietilpropiona): Mecanismo de accion: Disminuye ingestion alimentaria por mecanis- mo noradrenergico. Dosis: $40-120 \mathrm{mg} /$ dia. Efectos colaterales: Boca seca, insomnio, taquicardia, ansiedad.

Mazindol: Mecanismo de acción: Disminuye ingestion alimentaria por mecanismo noradrenergico y dopaminergico. No es derivado de la feniletilamina como los tres anteriores. Dosis: $1-3 \mathrm{mg} /$ dia.

Efectos colaterales: Boca seca, insomnio, taquicardia, ansiedad.

Se debe resaltar que los compuestos catecolaminergicos antes mencionados no deben ser confundidos con anfetaminas. Apesar de que pueden causar adiccion en personalidades predispuestas.

Fenilpropanolamina: Mecanismo de accion: Actua aumentando la accion adrenergica. Dosis:50 $75 \mathrm{mg} /$ dia. Efectos colaterales: Sudoracion, taquicardia, eventualmente aumenta la presion arterial.

Se vende sin restriccion en algunos paises.

\section{Serotoninergicos}

Fluoxetina: Mecanismo de accion: Inhibidor de la recaptacion de serotonina. Apesar de no ser reglamentado como medicamento anti-obesidad puede ser util en algunos tipos de pacientes obesos como los comedores compulsivos, bulimia nerviosa y obesos deprimidos. Dosis: 20 - $60 \mathrm{mg} /$ dia. Efectos secundarios: Cefalea, insomnio, ansiedad, somnolencia y disminucion de la libido.

Sertralina: Mecanismo de accion: Inhibidor de la recaptacion de serotonina. Apesar de no ser reglamentado como medicamento anti-obesidad puede ser util en algunos tipos de pacientes obesos como los comedores compulsivos, bulimia nerviosa y obesos deprimidos. Dosis: 50 - $150 \mathrm{mg} /$ dia. Efectos secundarios: Cefalea, insomnio, ansiedad, somnolencia y disminucion de la libido.

\section{Serotoninergico y catecolaminergico}

Sibutramina: Definicion: Es un inhibidor de la recaptura de serotonina y noradrenalina ( SNRI). Mecanismo de accion: Es central y periferico diminuyendo la ingesta alimentaria y aumentando el gasto calorico. Dosis: 10 a $20 \mathrm{mg} /$ dia. Efectos secundarios: sequedad de boca, constipacion, taquicardia, sudoracion, eventualmente aumento de la tension arterial.

\section{Termogenicos}

Efedrina: Mecanismo de accion: Agonista adrenergico. Dosis: $50-75 \mathrm{mg} /$ dia. Efectos Colaterales: Sudoracion, taquicardia, eventualmente aumenta la presion arterial.

Cafeina: Mecanismo de accion: aumenta la accion de la noradrenalina en terminaciones nerviosas poten- 
cializando el efecto de la efedrina. Dosis: $100-300$ $\mathrm{mg} /$ dia. Efectos colaterales: Gastritis, taquicardia.

Aminofilina: Mecanismo de accion: aumenta la accion de la noradrenalina en terminaciones nerviosas potencializando el efecto de la efedrina. Dosis: $300-$ $450 \mathrm{mg} /$ dia. Efectos colaterales: Gastritis, taquicardia.

Los anorexigenos catecolaminergicos tienen tambien una accion termogenica.

\section{INHIBIDOR DE ABSORCION DE GRASAS}

Orlistat: Definicion: Inhibidor de la lipasa pancreatica. Mecanismo de accion: Inactiva la accion enzymatica necesaria para absorber trigliceridos. Su accion se desarrolla en el lumen intestinal, siendo su absorcion minima. Dosis: $120 \mathrm{mg}$ maximo tres veces al dia con las comidas principales. Efectos secundarios: Produce esteatorrea por su propio mecanismo de accion. Si la ingesta de grasa es exagerada puede provocar diarreas e incontinencia fecal. Puede interferir en la absorcion de vitaminas liposolubles, por lo que ocacionalmente se precisa suplementacion.

\section{Formulas megistrales}

Se admite su uso en paises donde se encuentra el principio activo y no el producto comercial o cuando se pretende utilizar dosis diferentes de los productos acabados. Su uso debe respetar las reglamentaciones y normas eticas de cada pais.

\section{Asociaciones medicamentosas}

Las asociaciones medicamentosas no estan bien estudiadas y por esta razon no seran contempladas en este capitulo.

\section{Las dosis de medicamentos aqui sugeridas, deben estar sujetas a la normatizacion sanitaria oficial de cada pais.}

\section{LECTURAS RECOMENDADAS}

1. Halpern A. Trends in pharmacology for treatment of obesity: point of view of a clinician. Int J Obes 1998;22(Suppl 3):S68

2. Matos A. Tratamento da obesidade: Anorexigenos. In: Obesidade, São Paulo: Lemos Editora, 1998. pp.281-296

3. Gomez-Cuevas R. Critica a los sistemas de adegazamiento. Obesidad, una autopista hacia el infarto. Ed. Kasman, Bogotá, 1985.

4. Enfoque y manejo del paciente obeso. Consenso de la Asociacion Colombiana de Obesidad y Metabolismo. 1995
5. Mancini M. Tratamento farmacologico: Medicamentos calorigenicos. In: Obesidade, São Paulo: Lemos Editora, 1998. pp.297-303.

6. De Leon C. Tratamiento Quirurgico de la Obesidad. En: Obesidad del adulto. Julio Montero y col. Edit. Pare. Buenos Aires, 1997

\section{CAPÍtULO 10}

\section{TERAPIA HORMONAL}

\section{Alteraciones endócrinas en la obesidade}

En la obesidad se constatan alteraciones endócrinas. El aumento de la cantidad de grasa condiciona un aumento de los niveles circulantes de leptina y de TNF-b, ambos producidos por el adipocito. La obesidad visceral se asocia com niveles aumentados de ácidos grasos libres, resistencia a la insulina e hiperinsulinemia. El eje hipotálamo-hipófiso-adrenal se desajusta en la medida que hay un aumento en la producción de cortisol y en las tasas de recambio. Es probable que exista una mayor secreción de la hormona en respuesta al estrés. El eje hipófiso tiroideo suele estar normal en la obesidad aunque existen respuestas exageradas al ayuno, disminuyendo la conversión periférica de T4 hacia T3 libre com el aumento de T3 reversa.

Los niveles de las globulinas que ligan las hormonas sexuales ( $\mathrm{SHBG}$ ) en ambos sexos disminuyen en forma directamente proporcional con el aumento del índice de masa corporal. En la mujer la obesidad está asociada a un hiperandrogenismo y ciclos anovulatorios. Luego de la menopausia también se constatan mayores niveles de estrógenos producidos por aromatización de los andrógenos circulantes en el tejido adiposo. En el hombre, la testosterona total disminuye com el aumento del IMC. La obesidad visceral es una condición reconocida de hipogonadismo com disminución de la testosterona libre. Al mismo tiempo aumenta la formación de estrogenos por aromatización de andrógenos circulantes.

La hormona de crecimiento (GH) y su mediador IGF-1 producido en los tejidos periféricos tienen una estrecha relación com la regulación del crecimiento y de sus formas características de secreción. Los obesos suelen no responder a los estímulos que aumentan la secreción de GH como la hipoglucemia y la administración de arginina, posiblemente a través de un mecanismo de resistencia a la GHRH. Los niveles de IGF-1 pueden estar disminuidos o ser normales en la obesidad.

Finalmente otros sistemas hormonales (prolactina, vasopresina, noradrenalina, adrenalina, glucagon, etc) también pueden encontrarse alterados en la obesidad. 


\section{TRATAMIENTOS HORMONALES}

\section{DHEA}

Algunos reportes han indicado efectos beneficiosos de la administracióon de DHEA sobre la obesidad en estudios animales, sin embargo los estudios en humanos resultan menos claros y no hay datos que demuestren efectos positivos sobre el peso y la distribución de la grasa corporal.

\section{Testosterona}

En pacientes hipogonádicos la sustitución com testosterona tiende a producir cambios favorables disminuyendo la cantidad de grasa visceral, resultando en efectos positivos en las alteraciones metabólicas vinculadas a ésta.

En individuos no deficitarios, si bien los datos actuales resultan promisorios, son necesrios ensayos clínicos controlados en mayor escala que avalen estas observaciones.

\section{Estrógenos y Progesterona}

El período climaterico se caracteriza por alteraciones hormonales que promueven efectos sobre el metabolismo y distribución del tejido adiposo, com una tendencia al acúmulo de grasa visceral.Existen evidencias de que el tratamiento de reemplazo hormonal disminuye la cantidad de grasa corporal mejorando la relación masa magra/masa grasa com el consiguiente beneficio desde el punto de vista metabólico.

\section{HGH}

Los efectos favorables del tratamiento de sutitución com GH en adultos deficientes de GH sobre la obesidad visceral y sus consecuencias metabólicas han sido reportados en varios ensayos. Estos incluyen disminución de grasa visceral, mejoría de la insulino sensibilidad y preservación o incremento de la masa magra. Su indicación en individuos normales, no hiposomatotróficos, se encuentra en fase de observación.

\section{Triiodotiroxina (T3)}

Varios insvestigadores han intentado acelerar la pérdida de peso en el curso de un régimen hipocalórico en pacientes eutiroideos, adicionando altas o bajas dosis de T3. Dosis altas incrementan la pérdida de peso a expensas fundamentalmente de pérdida de masa magra por lo que no es recomendable. No es un tratamiento de rutina, se necesitan más estudios que avalen la indicación de dosis bajas.

\section{Melatonina}

No hay ninguna evidencia que sugiera beneficio en el tratamiento de la obesidad.

\section{Gonadotrofina coriónica}

No existen evidencias científicasque apoyen su uso en el tratamiento de la obesidad.

\section{Leptina}

Creciente expectativa se há creado en torno a los potenciales efectos de la administración de leptina recombinante sobre el control de la ingesta y diferentes parámetros metabólicos en la obesidad. Los resultados preliminares de diferentes grupos, si bien muy alentadores, necesitan se avalados por estudios mayores y a largo plazo.

\section{Resumen}

En general, existen pocos ensayos clínicos-terapéuticos controlados mostrando la efectividad de tratamientos hormonales en la obesidad.

En la literatura existen reportes mostrando que diversos tratamientos homonales pueden en casos especiales disminuir en forma aguda la cantidad de tejido adiposo y fundamentalmente resultar en beneficios metabólicos promoviendo descenso de grasa visceral.

Sin embargo, ninguno de estos han mostrado aún, ser efectivos en el manejo a largo plazo de pacientes obesos.

Resultados esperanzadores surgen de las primeras comunicaciones del tratamiento com leptina; probablemente en el futuro próximo podamos contar com una alternativa de tratamiento hormonal eficaz en el tratamiento de la obesidad

\section{LECTURA RECOMENDADA}

1. Bjorntorp, P. The origens and consecuence of obesity. Diabetes. Ciba Fundation Symposium. 201:68-80;1996

2. Bjorntorp, $P$. The regulation of adipose tissue distribution in humans. Int J Obes 1996;20(4):291-302.

\section{CAPÍTULO 11}

\section{CIRURGIA BARIÁTRICA}

Son candidatos para tratamiento quirurgico:

- Aquellos pacientes com IMC igual o mayor de 40;

- Aquellos pacientes con IMC entre 35 - 40 y comorbilidad de la obesidad.

La seleccion de pacientes para cirugia requiere un minimo de 5 años de evolucion de la obesidad y $\sin$ exito con tratamiento convencional por profesionales calificados. 
Se reconocen tres tecnicas de tratamiento quirurgico:

- Gastroplastia;

- Gastroplastia com by pass (gastro-yeyunal);

- Lap-band (colocacion de anillos mediante laparoscopia).

El manejo quirurgico de la obesidad debe ser multidisciplinario se sugieren: endocrinologo, nutriologo, cardiologo, neumologo, psiquiatra/ psicologo, cirujano.

\section{CAPÍTULO 12}

\section{TERAPIAS NĀO RECOMENDADAS}

Os avanços da medicina moderna são alcançados através de pesquisas básica e clínica, utilizando princípios bem estabelecidos de experimentação. Esses princípios incluem ensaios clínicos controlados para determinar eficácia e segurança de novas técnicas diagnósticas e terapêuticas. A publicação dos resultados e repetição do ensaio em experimentos adicionais executados por outros cientistas independentes são componentes necessários para o processo no qual a eficácia e a segurança são documentados.

Por outro lado, as terapias alternativas não comprovadas cientificamente, em geral, compartilham de certas características:

Tendem a ser desenvolvidas e promovidas à margem de recursos, aparelhagem e associações científicas;

Seus investigadores e proponentes geralmente não possuem credenciais clínicas e/ou científicas fortes;

A razão fundamental e a base lógica dessas terapias freqüentemente contêm aplicações errôneas e/ou interpretações pessoais equivocadas de dados da literatura científica;

Os investigadores e proponentes freqüentemente provêm afirmações exageradas e irreais dessas modalidades;

Essas terapias freqüentemente têm o potencial de serem financeiramente proveitosas para aqueles que as desenvolveram, promoveram ou apoiaram;

Essas terapias são geralmente propagadas e comunicadas fora de canais de comunicação científica e clínica e os detalhes das terapias são geralmente secretos;

Seus proponentes com frequiência desencorajam e/ou recusam consulta e/ou revisão dos seus métodos por médicos ou cientistas de reputação;

Seus investigadores e organizadores por vezes afirmam que existe uma "conspiração" médica ou científica contra eles.

Neste capítulo foram avaliados modalidades terapêuticas questionáveis, sendo revisado o que se conhece sobre a eficácia da modalidade terapêutica, incluindo o número e a qualidade dos estudos conduzidos, o grau de validação independente realizada e o potencial de risco de iatrogenia associada com as modalidades.

Modalidades terapêuticas novas, porém ainda não comprovadas, podem ser aplicadas a pacientes em duas circunstâncias básicas:

- Como parte de ensaios experimentais aprovados por um corpo de revisores adequadamente constituido e/ou comitê de investigações clínicas de instituição aprovada para conduzir a pesquisa;

- Quando um corpo de revisores adequadamente constituido e/ou comitê de investigações clínicas de instituição aprovada para conduzir a pesquisa aprove o seu uso ( 1 ).

Por outro lado, o dilema de administrar ou não determinada droga a um paciente é algo familiar à classe médica. Médicos experientes e com bom julgamento clínico têm uma habilidade implícita de avaliar os benefícios e riscos dos procedimentos terapêuticos e relacioná-los ao diagnóstico quando decidem iniciar um tratamento, farmacológico ou não. Porém, freqüentemente esse tipo de julgamento é feito sem uma análise detalhada de todos os fatores relevantes (2).

Em particular no tratamento da obesidade, não há padrões universalmente aceitos que definem sucesso terapêutico. Embora reconheça-se que este é um processo arbitrário, é importante definir padrões para que tratamentos propostos possam ser discutidos e analisados.

Obesidade é uma doença multifatorial e os indivíduos obesos diferem muito entre si. Desta forma, qualquer padrão de sucesso que seja estabelecido para a população geral pode subestimar ou superestimar o impacto do tratamento sobre determinado indivíduo. Além disso, a variável utilizada para definir sucesso pode diferir numa base inter-individual ou, ao longo do tempo, até mesmo intra-individual. Por exemplo, perda de peso poderia ser um critério, porém, numa pessoa com complicações da obesidade, reduções discretas de peso ou mesmo a simples eliminação do processo de doença pode ser considerado sucesso, enquanto que sucesso após o tratamento cirúrgico é geralmente considerado como uma perda de pelo menos metade do peso excessivo e manutenção da perda por 5 anos.

\section{TERAPIAS ANALISADAS:}

\section{Acupuntura e Auriculoterapia (3):}

Acupuntura e auriculoterapia são freqüientemente defendidos e usados como meio de controlar o apetite e reduzir o peso corpóreo. Da mesma maneira, o uso de palmilhas e outros instrumentos que exercem 
pressão em pontos definidos da região da planta dos pés são vendidos em larga escala para redução de peso. Essa utilização é baseada em estudos não controlados e relatos de casos que mostram resultados encorajadores. Os poucos ensaios clínicos controlados com placebo apresentam falhas metodológicas e seus resultados são contraditórios. Dois ensaios clínicos mais rigorosos demonstram ausência de efeito sobre o peso corpóreo.

- Número de estudos conduzidos: insuficiente;

- Qualidade dos estudos conduzidos: pobre, mal conduzidos, não controlados, resultados contraditórios;

- Grau de validação independente: não realizada;

- Potencial de uso no tratamento da obesidade: muito baixo;

- Potencial de risco de iatrogenia: desconhecido.

\section{CREMES PARA CELULITE E OBESIDADE ${ }^{(4)}$ :}

\section{Massagem com Cremes ${ }^{(5)}$ :}

Muita pesquisa deve ser efetuada antes que tratamentos possam ser validados como clinicamente efetivos. Atualmente, não há medicação tópica à qual obesidade e celulite avançada visivelmente respondam em períodos de tratamento de até dois meses.

Os dados que oferecem suporte à segurança e eficácia de cremes à base de aminofilina limitam-se a número pequeno de pacientes. Embora os estudos realizados tenham sido bem projetados e os dados preliminares sejam encorajadores, mais dados são necessários antes que a segurança e eficácia do seu uso possam ser adequadamente determinadas ${ }^{(6)}$.

- Número de estudos conduzidos: insuficiente;

- Qualidade dos estudos conduzidos: pobre, não controlados;

- Grau de validação independente: não realizada;

- Potencial de uso no tratamento da obesidade: baixo;

- Potencial de risco de iatrogenia: desconhecido.

\section{Fitoterapia:}

Fitoterapia é freqüientemente defendida como meio de controlar o apetite e/ou aumentar a termogênese, reduzindo o peso corpóreo. Essa utilização é baseada em estudos não controlados e relatos de casos que mostram resultados encorajadores. Os poucos ensaios clínicos controlados com placebo utilizando várias substâncias apresentam falhas metodológicas e seus resultados são contraditórios (7-9).

Várias preparações com ervas são promovidas em larga escala por organizações comerciais como remé- dios tradicionais de pouco valor médico real, podendo, em alguns casos conter substâncias perigosas (13). São exemplos de substâncias inúteis e desprovidas de qualquer respaldo científico para tratamento da obesidade: extrato de Ginkgo biloba, extrato de Kava kava, café, Garcinia cambogia.

- Número de estudos conduzidos: insuficiente;

- Qualidade dos estudos conduzidos: pobre, não controlados;

- Grau de validação independente: não realizada;

- Potencial de uso no tratamento da obesidade: baixo;

- Potencial de risco de iatrogenia: desconhecido.

\section{Mesoterapia (10-12):}

- Número de estudos conduzidos: insuficiente;

- Qualidade dos estudos conduzidos: pobre, não controlados;

- Grau de validação independente: não realizada;

- Potencial de uso no tratamento da obesidade: baixo;

- Potencial de risco de iatrogenia: mediano.

\section{Diuréticos e Laxativos:}

- Número de estudos conduzidos: não há.

\section{Yoga, hipnoterapia:}

- Número de estudos conduzidos: não há.

\section{Formulaçōes Magistrais "Naturais":}

Inúmeros medicamentos manipulados por farmácias magistrais são divulgados, promovidos e vendidos em larga escala sob a rotulação de "produtos naturais". Com freqüência, esses produtos contêm medicações controladas como anorexiantes e benzodiazepínicos não divulgados em seus rótulos, oferecendo grave perigo à saúde pública. São exemplos de substâncias desprovidas de respaldo científico e sem utilidade para tratamento da obesidade: 5-hidróxi-triptofano, picolinato de crômio, reposição de vitaminas e óligo-elementos (ditos "terapia ortomolecular").

- Número de estudos conduzidos: insuficiente;

- Qualidade dos estudos conduzidos: pobre, năo controlados;

- Grau de validação independente: não realizada;

- Potencial de uso no tratamento da obesidade: baixo;

- Potencial de risco de iatrogenia: muito elevado.

\section{Suplementos Dietéticos}

O que é um suplemento dietético? Um suplemento dietético é qualquer produto que se ingere por via oral 
e contém ingredientes dietéticos; seu rótulo o identifica como um suplemento dietético. Os ingredientes dietéticos nos suplementos podem incluir vitaminas, minerais, ervas e aminoácidos, além de substâncias como enzimas, tecidos orgânicos, metabólitos, extratos ou concentrados. Os suplementos dietéticos podem ser encontrados em forma de drágeas, comprimidos, cápsulas, líquidos ou pó.

Quem regulamenta os suplementos dietéticos? A regulamentação é diferente para cada país, a etiqueta deve conter suficiente informação sobre a composição dos produtos para que os consumidores possam fazer uma boa escolha. A responsabilidade da segurança e a informação sobre o produto está nas mãos do produtor. Os fabricantes e distribuidores não têm que registrar ou obter aprovação de nenhuma entidade específica para produzir ou vender suplementos dietéticos.

\section{Normas para definir os suplementos dietéticos:}

- determinar dose de consumo.

- informação de pelo menos 14 nutrientes, se estiverem em quantidades significativas, incluindo vitaminas e minerais.

- estabelecer se há vitaminas e minerais adicionados.

- se o produto contém ingredientes vegetais deve ser citado o nome da planta.

- quando o produto possuir um suplemento em dose maior que $100 \%$ da recomendada, é denominado "alta potência".

- anti-oxidantes podem ser usados em produtos que inativam radicais livres ou previnem o início das reações químicas dos radicais livres.

\section{Alguns suplementos nutricionais amplamente usados:}

5-HTP, zinco, extrato de Gingko biloba, extrato de raiz de Kava kava (produtos utilizados para redução de peso sem evidência científica para seu uso); Citrim, picolinato de crômio (usados para redução de peso sem respaldo cientifico para seu uso mas, ao contrário, existem estudos que mostram efeitos secundários como lesão renal); Efedra, chás e café (substâncias termogênicas, que elevam a taxa metabólica levemente, sem estudos científicos que respaldam seu uso no tratamento da obesidade. DHEA, Herbalife, BCAA, Garcinia cambogia (dizem ter ação no tratamento da obesidade, porém não há estudos científicos que respaldem seu uso).
Todos estos produtos e muitos outros não têm evidência científica de utilidade e segurança no tratamento da obesidade. Ao contrário, estão documentados alguns efeitos secundários e contra-indicações.

Muitos países têm sistemas médicos tradicionais que operam em adição ou em substituição a serviços médicos convencionais. Tratamentos tradicionais para uma série de doenças, incluindo obesidade, são freqüentemente disponíveis e comumente usados por pessoas em países em desenvolvimento. Embora os dados sobre a eficácia dessas preparações sejam limitados, por vezes há evidências não documentadas de valor potencial. Há necessidade de mais pesquisas para verificar a validade do uso potencial dessas medicações e produtos (9a).

\section{LEITURA RECOMENDADA}

1. American Diabetes Association: Unproven therapies. Diabetes Care 1994;17:1551.

2. Pauker MD, Kassirer JP. Therapeutic decision making: a cost-benefit analysis. N Engl J Med 1975;293:229-234.

3. Ernst E. Acupuncture/acupressure for weight reduction? A systematic review. Wien Klin Wochenschr 1997;109:6062.

4. Draelos ZD, Marenus KD. Cellulite. Etiology and purported treatment. Dermatol Surg 1997;23:1177-1181.

5. Arnem D von: (Is obesity influenced through massage)? Munch Med Wochenschr 1968;110:1163.

6. Dickinson BI, Gora-Harper ML. Aminophylline for cellulite removal. Ann Pharmacother 1996:30:292-293.

7. Chem M. Observation of curative effect of lipid lowering and fat restraining tablets on complicated obesity. J Tradit Chin Med 1995; 15:252-255.

8. Jin HM, Jiao DH. (Effect of jiang-zhi jian-fei yao on gastro-intestinal movement and adipose cell of abdominal wall). Chung Kuo Chung Hsi I chieh Ho Tsa Chih $1994 ; 14: 230-231$

9. Yoshida $T$, Sakane N, Wakabayashi $Y$, Umekawa $T$, Kondo $M$. Thermogenic, anti-obesity effects of bofutsusho-san in MSG-obese mice. Int J Obes Relat Metab Disord 1995: 19:717-722.

9a. WHO: Preventing and Managing the Global Epidemic. In: Obesity - Report of a WHO Consultation on Obesity. Geneva, 1997.

10. Tennstedt D, et al. Cutaneous adverse effects of mesotherapy. Ann Dermatol Venereol 1997; 124: 192-196.

11. Doutre MS, et al. (Side effects of mesotherapy). Therapie 1997; 52:93-96

12. Deleixhe-Mauhin $F$, et al. (ls mesotherapy without hazards)? Ver Med Liege 1991;46:213-215. 


\section{CAPÍTULO 13}

\section{OBESIDAD EN EL NIÑO Y EL ADOLESCENTE}

La obesidad en el niño y el adolescente es un trastorno frecuente, - más de la tercera parte de las consultas de endocrinología pediátrica -, de prevalencia creciente, con repercusión en el desarrollo psicosocial y que predispone a la obesidad en el adulto.

\section{Concepto}

La obesidad se define como el exceso de grasa corporal total en relación con el peso corporal. El desarrollo del tejido adiposo humano se inicia durante la etapa prenatal. Existen tres períodos críticos para el desarrollo de la obesidad y de sus complicaciones. El primero ocurre durante la gestación y primer año de vida; el segundo entre los 5 y 7 años de edad o "período de rebote de la obesidad" y el el tercero en la adolescencia. La obesidad que se desarrolla en estos períodos, en especial en el "período de rebote", se caracteriza por su persistencia y complicaciones.

La obesidad es el resultado de un desequilibrio permanente y prolongado entre ingestión calórica y gasto energético donde el exceso de calorías se almacena como tejido graso. El gasto energético total en el niño y el adolescente se compone de: metabolismo basal, termogénesis, actividad física y crecimiento.

El índice de masa corporal (IMC), también llamado Indice de Quetelet, es muy útil en el adulto para valorar la adiposidad. En el niño el valor del índice varía con la edad y muestra incremento durante el primer año de edad y después de los 6 años. Se deben usar los valores del índice para los diversos grupos etáreos pues al utilizar los criterios dados para los adultos se corre el riesgo de no diagnosticar obesidad en los niños y adolescentes.

El IMC se calcula por la fórmula:

$\mathrm{IMC}=\mathrm{P} / \mathrm{T}^{2} \quad$ (peso en kilogramos dividido por el cuadrado de la talla en metros).

Actualmente existen gráficos de centilas para clasificar por el IMC el grado de obesidad en el niño. Los producidos por Rolland-Cachera (1991) pueden ser útiles para este fin. En general se considera un niño obeso cuando su IMC se encuentra por encima de la centila 90 o dos desviaciones por encima de la media para su edad.

Otros utilizan como índice más preciso el \% del IMC, el cual se calcula con la fórmula:
(IMC del niño / IMC de la centila 50 de peso y talla para la edad) $\times 100$

El \% será 100 en un niño de peso y talla media. Se considerará sobrepeso en un IMC $110 \%$ y obesidad si es de $120 \%$.

La medición del grosor de los pliegues cutáneos es útil para medir el grado de adiposidad. Se realiza utilizando calibradores especiales, los pliegues mas utilizados son: el tricipital, el bicipital, el subescapular, el suprailiaco y el de la pantorrilla. En la práctica se utiliza sólo a nivel tricipital. Se considera que un niño es obeso cuando el grosor del pliegue tricipital es superior a la centila 95 o dos desviaciones superiores a la media.

Otros métodos mas sofisticados como son la densitometría, la ultrasonografia, la bioimpedancia eléctrica, la tomografia axial computada, la conductividad eléctrica corporal total (TOBEC) y el DEXA son utilizados en trabajos de investigación.

\section{Historia clínica}

Generalmente los padres, también obesos, consideran la obesidad como algo normal o como una afección "glandular" o endocrina.

La historia clínica para el estudio de estos pacientes debe hacer énfasis en diversos aspectos.

1. Historia familiar de obesidad, diabetes, hipertensión, hiperlipemias.

2. Características y hábitos alimentarios en la familia, actitud hacia la actividad física.

3. Nivel socio-económico y cultural familiar. Número de hermanos.

4. Actitud familiar ante la obesidad del niño.

5. Edad de comienzo de la obesidad y epifenómenos que se relacionen con ésta, traumas emocionales y físicos, disminución de la actividad física, adicción a la televisión y video-juegos, ingestión calórica.

6. Enfermedades asociadas a la obesidad.

7. Actitud del niño ante su obesidad, tratamientos realizados y resultados de los mismos.

8. Examen físico detallado con estudio auxológico completo, IMC, distribución de las grasas, estadios del desarrollo puberal, tensión arterial.

9. Si talla normal o superior a su edad exámenes complementarios sistemáticos y se diagnosticará como obesidad simple exógena.

10. En caso de retraso de la talla o dudas referentes a la asociación de otra afección o causa se indican exámenes complementarios según afección sospechada. Un examen radiológico de carpo que muestre edad ósea normal o moderadamente acelerada sugiere obesidad exógena o primaria. 
11.Exámenes complementarios sistemáticos: hemograma completo, glucemia ayuna y postprandial (determinar niveles de insulina si se sospecha hiperinsulinismo), colesterol, triglicéridos y HDL (si antecedentes de familiares con dislipidemia), y estudio psicológico.

12.Exámenes complementarios especiales: EKG, función respiratoria, ortopedia (si alteraciones clínicas); TAC-RMN cerebral, fondo de ojo y campimetría (si se sospecha tumor cerebral); exámenes hormonales (si se sospecha endocrinopatía); cariotipo (sospecha cromosomopatía).

\section{Implicaciones en la salud de la obesidad en el niño y el adolescente}

Psicosociales: Los niños obesos presentan trastornos de conducta, signos de depresión y angustia, con baja autoestima. Además, se sienten rechazados, torpes para actividades fisicas y de relaciones sociales, lo que hace que se refugien en el sedentarismo, el aislamiento y una mayor ingestión de alimentos con sentimientos de culpa y a veces trastornos en el comportamiento alimentario.

Ortopédicas:Pueden presentar pie plano, escoliosis, coxavara, epifisiolisis, genus valgum y tibia vara.

Dermatológicas: Vergetures en caderas, región superior de muslos y pecho Infecciones cutáneas, intertrigos, forunculosis, acantosis nigricans.

Cardiorrespiratorio: Entre ellos la hipertensión arterial y la apnea de sueño.

Riesgo de obesidad en el adulto: Los niños obesos tiene mayor riesgo de convertirse en adultos obesos. el $40 \%$ de los niños obesos se hacen adolescentes obesos y el $80 \%$ de los adolescentes obesos se convierten en adultos obesos. La obesidad del adulto que se ha iniciado en la infancia tiene peor pronóstico en relación con las complicaciones y la morbilidad y es mas rebelde al tratamiento.

Cambios endocrinos metabólicos. Como consecuencia del estado nutricional alterado, desaparecen con la pérdida de peso:

- hiperinsulinemia e insulino resistencia,

- aumento colesterol, trigiceridos y ApoB; disminución de HDL colesterol y Apo A 1 ,

- disminución de la secreción de hormona de crecimiento,

- disminución de respuesta de la prolactina a los estímulos,

- ritmo circadiano normal del cortisol, elevación de los andrógenos y la DHEA, adrenarca prematura,

- disminución de la globulina transportadora de los esteroides sexuales, aumento aromatización de la testosterona a estrógeno (no feminización) en los varones,

- hiperandrogenismo, hirsutismo poliquistosis ovárica, aumento de la progesterona, en las niñas.

\section{Tratamiento}

El objetivo del tratamiento de la obesidad en el niño y adolescente es conseguir y mantener un peso adecuado para la talla al mismo tiempo que se mantiene un crecimiento y desarrollo normal. Sin embargo, el tratamiento de la obesidad es uno de los problemas mas dificiles y frustrantes para el equipo multidisciplinario que atiende a estos niños y adolescentes, pues mas de un $80 \%$ de estos niños vuelven al peso que tenían antes de comenzar el tratamiento. Por lo que en el tratamiento del niño y adolescente obeso debemos recordar los siguientes principios básicos:

1. No hay "drogas maravillosas" para la reducción de peso;

2. El tratamiento es individualizado;

3. El tratamiento es responsabilidad de un equipo multidisciplinario de atención (paciente y familia, endocrinólogo, nutricionista, psicólogo, instructor de actividad fisica);

4. La familia y el niño son los miembros "mas importantes" de ese equipo;

5. No debemos esperar milagros en los resultados "es una batalla de tiempo";

6. Debe existir un cumplimiento y apoyo emocional permanentes.

El tratamiento contempla aspectos de la alimentación, actividad fisica, educación nutricional, apoyo psicológico y modificación de los hábitos de vida y alimentación.

\section{Aspectos de la alimentación}

El manejo de la ingesta energética es uno de los pilares fundamentales en el tratamiento.

Una alimentación bien balanceada que suministre todos los nutrientes necesarios es el tratamiento mas seguro y efectivo en la obesidad. Como regla general los niños obesos deben ser sometidos a un tratamiento donde el equilibrio entre ingesta calórica y gasto calórico proporcione un peso estable o un pérdida de peso moderada.

Nuestras recomendaciones nutricionales en el niño y el adolescente obeso son las siguientes:

\section{En el niño menor de 2 años:}

Revisar plan de alimentación, frecuencia y cantidades de alimentos, mantener la lactancia materna o artificial correspondiente, ablactación adecuada. No indicaciones especiales. 


\section{En preescolares:}

Alimentación isocalórica de 1000 calorías por el primer año más 100 calorías por año de edad restante constituida por: $50 \%$ de carbohidratos, $20 \%$ de proteínas y $30 \%$ de grasa ( $10 \%$ saturadas, $10 \%$ poliinsaturadas, $10 \%$ monoinsaturadas), repartidas en tres comidas y meriendas. Promover actividad física.

\section{Escolares:}

Igual recomendación que en preescolares. Puede utilizarse leche semidescremada. Recomendar la práctica de algún deporte

\section{Adolescentes:}

La alimentación puede ser hipocalórica hasta con un $25 \%$ de calorías menos o aportar no menos de 1200 $\mathrm{kcal} /$ día con igual composición de $50 \%$ carbohidratos, $20 \%$ de proteínas y $30 \%$ de grasas ( $10 \%$ saturadas, $10 \%$ poliinsaturadas, $10 \%$ monoinsaturadas), distribuir en tres comidas y tres meriendas

No consumir bebidas alcohólicas ni alimentos fritos. Actividad fisica regular: deportes, aeróbicos. Apoyo psicológico y familiar, educación nutricional y cambios de hábitos de vida y alimentación.

En sentido general, la alimentación debe ser agradable, sabrosa, que integre a todos los miembros de la familia; con el contenido calórico adecuado, con un buen aporte de nutrientes, microclementos y fibras.

Debe valorarse el uso de productos bajos en calorías, en especial los que usan edulcorantes no calóricos. Además es imprescindible la eliminación de las "chucherías" (refrescos, galletas, caramelos, helados, dulces) que se ingieren entre las comidas.

Una restricción severa en la ingesta origina pérdida de masa muscular, cambios metabólicos no deseables (balance negativo de nitrógeno, cetosis), deficit nutricional, detención del crecimiento y perturbación de la conducta alimentaria.

Por otra parte, un régimen alimentario con restricción severa de la ingesta calórica, provoca conflictos en la relación familiar al diferenciar la alimentación del niño (restricción, casi con sentido punitivo) de la del resto de la familia.

Todo lo anterior hace que NO RECOMENDEMOS: dietas de ayuno, dietas de ayuno con proteínas de alto valor biológico, dietas cetogénicas ni dietas con alto contenido en grasa y proteínas y bajo contenido en carbohidratos.

\section{Actividad Fisica}

Es un elemento importante en el tratamiento del niño y el adolescente obeso, como medida complementaria a la dietoterapia, sobretodo parece más útil para mantener la pérdida de peso.

La actividad fisica aumenta el gasto energético, mejora la sensibilidad a la insulina, disminuye la lipogénesis, aumenta la masa muscular y evita el sedentarismo.

El ejercicio debe ser individualizado de acuerdo a las características del niño, pues algunos niños padecen trastornos ortopédicos o su exceso de peso hace que algunos tipos de ejercicios no se recomienden. Por otra parte, los niños con mayor exceso de peso tienen un gasto energético mayor.

\section{Recomendamos:}

- Las actividades aeróbicas (marcha, carrera, ciclismo, patinaje, danza, natación) comenzando con un mínimo de 3 sesiones semanales hasta convertirla en parte de las actividades de la vida diaria.

- En los adolescentes recomendamos la incorporación a grupos de deportes colectivos (baseball, balompié, baloncesto, caminatas, natación)

- Evitar el sedentarismo y en especial las largas sesiones de televisión y video-juegos que aportan un reducido gasto energético y apartan a los niños de la actividad física. La televisión, por otra parte, promociona alimentos infantiles hipercalóricos.

En los niños pequeños su intensa actividad espontánea, hace que no tengamos recomendaciones especiales sino solo estimular las mismas.

\section{Apoyo emocional}

En ocasiones el niño obeso, se encuentra bajo estrés psicológico al sentirse rechazado por sus compañeros al comportarse menos diestramente en la actividad fisica y aun en las relaciones sociales. Todo ello genera sentimientos de angustia, depresión y aislamiento, que pueden afectar el desarrollo de su personalidad.

Es necesario estimular al niño a llevar una vida normal con plena participación de las actividades escolares y extraescolares, a la vez que tratamos de modificar su conducta y hábitos de vida con el fin de lograr mas resultados positivos y duraderos en su tratamiento.

La orientación del psicoterapeuta y la intervención en la dinámica familiar y su estilo de vida son de gran apoyo en el tratamiento general de la enfermedad, sobretodo cuando existen conflictos interfamiliares, sentimientos de rechazo al tratamiento o perturbaciones de la conducta alimentaria.

\section{Apoyo familiar y modificación de hábitos}

La participación del paciente y la familia es obligada en el tratamiento y prevención de la obesidad. 
Es en la familia donde se aprenden y desarrollan los hábitos de vida (nutrición, actividad física, conceptos de salud, sentimientos estéticos y culturales), por lo que es necesario proporcionar la información suficiente y permanente a la familia sobre la obesidad, sus complicaciones, su prevención y tratamiento; que el tratamiento dependerá como parte esencial, de la reducción de la ingesta calórica y del incremento de la actividad física, y de un modo especial aclarar que no existen "drogas maravillosas" que hagan bajar de peso. Además debemos enfatizar que la familia tiene la mayor responsabilidad en el cumplimiento del tratamiento y prevención de la obesidad, que su apoyo es esencial y permanente en la creación de nuevos hábitos nutricionales y un nuevo estilo de vida sana.

\section{Medicamentos}

Los fármacos son poco útiles en el tratamiento de la obesidad en el niño y el adolescente.

\section{Cirugía}

No están establecidos los criterios para utilizar estos métodos en pediatría.

\section{LECTURAS RECOMENDADAS}

1. Alemzadeh R, Lifshitz F. Childhood obesity. En Lifshitz F, ed. Pediatric Endocrinology, 3rd edition, New York: Marcel Dekker 1996:pp.753-774

2. Bueno M. Sarría A. Obesidad. En: Pombo M, ed. Tratado de Endocrinología Pediátrica, 2da edición, Madrid: Díaz de Santos 1997:pp.1135-1147

3. Bueno M, Sarría A, Bueno O. Obesidad en el niño y en el adolescente. En Chavarría C, ed. Endocrinología, México: McGraw Hill Interamericana 1998:pp.207-225

4. Cole TJ. A method for assessing age-standardized weight for height in children seen cross sectionally. Ann Hum Biol 1979:6:249-268

5. Dietz WH. Critical periods in childhood for the development of obesity. Am J Clin Nutr 1994:59:955-959

6. Dietz WH, Gortmaker SL. Do we fatten our children at the television set? Obesity and television viewing in children and adolescents. Pediatrics 1985;75:807-812.

7. Epstein LH, Valoski A, McCurley J. Effect of weight loss by obese children on long-term growth. Am J Dis Child 1993; 147:1076-1080

8. Güell R. Obesidad y delgadez. En: Güell R, ed. Introducción a la Endocrinología Pediátrica. La Habana: Científico -Técnica 1987:pp.39-44

9. Knittle JC, Timmers K, Ginsberg-Felliner F. The growth of adipose tissue in children and adolescents. J Clin Invest 1979:63:239-245

10. López Siguero JP. El niño obeso. En: Soriguer Escofet FJC. ed. La Obesidad. Monografia de la Sociedad Española de Endocrinologia, Madrid: Díaz de Santos 1994:pp.77-94
11. Mahan LK. Family-focused behavioral approach to weight control in children. Pediat Clin N Amer 1987;34:983-996

12. Must A. Dallal GE, Dietz WH. Reference data for obesity: 85th and 95th percentiles of body mass index $\left(\mathrm{wt} / \mathrm{ht}^{2}\right)$ and triceps skinfold thickness. Am J Clin Nutr 1991;53:839-846.

13. Poskitt EME. Defining childhood obesity: the relative body mass index (BMI). Acta Paediatr 1995;84:961-963.

14. Poskitt EME. El niño obeso. En: Brook CGD, ed. Endocrinología Clínica Pediátrica, 2da edición, Barcelona: Ancora SA 1989:pp.149-172.

15. Rodríguez Hierro F. Obesidad. En: Argente J, Carrascosa A, Gracia R, Rodríguez F, eds. Tratado de Endocrinologia Pediátrica y de la Adolescencia, Madrid: EDIMSA 1995:pp.897-913.

16. Rolland-Cachera MF, Sempe M, Guilloud-Bataille M, Patois $E$, Pequignot-Guggenbuhl F, Fautrad V. Adiposity indices in children. Am J Clin Nutr 1982;36:178-184

17. Rolland-Cachera MF, et al. Body mass index variationscentiles from birth to 87 years. Eur J Clin Nutr 1991:45: 13-21.

18. Rosembaun M, Leibel R, Hirsch J. Obesity. N Eng J Med $1997 ; 337: 396-407$

\section{CAPÍTULO 14}

\section{OBESIDAD EN EL EMBARAZO Y LACTANCIA}

El embarazo representa una prueba de esfuerzo metabólico importante que tiende a adaptar el organismo para optimizar el paso de nutrientes a traves de la placenta.

En ocasiones una ganancia excesiva de peso durante la gestación puede favorecer la aparición de patologías asociadas, como la diabetes gestacional, hipertensión arterial y/o preeclampsia.

La mujer obesa es aquella que inicia su gestacion con una cantidad de grasa corporal mayor a la recomendada como normal, definida en funcion al IMC igual o mayor a 27.

Una vez conocido el peso al inicio de la gestación, se debe evaluar la evolución del mismo, no solamente en cuanto a incrementos netos en peso, sino a como los distribuye a lo largo del tiempo del embarazo. La ganancia de peso esta condicionada por factores como la estatura y el peso pregestacional, pero tambien por la edad, el número de partos previos y la raza.

\section{TRATAMIENTO}

\section{Dietoterapia}

Durante el ler y 2 do trimestre en una embarazada no obesa hay utilizacion acelerada de la glucosa produciendose una disminucion de la glucosa materna. 
El incremento de peso debe estar de acuerdo al IMC. Para la mujer obesa se acepta incremento de $9 \mathrm{~kg}$.

La mayor parte del aumento del peso durante el embarazo es atribuible al feto y sus anexos y este incremento de masa en forma significativa es a partir de la Segunda mitad de la gestacion. Las reservas maternas de grasa y proteina se forman con rapidez antes de la mitad del embarazo y despues aumentan poco, para completar entre 3 y 4 kilos extras al final del embarazo.

En el ler trimestre es necesario modificar el aporte calórico en menos del $10 \%$.

En el 2 do y $3 \mathrm{er}$ trimestre se incrementan $350 \mathrm{kcal}$ diarias de aporte calorico.

Despues de la vigesima semana de gestacion se debe calcular un consumo de 30 kilocalorias por kilo- gramo de peso esperado. En el cuadro I. se anota las recomendaciones de la distribcion de los nutrientes y sales, minerales y vitaminas.

La clave para valorar si la dieta indicada a la mujer enbarazada esta teniendo los resultados esperados es mediante la valoración de los incrementos en peso.

\section{ACTIVIDAD FÍSICA}

Previo al embarazo si la realizaba puede continuar.

$\mathrm{Si}$ no realizaba poderá efctuar caminadas y natación, no competitivas.

La indicación debe ser individual y la alimentación debe prevenir hipoglucemia y cetosis.

\begin{tabular}{|c|c|c|c|c|c|c|}
\hline \multirow{2}{*}{ Recomendaciones } & \multicolumn{3}{|c|}{ Obesa } & \multicolumn{3}{|c|}{ No obesa } \\
\hline & \multicolumn{3}{|c|}{ Trimestres } & \multicolumn{3}{|c|}{ Trimestres } \\
\hline & 1 & 2 & 3 & 1 & 2 & 3 \\
\hline $\begin{array}{c}\text { Valor Calorico } \\
\text { Total }\end{array}$ & $-10 \%$ & $350 \mathrm{Kcal}$ & $350 \mathrm{Kcal}$ & $N<=$ & 350 a $500 \mathrm{Kcal}$ & 350 a $500 \mathrm{Kcal}$ \\
\hline $\begin{array}{l}\text { Hidratos de } \\
\text { Carbono }\end{array}$ & $\begin{array}{c}50-55 \% \\
\text { complejos }\end{array}$ & $\begin{array}{c}50-55 \% \\
\text { complejos }\end{array}$ & $\begin{array}{c}50-55 \% \\
\text { complejos }\end{array}$ & $\begin{array}{c}50-55 \% \\
\text { complejos }\end{array}$ & $\begin{array}{c}50-55 \% \\
\text { complejos }\end{array}$ & $\begin{array}{c}50-55 \% \\
\text { complejos }\end{array}$ \\
\hline Proteinas & $\begin{array}{c}1,5 \propto 2 \mathrm{~g} / \mathrm{KPD} \\
60 \% \\
\uparrow \vee \mathrm{B}\end{array}$ & $\begin{array}{c}1,5 \text { a } 2 \mathrm{~g} / \mathrm{KPD} \\
60 \% \\
\uparrow \mathrm{VB}\end{array}$ & $\begin{array}{c}1,5 \text { a } 2 \mathrm{~g} / \mathrm{KPD} \\
60 \% \\
\uparrow \vee \mathrm{B}\end{array}$ & $\begin{array}{c}1.5 \text { a } 2 \mathrm{~g} / \mathrm{KPD} \\
60 \% \\
\uparrow \vee \mathrm{B}\end{array}$ & $\begin{array}{c}1.5 \text { a } 2 \mathrm{~g} / \mathrm{KPD} \\
60 \% \\
\uparrow \vee \mathrm{B}\end{array}$ & $\begin{array}{c}1.5 \text { a } 2 \mathrm{~g} / \mathrm{KPD} \\
60 \% \\
\uparrow \vee \mathrm{B}\end{array}$ \\
\hline Grasas & $\begin{array}{c}25 \text { a } 30 \% \text { rico } \\
\text { em AGPIS. } 7 \% \\
\text { saturado } \\
\text { - } 300 \mathrm{mg} \\
\text { colesterol }\end{array}$ & $\begin{array}{c}25 \text { a } 30 \% \text { rico } \\
\text { em AGPIS. } 7 \% \\
\text { saturado } \\
\text { - } 300 \mathrm{mg} \\
\text { colesterol }\end{array}$ & $\begin{array}{c}25 \text { a } 30 \% \text { rico } \\
\text { em AGPIS. } 7 \% \\
\text { saturado } \\
\text { - } 300 \mathrm{mg} \\
\text { colesterol }\end{array}$ & $\begin{array}{c}25 \text { a } 30 \% \text { rico } \\
\text { em AGPIS. } 7 \% \\
\text { saturado } \\
\text { - } 300 \mathrm{mg} \\
\text { colesterol }\end{array}$ & $\begin{array}{c}25 \text { a } 30 \% \text { rico em } \\
\text { AGPIS. } 7 \% \text { satura- } \\
\text { do } \\
-300 \mathrm{mg} \\
\text { colesterol }\end{array}$ & $\begin{array}{c}25 \text { a } 30 \% \text { rico em } \\
\text { AGPIS. } 7 \% \text { satura- } \\
\text { do } \\
-300 \mathrm{mg} \\
\text { colesterol }\end{array}$ \\
\hline Hierro & $\begin{array}{l}30 \mathrm{mg} \mathrm{Fe} \\
\text { Ferroso }\end{array}$ & $\begin{array}{l}30 \mathrm{mg} \mathrm{Fe} \\
\text { Ferroso }\end{array}$ & $\begin{array}{l}30 \mathrm{mg} \mathrm{Fe} \\
\text { Ferroso }\end{array}$ & $\begin{array}{l}30 \mathrm{mg} \mathrm{Fe} \\
\text { Ferroso }\end{array}$ & $\begin{array}{l}30 \mathrm{mg} \mathrm{Fe} \\
\text { Ferroso }\end{array}$ & $\begin{array}{l}30 \mathrm{mg} F \mathrm{Fe} \\
\text { Ferroso }\end{array}$ \\
\hline Ácido Folico & $400 \mathrm{mcg}^{*}$ & $400 \mathrm{mcg}^{* *}$ & $400 \mathrm{mcg}^{* *}$ & $400 \mathrm{mcg}^{*}$ & $400 \mathrm{mcg}^{* *}$ & $400 \mathrm{mcg}^{* *}$ \\
\hline Calcio & $1200 \mathrm{mg}$ & $1500 \mathrm{mg}$ & $1500 \mathrm{mg}$ & $1200 \mathrm{mg}$ & $1500 \mathrm{mg}$ & $1500 \mathrm{mg}$ \\
\hline Vitamina A & $800 \mathrm{mcg}$ & $800 \mathrm{mcg}$ & $800 \mathrm{mcg}$ & $800 \mathrm{mcg}$ & $800 \mathrm{mcg}$ & $800 \mathrm{mcg}$ \\
\hline Vitamina D & $10 \mathrm{mcg}$ & $10 \mathrm{mcg}$ & $10 \mathrm{mcg}$ & $10 \mathrm{mcg}$ & $10 \mathrm{mcg}$ & $10 \mathrm{mcg}$ \\
\hline $\begin{array}{c}\text { Fibras soluble } \\
\text { e insoluble }\end{array}$ & $20 \mathrm{~g}$ & $30 \mathrm{~g}$ & $30 \mathrm{~g}$ & $20 \mathrm{~g}$ & $30 \mathrm{~g}$ & $30 \mathrm{~g}$ \\
\hline lodo & $200 \mathrm{mcg}$ & $200 \mathrm{mcg}$ & $200 \mathrm{mcg}$ & $200 \mathrm{mcg}$ & $200 \mathrm{mcg}$ & $200 \mathrm{mcg}$ \\
\hline Distribuición & $4+2$ colaciones & $4+2$ colaciones & $4+2$ colaciones & $4+2$ colaciones & $4+2$ colaciones & $4+2$ colaciones \\
\hline
\end{tabular}

* Imprescindible

** asegura la calidad del glóbulo rojo 


\section{SUS COMPLICACIONES:}

La diabetes mellitus se presenta com mayor frecuencia en las embarazadas obesas. La incidencia se reporta entre el $4 \%$ y el $18 \%$.

Todas las formas de diabetes observadas en al obesidad durante el embarazo, ya sea previa al mismo o al inicio de él, excede a la que se presenta en las mujeres delgadas, por más de 6 veces, con riesgos intermedios entre aquellas con presentaciones menos severas de obesidad. Dentro de los cuadros de diabetes y embarazo el más frecuente es el de la diabetes gestacional.

Durante la gestación se presenta un incremento en la resistencia en la insulina, que se suma al que se presenta por la obesidad misma. El fenómeno de la resistencia a la insulina se explica por la presencia de hormona lactógeno placentario, estrógenos y otros factores hormonales, juntos com ciertas enzimas placentarias que degradan la insulina. Sin embargo algunos autores sugieren que éste no es el único mecanismo, sino que se encuentan un defecto en la secreción de insulina en aquellas mujeres que desarrollan diabetes gestacional. A estos factores se aunan un defecto genético y la edad.

\section{LACTANCIA}

Se recominda como minimo hasta los 6 meses de vida del niño.

En la madre se puntualizará los aportes de:

$\mathrm{Fe}=15 \mathrm{mg} ; \mathrm{Ca}=1200 \mathrm{mg} ; \mathrm{I}=200 \mathrm{mcg} ;$ Água ad libitum

Se tebe evitar tanto en el embarazo, la lactancia el consumo de bebidas gaseosas - glucocarbonatadas comunes y dieteticas.

\section{CAPÍTULO 15}

\section{ETICA PROFESIONAL}

Nota aclaratoria: Dado que FLASO es una Asociación que involucra médicos, nutricionistas, especialistas en terapia fisica y otros profesionales afines, se ha procurado respetar, en lo posible, los códigos de ética de todas las profesiones incluidas. Cuando no fue posible, se decidió utilizar los códigos de ética médica.

\section{DEL ESPECILISTA EN OBESIDAD Y LA ETICA.}

Etica, palabra derivada del griego ETHOS, significa costumbre. La utilizamos en el sentido de aquellas costumbres que son admitidas por los que ejercen la profesión y es norma y obligación ajustarse a ellas en el desempeño de las mismas.

La cuidadosa observación de estos postulados nos permitirá hacer profilaxis de los posibles juicios por MALA PRAXIS y ampliar nuestros conocimientos científicos, así como observar una digna conducta gremial.

Una de las obligaciones morales del especialista en Obesidad es la formación profesional y así será explicado en el Artículo correspondiente. Es mucho lo que se puede decir acerca de la Etica y por ello creemos que se debe en cada Congreso, Curso, Seminario, etc, dedicar un espacio importante para tratar estos temas y la implicancia que tienen en lo jurídico y gremial. Las Sociedades miembros, en su jurisdicción, deberán insistir en el cumplimiento del código.

Por lo tanto, estimados colegas, deseamos no solamente que realizen una lectura detenida, sino que cumplan y se esfuerzen por hacer cumplir los postulados enunciados en el código. De esta manera nos jerarquizamos, no sólo ante el resto de los médicos sino también ante los pacientes y con ello engrandecemos nuestra querida especialidad.

\section{¿QUE ES LA ETICA PROFESIONAL?.}

La mayor parte de los problemas que se le presentan al hombre contemporáneo, tienen que ver con el ejercicio de un trabajo o de una profesión. La cultura actual le exige al hombre algún tipo de especialización profesional para incorporarse adecuadamente al mundo del trabajo y social. Quien no posee hoy una profesión o especialización profesional no tendrá los elementos indispensables para considerarse plenamente integrados a la Sociedad. Sus expectativas de éxito y de futuro estarán seriamente amagadas y su idea de felicidad se siente, igualmente resentida por estas circunstancias.

La ética profesional es una parte de la ética general; se trata de "una ciencia normativa que estudia los deberes y derechos de los profesionales en cuanto tales". A esta disciplina se le suele llamar DEONTOLOGIA, pero en español, ética profesional expresa mejor el sentido de esta ciencia.

Se suelen dar algunas características generales a esta ciencia: a) es una ciencia práctica que a la luz de los principios de la razón estudia las acciones humanas en cuanto están insertas en la vida social; b) es un control 
ejercido por el ideal de servicio sobre el ideal de beneficio; c) es el estudio de las acciones humanas en cuanto insertas en la vida social y por las que el individuo coopera al bien común de la Sociedad y de las que el profesional recaba beneficios para su existencia.

La preocupación por el proceder empírico del profesional es tan antigua como la especializacón que éste demostraba poseer en el orden de la ciencia y de la práctica. Ya Hipócrates les prescribía a sus discípulos, algunas normas éticas elementales a las que debian ceñirse quienes practicarían la medicina por su cuenta. En su obra "DE LOS DEBERES", Cicerón entrega interesante recomendaciones éticas que aún hoy día nos sorprenden por su actualidad. Santo Tomás en uno de los capítulos dedicados a los Estados, se refiere al modo de proceder de los profesionales de su tiempo. Así en todas las épocas han existido normas que pretenden regular la vida profesional. En la actualidad, los Colegios y Asociaciones Gremiales resguardan con mucha vehemencia la actuación de sus miembros. Para ellos se ha generalizado el uso y declaración de códigos de ética.

La ética profesional se relaciona con una serie de disciplinas como el Derecho, la Psicología, la Sociología, la Educación, etc. En todo caso los resguardos que la sociedad exige en la práctica profesional tienen que ver con fundamentales cuestiones de esa cultura: Las tradiciones, el respeto de los valores, la motivación de actitudes deseables, el imperio de la justicia, etc.

En suma, el Objeto de la ética profesional es lograr el ejercicio de una actitud personal de sujeto comprometido ante la actividad profesional que éste desarrolla, de acuerdo con los principios de la ética general. Esta disciplina tiene una creciente importancia y así como se han ido creando en el tiempo un creciente número de nuevas profesiones como consecuencia del progreso de la ciencia y la tecnología, en el orden especulativo, cada vez más se extiende el interés por estudiar los principios de la vida moral, individual y social para ponerlos como normas reguladoras de los actos y responsabilidades profesionales. Asimismo la Etica Profesional trata de definir con claridad la naturaleza de cada profesión, las relaciones dadas entre su ejercicio y aquellos elementos humanos que sufren su influencia.

Por lo general los institutos superiores de enseñanza donde el joven aprende su profesión no ponen énfasis en la formación moral. Excepcionalmente lo hacen con respecto a una formación de Etica Profesional, y así cuando se enfrenta con la vida laboral cae en un desamparo moral frente a actitudes de terceros que contradicen sus inocentes ideales éticos. Así no es infrecuente que el mismo caiga en la trampa de la corrupción o de la indiferencia moral con lo cual se hace participe de un principio negativo que menoscaba profundamente los cimientos de la profesión que ejerce y las normas de convivencia en que descansa el grupo o comunidad en la que labora. Con nostalgia recordará entonces a su universidad y la acusará de no haberle informado ni formado en esta clase de cuestiones tan indispensable para su vida profesional.

En el orden práctico la Etica Profesional ayuda a considerar la importancia que tienen las relaciones entre los miembros de una actividad y la clientela que atiende, y descubrirá muy pronto que la mejor garantía de su éxito descansará en el leal y escrupuloso cumplimiento de sus deberes. La clientela rehuye de los improvisadores de los incumplidores, y de todas aquellas actitudes que desprestigian a una profesión y a un profesional. Una persona así demuestra con estas actitudes tener serias deficiencias en su formación profesional, porque ésta no sólo incluye el SABER de una ciencia o disciplina sino que necesita de una práctica que indique como hay que APLICAR este saber de acuerdo con una normativa ética.

\section{CONDICIONES PARA EJERCER UNA PROFESION.}

Podemos resumirlas en cuatro puntos:

a) Físicas: Salud y Condición corporal afin con la profesión;

b) Psicológicas: en ella entran especialmente la vocación y la aptitud;

c) Intelectuales: tiene que ver con el conocimiento y la experiencia del arte que ejerce el sujeto;

d) Eticas o morales: Virtudes y valores que dignifican la profesión.

\section{FALTAS PROFESIONALES.}

En su desempeño diario el profesional suele corromperse cuando actúa movido por fines subalternos o cuando está inspirado en disvalores. Comete algunos FRAUDES que distorcionan su naturaleza ética como sujeto e instaura severos juicios en contra de su profesión. Suele olvidar el profesional que está siempre al servicio de los demás ya que toda profesión por definición es signo de SOCIABILIDAD. La sociabilidad que se desprende de esta inclusión tiene raíces muy profundas. Se basan primero en la indigencia del ser humano, cuya precariedad se suple en la convivencia con los demás. Para enfrentarla el hombre posee inteligencia con las cuales puede ejercer su señorio sobre la naturaleza. Además todo el grupo social es capáz de ordenar las cooperaciones individuales al bien común. Esto significa que los trabajos ejercidos dentro 
de la sociedad humana está divididos, haciendo cada hombre o grupo, una contribución distinta, sea a través de la prestación de un servicio o de la producción de un bien de consumo. En la suma de estas complejidades la que produce la convivencia armónica de una Sociedad.

\section{Desde un punto de vista general el profesional puede cometer los siguientes tipos de fraude:}

a) EL QUE NADA HACE: Es aquel que vive a expensas de la Sociedad y no contribuye con su cooperación organizada al Bien Común. Puede tratarse a sí mismo de un profesional que hace el mínimo esfuerzo para merecer la aprobación de los demás.

b) EL QUE HACE LO QUE TIENE QUE HACER, PERO LO HACE MAL: Se trata del sujeto que comete errores en forma reiterada en su trabajo, que no tiene vocación para su desempeño profesional o que actúa en forma rutinaria lejos de poner empeño en su quehacer. Puede ser un peligro para la sociedad cuando se trata de un profesional calificado donde la negligencia y la meticulosidad son requisitos indispensables.

c) EL QUE HACE LO QUE NO DEBE HACER: Son aquellos profesionales que amplian su actividad a rangos que no le competen o para los cuales no tienen competencia necesaria.

d) EL QUE HACE MÁS DE LO QUE NORMALMENTE DEBE HACER: Es aquel que traspasa ampliamente el ámbito de competencia asignado y a veces pasa a llevar roles que están entregados a profesionales distintos.

e) Desde un punto de vista más especial podemos distinguir los siguientes fraudes profesionales:

AL HONOR PROFESIONAL. Un profesional pertenece indisolublemente a un gremio u orden profesional a la que se integran todos aquellos que tienen una afinidad sustantiva en un quehacer. Esta integración produce un vínculo solidario que se expresa en una responsabilidad profesional sometida a reglas y vigilancia de sus pares. Existe la costumbre de achacar los defectos de un profesional a todos los que integran el gremio, razón por la cual es necesario cautelar el desempeño de todos para no menos cabar la imagen pública de los profesionales de una determinada orden. La sociedad es muy dura en la calificación moral de los profesionales, de aquí la importancia que reviste el desempeño honesto de la profesión para resguardar el prestigio y honor de todos los miembros. Cada uno tiene un compromiso con los demás colegas y en algu- nas profesiones hasta se exige un juramento simbólico relacionado con la ética del desempeño.

FALTA DE CONSIDERACION EN EL TRATO. Las personas que ejercen una actividad profesional necesitan tratar y ser tratadas con ciertas consideraciones. Se trata de un respeto a la persona y se acrecienta cuando esa persona representa una dignidad o autoridad dentro de la organización. Quien ejerce la dignidad tiene ante sí dos tipos de autoridad: Una Jurídica y otra Moral. La primera está representada por el cargo que ejerce, con sus atributos de poder y soberanía. La segunda es intangible pero más importante, porque en ella se representa el pretigio personal de la autoridad, y la imagen que ha logrado forjarse ante los demás, especialmente ante sus subordinados. La autoridad jurídica no basta para ejercer adecuadamente un cargo; necesita complementarse con la autoridad moral porque ésta es la que despierta sentimientos de simpatía, adhesión y docilidad de parte de los subordinados, lo que se manifestará en la cooperación en el trabajo y en una obediencia más solidaria para ejecutar las labores en una forma más perfecta y oportuna. Así como el profesional requiere consideración para darle dignidad a su cargo, así también este tiene la obligación de actuar con respeto y consideración de su cargo para con los demás.

EL DEBER DE RESTITUCION. Es el derecho a exigir lo que es suyo. Cuando las leyes y procedimientos establecen una propiedad sobre una cosa legítima, se tiene el derecho a exigir esa propiedad, en cualquier sentido que sea.

\section{RESPONSABILIDAD PROFESIONAL.}

Este es un acto típicamente ético. Se trata de responder de todas nuestras decisiones personales, es decir, de aquellas opciones que libremente hemos decidido seguir en nuestra conducta. El problema de responder por nuestros actos no es fácil. Al sujeto se le presenta la disyuntiva de expresar una cierta sumisión a reglas, normas, usos y costumbres del medio en que vive y además, reafirmar su independencia con respecto a estas mismas regulaciones. El conflicto se hace evidente cuando debe adecuar un término medio que no violente ninguno de estos límites. En suma el hombre necesita responder de sus obediencias y reveldias.

A través de la responsabilidad se tiene conciencia de la obligación de dar cuenta de los propios actos, lo cual comporta un deber para el sujeto. Si este deber es sentido por el sujeto como una obligación moral entonces decimos que es "RESPONSABLE". Si el sujeto no siente esta obligación decimos que es "IRRESPONSABLE". 
El profesional no está exento de responsabilidad. Mientras más compleja es su actividad, mayor responsabilidad tiene. Nadie puede exigir impunidad por sus actos ni tampoco neutralidad en lo que hace. La responsabilidad profesional también tiene una cara moral y otra jurídica. La primera está circunscrita a la propia conciencia del sujeto, la cual debe ser evaluada por sus pares. La segunda tiene una proyección social y constituye un asunto relacionado con la ley.

Un profesional debiera regirse a lo menos por estos dos simples principios:

a) Evitar toda trasgresión voluntaria a la norma profesional y social;

b) Disminuir al máximo las trasgresiones involuntarias a la norma profesional y social, producto de las debilidades humanas que le aquejan.

Algunos de los casos genéricos de "Irresponsabilidad Profesional" son los que siguen:

a) Aquel que exhibe títulos, cargos o méritos de los que carece. Es el ejemplo del charlatán que quiere ejercer irresponsablemente una profesión sin estar preparado ni autorizado.

b) El que condiciona el ejercicio de su profesión al pago anticipado de sus servicios, sin asegurar resultados positivos del éxito de su trabajo. Es el mercantilista que subordina su colaboración social exclusivamente al dinero.

c) El que rehuye la responsabilidad de sus deberes, retardando innecesariamente su trabajo o actuando con desgano. Es el burócrata que actúa sin vocación y escasa consideración por los demás.

d) El que no delega jamás responsabilidades en otros colegas, reservándose todas las opiniones y decisiones.

e) El que no cumple a cabalidad las obligaciones y deberes para los cuales fue expresamente contratado o requerido.

Digamos finalmente que la responsabilidad profesional debe estar siempre individualizada para que realmente sea efectiva. Una de las formas de irresponsabilidad es diluir en muchos la responsabilidad a fin de evitar sus consecuencias.

\section{CONCLUSIONES.}

De acuerdo con algunos entendidos en la materia, la ETICA es la disciplina intelectual más antigua de la tradición judeo-cristiana. Representa un conjunto de normas culturalmente definidas que rigen determinadas actividades humanas. Cabe señalar que etimológicamente el término proviene de la palabra griega ETHOS, que significa costumbres. Por cierto el voca- blo MORAL, del latin MORES, también significaba costumbres.

La posesión de un conjunto de valores morales no es una condición innata y éstos tienen que ser inculcados con la esperanza que se internalicen y entonces se conviertan en una especie de segunda naturaleza. Existen una serie de códigos modernos que complementan al ya mencionado Código Hipocrático, y puesto que fueron consultados, nos permitiremos mencionar los principales, a saber:

a) El Código Internacional de Etica Moderna o Código de Londres, que regula los deberes de los médicos en general, su obligación con los pacientes y con sus colegas.

b) El Código de Nuremberg y la Declaración de Helsinski, que establecen normas en la experiementación o investigación clínica en seres humanos.

c) La Declaración de Tokyo que prohibe la participación activa de los médicos en la tortura u otros tratos crueles, inhumanos o degradantes incluyendo castigos.

La Etica médica es mucho más que una serie de prescripciones y prohibiciones en el devenir profesional. Creemos que el profesional debe adquirir una conciencia clara de cómo se han establecido esos valores morales, en que forman se justifican y como realmente protegen al paciente, a la sociedad, $y$ al propio profesional de la medicina. Para ello creemos en un modelo BIO-PSICO-SOCIAL como apropiado, es decir, insistimos en que estamos atendiendo ENFERMOS y no simplemente Enfermedades. El objeto de todo esto es lograr el mayor bienestar posible para el mayor número de personas. Hay ciertos ideales de nuestra profesión que son eternos. Ante todo, el médico busca servir a la comunidad con el propósito de preservar la salud o al menos aliviar el sufrimiento. Este principio es incompatible con cualquier forma de explotación a un paciente. El esfuerzo contínuo por mejorar nuestros conocimientos nos compromete a ser estudiantes por el resto de nuestras vidas.

Es necesario tomar conciencia de nuestras limitaciones y solicitar ayuda cuando fuese necesario. No hay cabida para la soberbia en esta profesión.

En todo momento hay que mantener el respeto por la dignidad del paciente y muy especialmente por su privacidad, aunque ya dijimos que el secreto tiene sus limitaciones y en ningún momento puede ser más importante que el bien común u ocasionar perjuicios graves a terceros inocentes.

Los honorarios y estipendios deben estar de acuerdo con la naturaleza de los servicios prestados y debe 
tomar en cuenta el esfuerzo de la formación académica y la responsabilidad inherente al cargo. Todo trabajo bien hecho merece ser remunerado aún cuando la medicina jamás debe tener como meta principal el fin de lucro. No es un comercio y se considera desde hace mucho tiempo, como no ético la búsqueda activa de pacientes. Esto incluye anuncios chabacanos prometiendo toda clase de curas y peor aún, atraerse los pacientes ajenos desprestigiando de alguna forma a otros colegas.

Es necesario desarrollar un sentido claro de nuestras obligaciones. Excepto en casos de urgencia no estamos obligados a atender todos los casos que soliciten nuestra atención. Habrá circunstancias que lo correcto será excusarse, pero una vez que se acepta el caso tendremos que dedicarle nuestro mejor esfuerzo y no puede ser abandonado, a menos que el paciente se cure. Tenemos responsabilidades para con la Sociedad. Esto incluye, entre otras, la lucha contínua contra la ignorancia, y la charlatanería.

Por último la conducta habitual del médico debe estar revestida de dignidad y honorabilidad. El profesional, a menudo, sólo dispone de su propia conciencia para determinar si en efecto está cumpliendo a cabalidad su responsabilidad. Sólo una base sólida en una serie de principios generale puede prepararnos para afrontar los complejos dilemas a que nos obliga la tecnología contemporánea y los vertiginosos cambios en la estructura social. A menudo no existen precedentes claros y mucho menos uniformidad de criterios que nos guien, evitando ambigüedades.

Por otra parte el campo de la salud ya no es patrimonio exclusivo del médico; desgraciadamente las relaciones con profesionales afines no están todavia bien definidas. Pareciera que las polémicas que se suscitan obedecen más a motivos económicos, en lugar de tomar en cuenta la esfera de competencia del profesional y el beneficio que esto signifique para los enfermos.

Es indudable que los principios y reglas éticas trascienden la profesión médica, y necesitamos la orientación y opinión de abogados, jueces, historiadores, sociólogos, psicólogos, economistas y sobre todo filósofos y teólogos. Manteniendo la mente abierta quizás retomemeos conciencia de que el campo médico es una CIENCIA, un ARTE y sobre todo todavía siendo un APOSTOLADO.

Cada disciplina médica conlleva en el diagnóstico, terapia e investigación sus propias condiciones determinadas; cada enfermedad impone exigencias características al médico y al cuidado. Las representaciones con respecto al mundo y de los hombres, tanto del médico como del paciente y la sociedad tienen amplias consecuencias. De las diferentes religiones y culturas surgen diferencias esenciales. Sin embargo, y al mismo tiempo, se pueden reconocer principios, valores y estructuras de validez general y duraderos. Así ETICA médica significa cambio y permanencia; consiste en tradición e innovación. La necesidad de una ética en la medicina es hoy día cada vez más reconocida mundialmente aún cuando las opiniones acerca del contenido y la función, de la fundación y difusión difieren. El progreso médico está tan relacionado con chanses como con riesgos. La conciencia del hombre individual y la moral individual - por importantes que sean evidentemente no son suficientes en la medicina; son necesarios análisis éticos y decisiones éticas; son necesarios esclarecimiento y formación, así como lo son las correspondientes instituciones y leyes.

Para terminar quisiera expresar la opinión del filósofo Arthur Schopenhauer: "Predicar la Moral es fácil, fundamentarla es dificil". Con esto el filósofo llama la atención sobre las diferencias decisivas entre práxis ética y fundamentación filosófica, y por lo tanto nos permite decir que "Efectivizar una Moral es aún más Dificil".

\section{LITERATURA CONSULTADA}

1. Código de Nuremberg: Normas Eticas sobre Experimentación en Seres Humanos; Nuremberg Agosto. 1947.

2. Código Internacional de Etica Médica: Tercera Asamblea General de la Asociación Médica Mundial. Octubre, 1949 y Modificaciones de la 22a. Asamblea Médica Mundial, Sydney, Australia, Agosto 1968, y la 35a. Asamblea Médica Mundial, Venecia, Octubre de 1983.

3. Declaración de Ginebra, adoptada por la Asamblea General de la Asociación Médica Mundial, Ginebra, Septiembre de 1948 y enmendada por la 22a. Asamblea Médica Mundial, Sydney, Agosto de 1968.

4. Declaración de Helsinki de la Asociación Médica Mundial para orientar a los médicos que realizan investigación bio-médica en seres humanos. 18a. Asamblea Médica Mundial, Helsinki, Junio 1964; enmendada por la 29a. Asamblea Médica Mundial, Tokyo, Octubre 1975, la 35a. Asamblea Médica Mundial, Venecia, Octubre 1983 y la 4 la. Asamblea Médica Mundial. Hong Kong, Septiembre de 1989.

5. Declaración de la Asociación Latinoamericana de Academias de Medicina (ALANAM) sobre Etica en Medicina. Aprobada por el Consejo Directivo de ALANAM, Quito, Mayo de 1983.

6. Declaración de la Asociación Médica Mundial sobre el Acceso a la Atención Médica. Adoptada por la 40a. Asamblea Médica Mundial, Viena, Septiembre de 1988.

7. Declaración de la Asociación Médica Mundial sobre la Defensa y Secreto del paciente. Adaptada por la 45a. Asamblea Médica Mundial, Budapest, Octubre 1993.

8. Declaración de la Asociación Médica Mundial sobre Negligencia Médica. Adoptada por la 44a. Asamblea Médica, Marbella, Septiembre 1992.

9. Declaración de Lisboa sobre los Derechos de los Pacientes, 34a. Asamblea Médica Mundial de Lisboa. 
Octubre 1981.

10. Declaración de Madrid de la Asociación Médica Mundial sobre Autonomía y Autorregulación Profesional. Adoptada por la 39a. Asamblea Médica Mundial, Madrid, Octubre, 1987.

11. Declaración de Tokyo, 29a. Asamblea Médica Mundial, Tokyo, 1975.

12. Declaración sobre la Libertad de Paticipar en Reuniones Médicas: Asamblea Médica Mundial, Singapur, Octubre 1984.

13. Declaración Universal de los Derechos Humanos, ONU, Diciembre 1948.

14. Juramento Hipocrático.

15. Moción que condena la Discriminación, 27a. Asamblea Médica Mundial, Munich, Octubre 1973.

16. Postulado sobre el Uso y Mal uso de Drogas Psicotrópicas: 29a Asamblea Médica Mundial, Tokyo. Octubre 1975, enmendado por la 34a Asamblea Médica Mundial, Venecia, Octubre 1983.

\section{LITERATURA NO CONVENCIONAL}

1. Etica en la Profesión Médica. L.A. Picard-Amí.

2. Etica Médica: Estructura, Desarrollo y Difusión, en: Bio-Etica, Educación y Humanidades Médicas 2 (1996) (2):5-15. Dr. Dietrich Von Engelhardt.

3. Etica Profesional. Miguel D'Acosta Leiva. El Juramento Hipocrático. Publicaciones Especiales $\mathrm{N}^{\circ} 1$. Serie "Ciclo de Extensión". 1987. Departamento de Filosofia y Ciencias de la Educación, Universidad de Concepción. "La naturaleza de los Actos humanos". p.87 y ss.

4. Etica Profesional: Aquiles Muñoz, Etica Profesional. Herro Hermanos, 2a Edición, México, 1965.

\section{PARTICIPANTES E COLABORADORES DO CONSENSO}

\section{Alfredo Halpern}

Médico, Professor Livre-Docente da Disciplina de Endocrinologia e Metabologia,

Faculdade de Medicina da Universidade de São Paulo. São Paulo, Brasil

\section{Aline de Mesquita Carvalho}

Psicologa - Mestranda em Saúde Pública - Escola Nacional de Saúde Pública - Fiocruz

\section{Amélio F. de Godoy Matos}

Médico, Professor de Endocrinologia da Pontificia Universidade Católica do Rio de Janeiro, Instituto Estadual de Diabetes e Endocrinologia.

Rio de Janeiro, Brasil

\section{Cesar De Leon P.}

Médico Cirurgião, Professor da Cátedra de Cirurgia, Fac uldad de Medicina da Universidad de Panama. Panama, Panama

\section{Carlos Bayard Rodrigues}

Médico Endocrinologista, Sócio da ABESO

Santana do Livramento, RS, Brasil

\section{Daise dos Santos Amaral Baptista}

Nutricionista - Especialista em Nutrição Clinica, Universidade do Estado do Rio de Janeiro

Rio de Janeiro, Brasil.

\section{Ernesto Irrazabal}

Médico Endocrinologista, Médico Assistente da Clínica de Endocrinologia,

Faculdad de Medicina da Universidad Republica Oriental de Uruguay.

Montevideo, Uruguai

\section{Fernando Manuel Escobar}

Médico Endocrinólogo Universitario, Docente Adscripto en Medicina Interna,

Facultad de Medicina Universidad de Buenos Aires

Secretario de la Sociedad Argentina de Obesidad y Trastornos Alimentarios

\section{Giuseppe Repetto}

Médico Endocrinologista, Professor Titular da Disciplina de Endocrinologia,

Faculdade de Medicina da Pontifícia Universidade Católica do Rio Grande do Sul.

Porto Alegre, RS, Brasil

\section{Gladys Olaya Bello}

Médica, Médica da Universidad Javariana. Membro de ASCOM.

Bogotá, Colômbia

\section{Jaime Ariza}

Médico Nutriologo, Catedrático da Escuela Graduada de Salud Publica,

Recinto de Ciencias Médicas, Universidad de Puerto Rico.

San Juan, Puerto Rico

\section{Jorge Gonzalez Barranco}

Médico, Chefe da Clinica de Obesidad, Departamento de Endocrinologia,

Instituto Nacional de la Nutrición Salvador-Zubiran. Ciudad de Mexico, México

\section{José Carlos Appolinário}

Médico Psiquiatra, Doutor em Psiquiatria, Universidade Federal do Rio de Janeiro.

Rio de Janeiro, Brasil

\section{Julio Montero}

Médico Nutricionista, Vice-Presidente da FLASO. Buenos Aires, Argentina 


\section{Luis Cesar Póvoa}

Professor Titular de Endocrinologia da Pontificia Universidade Católica do Rio de Janeiro

Professor Titular de Endocrinologia da Universidade Federal do Rio de Janeiro

Membro Titular da Academia Nacional de Medicina

Rio de Janeiro, Brasil

\section{Marcio C. Mancini}

Médico-Assistente do Grupo de Obesidade e Doenças Metabólicas,

Serviço de Endocrinologia e Metabologia do Hospital das Clínicas,

Faculdade de Medicina da Universidade de São Paulo.

São Paulo, Brasil

\section{Mário Kehdi Carra}

Médico Endocrinologista, Médico-Supervisor do Pronto Socorro,

Serviço de Clínica Médica de Emergência do Hospital das Clínicas,

Faculdade de Medicina da Universidade de São Paulo. São Paulo, Brasil

\section{Mônica Duchesne}

Psicóloga, Pós-Graduada pela Universidade Gama Filho.

Especialista em Psicoterapia Cognitivo - Comportamental

Rio de Janeiro, Brasil

\section{Patricia Restrepo}

Médica Nutricionista, Médica do Instituto de Ciencias de la Salud.

Medellin, Colômbia

\section{Patricio Mois Yudilevich}

Médico Cirurgião, Presidente da Sociedad Chilena de Obesidad.

Santiago, Chile

\section{Pedro Kaufmann}

Médico Gastroenterologista,

Ex-Presidente da Sociedad Uruguaya para Estudio de la Obesidad.

Montevideo, Uruguai.

\section{Rafael Gómez Blasco}

Médico Nutricionista, Médico da Universidad Complutense de Madrid.

Madrid, Espanha

\section{Rafael Gómez-Cuevas}

Médico Endocrinologista da Universidad Central de Madrid.

Bogotá, Colômbia

\section{Raul Pisabarro}

Médico Endocrinologista, Professor Adjunto da Clínica de Endocrinologia,

Faculdad de Medicina da Universidad Republica Oriental de Uruguay.

Montevideo, Uruguai

\section{Ricardo Güell}

Médico Endocrinologo Pediatra, Professor e Investigador Titular,

Instituto Superior de Ciencias Medicas e Instituto Nacional de Endocrinologia.

Habana / Cuba

\section{Ricardo Meirelles}

Professor de Endocrinologia da Pontifícia Universidade Católica do Rio de Janeiro

Diretor do Instituto Estadual de Diabetes e Endocrinologia do Rio de Janeiro

Rio de Janeiro, Brasil

\section{Rosa Labanca}

Médica Nutricionista, Docente Adscripta a la Cátedra de Nutrición,

Facultad de Medicina, Universidad de Buenos Aires.

Presidente de la Sociedad Argentina de Obesidad y Trastornos Alimentarios (SAOTA).

\section{Victor Saavedra Gajardo}

Médico Cirurgião, Ex-Presidente da FLASO.

Santiago, Chile

\section{Walmir Ferreira Coutinho}

Professor de Endocrinologia da Pontifícia

Universidade Católica do Rio de Janeiro.

Vice-Presidente da Associação Brasileira para o

Estudo da Obesidade

Rio de Janeiro, Brasil 